PNL-3395

UC-94b.

\title{
Annual Report for 1979
}

COMPRESSED AIR ENERGY

STORAGE TECHNOLOGY

PROGRAM

June 1980

Prepared for

Division of Energy Storage Systems

Division of Electric Energy Systems

U.S. Department of Energy

under Contract DE-AC06-76 RLO 1830

Pacific Northwest Laboratory

Operated for the U.S. Department of Energy

by Battelle Memorial Institute 
This report was prepared as an account of work sponsored by the United States Government. Neither the United States nor the Department of Energy, nor any of their employees, nor any of their contractors, subcontractors, or their employees, makes any warranty, express or implied, or assumes any legal liability or responsibility for the accuracy, completeness or usefulness of any information, apparatus, product or process disclosed, or represents that its use would not infringe privately owned rights.

The views. opinions and conclusions contained in this report are those of the contractor and do not necessarily represent those of the United States Government or the United States Department of Energy.

\author{
PACIFIC NORTHWEST LABORATORY \\ operated by \\ BATTELLE \\ for the \\ UNITED STATES DEPARTMENT OF ENERGY \\ Under Contract DE-AC06-76RLO 1830
}

\author{
Printed in the United States of America \\ Available from \\ National Technical Information Service \\ United States Department of Commerce \\ 5285 Port Royal Road \\ Springfield, Virginia 22151
}

Price: Printed Copy $\$$ $\approx$ Micrafiche $\$ 3.00$

NTIS

-Pages Selling Price

001-025 $\$ 4.00$

026-050 $\quad \$ 4.50$

051-075 \$5.25

076-100 $\quad \$ 6.00$

$101-125 \quad \$ 6.50$

126-150 \$7.25

$151-175 \quad \$ 8.00$

$176-200 \quad \$ 9.00$

$201-225 \quad \$ 9.25$

$226-250 \quad \$ 9.50$

$251-275 \quad 510.75$

$276-300 \quad \$ 11.00$ 


\section{COMPRESSED AIR ENERGY STORAGE TECHNOLOGY PROGRAM}

ANNUAL REPORT FOR 1979

W. V. Loscutoff

Staff Members and Subcontractors of Pacific Northwest Laboratory

June 1980

Prepared for the U.S. Department of Energy under Contract DE-AC06-76RLO 1830

Pacific Northwest Laboratory Richland, Washington 99352 


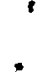

.

-

14 


\title{
PREFACE
}

This is the Compressed Air Energy Storage Technology Program Annual Report for 1979 from the Pacific Northwest Laboratory (PNL) to the DOE Divisions of Energy Storage Systems and Electric Energy Systems.

The report describes all of the major research conducted during the period January 1979 to March 1980.

The report is divided into two segments: Reservoir Stability Studies and Second-Generation Concepts Studies. The first represents research performed to establish stability criteria for CAES reservoirs while the second reports progress on research performed on secondgeneration CAES concepts. The report consists of project reports authored by research engineers and scientists from PNL, Re/Spec Inc., Acres American, Incorporated, United Technologies Research Center, University of Wisconsin, Louisiana State University, and several representatives of the industry. For additional information on any of the projects in this report, contact the authors of the articles.

Activities of the researchers whose work is described in this annual report are broader in scope than the articles indicate. In addition the contributing staff at PNL has also responded to numerous requests from DOE for planning and special assistance during the year.

Credit for this annual report goes to the many engineers and scientists who performed the research and wrote the individual project reports, to the project managers who directed the research, and to Sue Arey who assembled, typed and assisted in editing the annual report.

\author{
W.V. Loscutoff \\ Project Manager \\ Compressed Air Energy Storage
}




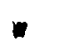




\section{SUMMARY}

The compressed air energy storage (CAES) concept includes nearand mid-term technologies for central station electric utility applications. This concept greatly improves the effectiveness of a gas turbine using petroleum fuels and could reduce petroleum fuel consumption of electric utility peaking plants by more than $100 \mathrm{million}$ barrels of oil per year. Studies show that the CAES concept is technically feasible and economically viable.

To facilitate technological development and commercialization of CAES, this program plan has been prepared at the request of the U.S. Department of Energy's (DOE) Divisions of Energy Storage Systems (STOR) and Electric Energy Systems (EES).

The CAES Technology Program has evolved into two major research and development elements. Recognizing that long-term reservoir stability is crucial to the commercialization of CAES systems, the CAES Reservoir Stability Studies element receives major emphas is in the early phases of the program. Recognizing also that even the modest petroleum fuel requirements of a conventional CAES system may be an obstacle to largescale acceptance, the Second-Generation CAES Concepts Studies element will dominate the research and development activity during the latter phases of the program. The second-generation CAES concepts studies also include a number of technologies suitable for nonutility applications.

The objectives of the program are:

- CAES Reservoir Stability Studies - Establish stability criteria for large underground reservoirs in salt domes, hard rock, and porous rock used for air storage in utility applications.

- Second-Generation CAES Concepts Studies - Develop second-generation CAES technologies that have minimal or no dependence on petroleum fuels.

The program is organized into the major elements and subelements as shown in Figure $A$. 


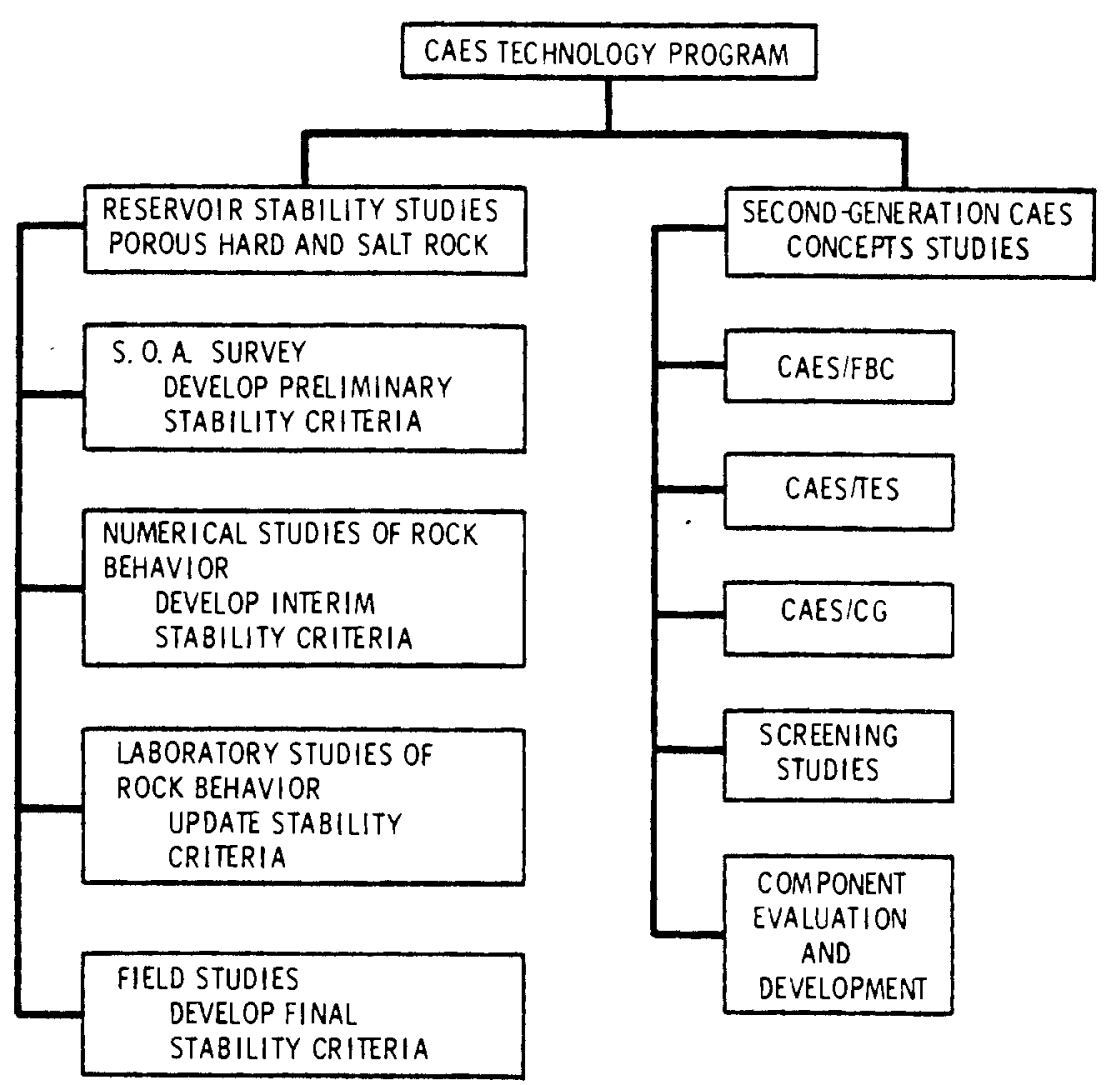

FIGURE A. Compressed Air Energy Storage Technology Program Work Structure Outline

The strategy of accomplishing the goals and objectives of the CAES Technology Program are discussed in the Introduction. A schedule for fulfilling the goals of the program is given in Figure $B$. Progress in the reporting period is summarized below.

A. Reservoir Stability Studies

a. Porous Media Reservoirs

The major concerns in the development of stability criteria for porous media reservoirs are related to 1) the performance of CAES welis in aquifers over a wide range of operating and geophysical conditions, 


\begin{tabular}{|c|c|c|c|c|c|c|c|}
\hline MILESTONE /ACTIVITY FISCAL YEAR & 1979 & 1980 & 1981 & 1982 & 1983 & 1984 & $\begin{array}{c}\text { AFTER } \\
1984 \\
\end{array}$ \\
\hline A. RESERVOIR STABILITY STUDIES & & & & & \multirow{9}{*}{6} & & \multirow[b]{9}{*}{10} \\
\hline 1. STATE-OF-THE-ART SURVEY & $\leq$ & & & & & & \\
\hline 2. NUMERICAL STUDIES & & & & 2 & & & \\
\hline 3. LABORATORY STUDIES & & & & $\hat{3}$ & & & \\
\hline 4. FIELD STUDIES & $\nabla$ & & & 4 & & & \\
\hline 5. STABILITY CRITERIA & 5 & & & & & & \\
\hline 8. SECOND-GENERATION CONCEPTS STUDIES & & \multirow{2}{*}{\multicolumn{2}{|c|}{$2 \sqrt{8}$}} & & & & \\
\hline 1. SECOND-GENERATION CONCEPT EVALUATION & & & & & & & \\
\hline 2. COMPONENT EVALUATION AND DEVELOPMENT & & & $\leq$ & & & & \\
\hline & & & $\underline{A}$ & & & & 18 \\
\hline
\end{tabular}

$\nabla$ initiate activity

$\triangle$ MILESTONE

$\bigcirc$ DOE DECISION POINT

- ACTIVITY BAR

$\Lambda$ - COMPLETE S-O-A SURVEY

2. COMPLETE NUMERICAL STUdies

3 - COMPLETE LABORATORY STUDIES

$\triangle$ - COMPLETE FIELD STUDIES

S) - ESTABLISH PRELIMINARY STABILITY CRITERIA

(6) - ESTABLISH FINAL STABILITY CRITERIA
A. COMPLETE SECOND-GENERATION CAES FEASIBILITY STUDY

8) DOE DECISION TO PROCEED ON DEVELOPMENT OF SECONDGENERATION TECHNOLOGIES

9. - COMPlete COMPONENT EVAluation

10. COMPLETE COMPONENT DEVELOPMENT

11. - INITIATE SECONDGENERATION DEVELOPMENT PROJECT

1. BEGIN TESTING OF SECOND-GENERATION PLANT

FIGURE B. Compressed Air Energy Storage Technology Program Milestones

2) the geochemical stability of typical CAES porous rock and caprock, and 3 ) the structural stability of porous rock and caprock. The second and third concerns are primarily for injection of hot compressed air.

Numerical modeling in the FY-79 reporting period focused on 1 ) the development and parametric application of a two-dimensional fluid thermal flow model to evaluate the effects of wellbore heat transfer, vertical permeability reduction, and completion interval, and 2) the modification and application of a two-dimensional structural model to determine the effect of near wellbore thermal gradients (predicted by 
the fluid thermal flow model) on porous rock and caprock stresses and potential for failure. These efforts were completed. Results indicate that uninsulated wellbores cause substantial loss in thermal energy recovery, that vertical permeability variations are not particularly significant, and that shallow well completion could significantly impair reservoir performance for CAES. Structural modeling identified the need for fatigue data for porous rock and caprock and demonstrated that regions of failure exist for the caprock for certain reservoir conditions and assumptions.

Porous media laboratory studies eliminated several unknowns as major CAES concerns for aquifer storage. It was shown that porous rock exposed to CAES conditions remained a viable storage media for long periods of time even at over $150^{\circ} \mathrm{C}$. Although some increase in friability was observed for high temperature humid air atmospheres, lack of confinement may have limited the applicability of test results for CAES reservoirs. Exposure of numerous types of porous rock to dry air ventilation at modest temperatures and pressures continued to show little impact on rock properties. A flow facility for porous rock desaturation and cyclic ventilation with moist air was designed and procurement initiated. Interim testing at an industrial laboratory was initiated to try to explain permeability increases for water flow through porous rock at elevated temperatures.

Structural testing of porous rock at elevated temperatures at another national laboratory has shown anticipated increases in strength and reduction in Poisson's ratio as temperature was increased al though data scatter was severe. These studies also revealed a substantial anisotropic coefficient of thermal expansion.

A porous media field studies plan was completed as was a draft review of related field experience in other underground aquifer storage technologies including natural gas storage, geothermal reservoirs and aquifer thermal energy storage. Experience in CAES related technologies can not satisfy the needs of CAES stability studies relative to modeling and laboratory 
limitations, investigation of geotechnical issues not amenable to other studies and demonstration of the technology. A field studies plan was developed which defines the functional requirements, siting criteria, and exploratory and test methodology. Preliminary site evaluation was performed and a site in Illinois tentatively selected.

\section{b. Hard Rock Caverns}

A report on prel iminary CAES hard rock reservoir stability criteria was received in draft form in April 1979 and a draft report on preliminary UPHS hard rock reservoir stability criteria was received in February 1980. These reports determined the major hard rock geotechnical issues of concern for CAES in hard rock, suggested a methodology for evaluating stability and provided preliminary guidance on determination of stable cavern designs.

Major concerns related to compensated CAES in hard rock include 1) determination of rock properties and behavior under cyclic therma?, pore liquid saturation, and mechanical loading conditions, 2) determination of the effect of local rock failure on cavern stability, 3) evaluation of the relative value of rock structural improvement methods, and 4) determination of the impact of fracture networks on global air leakage. Studies to address these issues have been initiated with progress summarized below.

Numerical modeling continued under contract with Re/Spec Inc. A preliminary report on numerical analysis methodologies was prepared to serve as a guide to further development. General parametric simulations of stresses in various cavern configurations and in-situ stress conditions were performed. Simulations of the alteration of stress states throughout the rock mass were performed as water level and pressures were cycled as in a prototypic CAES plant. Alterations in near surface wall stresses between compression and tension were observed for some portions of the wall under certain conditions. Cyclic thermal and pressure profiles were shown to be confined to the first meter of the cavern wall. A probabilistic 
method of analysis was formulated, however, investigation of this technique awaits completion of more classical analyses and collection of a more substantial data base.

Laboratory studies of hard rock response to CAES loading conditions were initiated shortly before the beginning of this reporting period. Over 300 conventional strength and moduli laboratory tests were performed on selected samples of granite, gneiss, quartzite, and dolomite at ambient and elevated temperatures and (for the dolomite) dry and total liquid water saturation. As saturation with liquid water increased the shear strength of the dolomite decreased. Inelastic behavior was observed for the dolomite at a stress of $40 \%$ of the peak stress with eventual dilatancy (volume increase) observed. The gneiss was strongly foliated and displayed marked anisotropic properties. Additional work is being carried on for characterization of artificially jointed rock behavior under CAES conditions.

No field studies are planned in hard rock at this time due to the great expense of such tests and the possibility of satisfying in-situ testing needs by field efforts being performed by other groups.

\section{c. Salt Cavern Reservoirs}

Major concerns related to CAES in underground salt caverns include 1) evaluation of long term salt response to cyclic mechanical and thermal loads, 2) determination of the potential for and consequences of surficial air penetration of cavern wal1, and 3 ) resolution of the response of varying types of salt to CAES loadings. Studies have been initiated to address these and other issues. Progress on these studies is summarized below.

Numerical modeling activities were curtailed during the reporting period until resumption in February 1980. No substantial results can be reported at this time from this most recent effort. Activities reported in the previous annual report included the parametric evaluation 
of cavern closure over 30 year 1 ifetimes for CAES conditions. One important observation was that the strain of cyclic loading could be conservatively approximated by using the strain produced by the greatest deviatoric stress encountered during cycling.

Laboratory studies of salt response to CAES conditions include laboratory scale and in-mine bench scale testing. Six test cells were designed and constructed for the triaxial cyclic thermal and mechanical loading of salt specimens from several Louisiana salt mines, the Huntorf site in West Germany, and Kansas and Nevada bedded salt. Preliminary cyclic mechanical loading has indicated strain cycling is very small in response to cyclic stress having a larger range. Salt demonstrates much greater strain during high temperature portions of thermal cycling than low temperature segments. Acoustic emission patterns appear to trace cyclic strain very closely showing potential as an in-situ salt cavern stability monitoring technique. Tests in boreholes in the floor of the Jefferson Island salt mine have only recently been initiated and slant boreholes in a pillar of the Cote Blanche mine are now being prepared for testing.

Major field study efforts associated with the Office of Nuclear Waste Isolation, the Strategic Petroleum Reserve Program and the Solution Mining Research Institute do not meet the needs for CAES evaluation of salt cavern storage in the field. Therefore a salt field studies review and $\mathrm{plan}$ were prepared which included site development and testing methodology. Preliminary salt cavity leasing negotiations have been initiated with the Morton Salt Company.

\section{B. Second-Generation Concepts Studies}

The primary thrust of the second-generation concepts studies was to identify, evaluate, and promote technological development of concepts that require very little or no petroleum fuels for firing of the turbines. Two approaches were taken. One was to reduce or el iminate the fuel consumption to zero by integrating thermal energy storage (TES) with CAES. The other was to look at alternate fuels. The most logical 
candidate for alternate fuel was coal, used with CAES through fluidized bed combustion ( $F B C$ ) or through coal gasification ( $C G)$. Activity during the reporting period concentrated on examining these three concepts (Figure B), screening their technical and economic viability, and recommending to DOE which, if any, of these concepts should be promoted.

a. Thermal Energy Storage Integrated with CAES

The integration of TES with CAES appears to be a near-term option (in terms of technological readiness) that is a logical use of what is, otherwise, waste heat. There are a number of problems associated with the CAES/TES combination. Compressors must be pushed beyond the current operating temperature 1 imits in order to optimize performance. Turbines must operate in the lower temperature regimes. Thermal energy storage beds are untested components. In addition, CAES/TES systems require large pipes and valves that must undergo thermal cycling. Finally, the economic viability of CAES/TES is not immediately obvious. These are some of the major issues that are being addressed by the program.

Decisions concerning CAES/TES involve studies of two combinations:

- hybrid CAES/TES in which only part of the heat of compression is stored and fuel must be used to supplement the required energy before air is expanded in a turbine

- adiabatic CAES/TES, in which all of the energy of compression is stored and recovered and thus no fuel is used by the plant. Previous studies at PNL, the Massachusetts Institute of Technology and the Central Electricity Generating Board (England) have shown that the cost of the TES component would be high. However, the resulting CAES/TES system could be cost competitive under certain conditions. As a result, this concept was subjected to preliminary engineering designs and cost analysis studies beginning in the reporting period. PNL reviewed a 11 of the studies related to CAES/TES and, based on positive results, awarded a contract to study adiabatic CAES to Acres American, Incorporated. 
This study will use the PEPCO design of a conventional CAES plant as baseline information. This study is scheduled for completion in September 1980. It will be used to evaluate if the concept is economically viable and, if so, what additional component developments are required before the program moves into the demonstration phase.

\section{b. Fluidized Bed Combustion Integrated with CAES}

The integration of $F B C$ with CAES offers a promising solution to replacing petroleum fuel with coal. Several other techniques using coal to fire turbines were examined but most were secondary in potential to $F B C$. $F B C$ technology is progressing rapidly in conjunction with advanced steam, gas turbine, and combined cycle plants. However, the integration of FBC with CAES presents a number of issues that would not arise in non-CAES studies. Specifically, a CAES/FBC system requires an air heater, a system that has to withstand daily cycling, very high pressures in the tubes (up to 70 bars), and the most efficient CAES design, a high pressure (up to 20 bars) combustor. For these reasons a detailed economic and technical feasibility study of CAES/FBC was undertaken. A contract was awarded to the United Technologies Research Center beginning in August 1978 and ending in December 1980. The study has so far identified an optimal CAES/FBC configuration which has a pressurized FBC. UTRC has estimated that it is economically feasible, and is currently evaluating part-load and load-following characteristics of CAES/FBC. In addition, the program has identified a number of component development requirements. The results of this study will be used to decide whether this concept has sufficient merit to proceed with component development and demonstration.

\section{c. Coal Gasification Integrated with CAES}

The integration of CAES with coal gasification (CG) could result in a synergistic combination of two technologies: one that produces a very expensive synthetic fuel and one that uses fuel very efficiently 
(4,000 Btu/kWhr of electricity for a conventional CAES plant). However, in addition to being expensive, a $C G$ plant is also inflexible in operation. New cycles must be examined in order to take advantage of the operating characteristics of a CAES/CG plant. Initial screening studies have identified CAES/CG as a viable concept. A subsequent study by United Technologies Research Center (for EPRI) has produced a number of results that are currently being evaluated by PNL and its consultants. In addition other independent studies of $C G$ are available. These and the EPRI study will be used to evaluate the economic viability of CAES/CG and identify what component developments are required. Based on these studies, a recommendation to DOE on whether the concept should be promoted into the technological development and/or demonstration phases will be made early in FY-1981.

\section{Summary of Accomplishments}

Main accomplishments (corresponding to milestones) during the reporting period include the following:

- Completed State-of-the-Art Survey in Hard Rock (scheduled May 1979, three reports received, one hard rock properties report in preparation) (CAES and UPHS in Hard Rock Caverns: I. Geological and Geotechnical Aspects, Debra S. Port-Keller and Paul F. Gnirk, Re/Spec, Inc., Draft PNL-2886, report no. RSI-0076, January, 1979) (CAES and UPHS in Hard Rock Caverns: III. Preliminary Stability and Design Criteria for Compressed Air Energy Storage, Paul F. Gnirk, Re/Spec Inc., Draft PNL-2916, report no. RSI-0079, February 1979)

(CAES and UPHS in Hard Rock Caverns: IV. Preliminary Stability and Design Criteria for Underground Pumped Hydro-Storage Caverns, Paul F. Gnirk, Re/Spec Inc., Draft, PNL-3373, report no. RSI-0110, February 1980)

- Completed Preliminary Hard Rock CAES Reservoir Stability Criteria (scheduled May 1979, completed ahead of schedule) 
- Completed Field Study Plan for CAES in Aquifers (scheduled March 1980, completed ahead of schedule) (CAES Aquifer Field Studies Plan, Draft not cleared at this time, R. D. Allen and P. J. Gutknecht, December 1979)

- Completed Field Study Plan for CAES in Salt (scheduled March 1980, completed ahead of schedule) (CAES Salt Field Studies Plan, Draft not cleared at this time, J. J. Jacobson, December 1979)

No major Second-Generation milestones were encountered in the reporting period.

Additional significant accomplishments during the reporting period include the following:

Reservoir Stability Studies

- Completed initial laboratory studies of air-water-rock interactions (Potential Petrophysical and Chemical Property Alterations in a Compressed Air Energy Storage Porous Rock Reservoir, J. A. Stottlemyre, R. L. Erikson, and R. P. Smith, PNL-2974, October 1979)

- Completed numerical studies of moisture effects on air storage in porous rock (The Effects of Water on Compressed Air Energy Storage in Porous Rock Reservoirs, L. E. Wiles, PNL-2869, March 1979)

- Completed a two-dimensional numerical study of CAES in a porous rock reservoir (Numerical Analysis of Temperature and Flow Effects in a Dry, Two-Dimensional, Porous-Media Reservoir Used for Compressed Air Energy Storage, L. E. Wiles, PNL-3047, October 1979)

- Designed a flow facility for laboratory studies of porous rock.

Second-Generation CAES Concepts Studies

- Completed report of the study of CAES/TES and CAES/solar systems (Application and Design Studies of CAES for Solar Applications, G. T. Flynn and J. L. Nash-Webber, MIT CAES-7, September 1979) 
- Completed report on the economics of CAES/TES system (The Economics of CAES Employing Thermal Energy Storage, S. C. Schulte and R.W. Rei11y, PNL-3191, November, 1979)

- Selected preferred coal-fired fluidized bed combustor system for CAES (Technical and Economic Assessment of FBC Augmented CAES Systems, R. D. Lessard, United Technologies Research Center, Progress Reports 3 and 4, December 1979)

- Initiated engineering design studies of adiabatic CAES plants (Conceptual Design and Engineering Studies of Adiabatic CAES, Acres American, awarded September 1979)

- Initiated activity on design of thermal energy storage test facility for CAES

- Evaluated novel CAES concepts, e.g., a two-reservoir, closed-loop low pressure ratio system (Advanced CAES Concepts Studies, R. T. Allemann and M. K. Drost, PNL, 1979 Contractors' Review, August 1979)

- Evaluated adiabatic CAES cycles using aquifers for air and thermal storage (M. K. Drost, PNL report to be published). 


\section{CONTENTS}

PREFACE. . . . . . . . . . . . . . . . . . . . .

Page

SUMMARY. . . . . . . . . . . . . . . . . . . . . v

FIGURES. . . . . . . . . . . . . . . . . . . . $\quad x x i$

TABLES . . . . . . . . . . . . . . . . . . . . . $\quad x X V$

1.0 COMPRESSED AIR ENERGY STORAGE TECHNOLOGY PROGRAM. . . . . . . 1

1.1 BACKGROUND . . . . . . . . . . . . . . . . . 1

1.2 PURPOSE. . . . . . . . . . . . . . . . . . . 1

1.3 RATIONALE. . . . . . . . . . . . . . . . . 2

1.4 GOALS. . . . . . . . . . . . . . . . . 2

1.5 OBJECTIVES . . . . . . . . . . . . . . . 3

1.6 PROGRAM STRUCTURE. . . . . . . . . . . . . . . 3

1.7 MAJOR PROGRAM MILESTONES . . . . . . . . . . . . . 4

1.8 RESOURCE REQUIREMENTS. . . . . . . . . . . . . . . . . 4

2.0 CAES RESERVOIR STABILITY STUDIES. . . . . . . . . . . . 9

2.1 INTRODUCTION . . . . . . . . . . . . . . . . 9

2.2 GOALS. . . . . . . . . . . . . . . . . . 10

2.3 OBJECTIVES . . . . . . . . . . . . . . . . . 11

2.4 STRATEGY . . . . . . . . . . . . . . . . . . 11

2.5 RESERVOIR STABILITY STUDIES PROJECT DESCRIPTIONS . . . . 12

2.5.1 Porous Media Studies. . . . . . . . . . . 12

2.5.2 Hard Rock Studies.............. . 17

2.5.3 Salt Studies................ 19

2.6 MILESTONES AND ACCOMPLISHMENTS . . . . . . . . . . . 21

2.6.1 Milestones. . . . . . . . . . . . . . . 21

2.6.2 Accomplishments .............. . . 23

3.0 SECOND-GENERATION CAES CONCEPTS STUDIES . . . . . . . . . 25

3.1 INTRODUCTION . . . . . . . . . . . . . . . . . . 25

3.2 GOALS. . . . . . . . . . . . . . . . 25

3.3 OBJECTIVES . . . . . . . . . . . . . . . . . . . . . . . . . . . . . . .

3.4 STRATEGY . . . . . . . . . . . . . . . . 27 
3.5 SECOND-GENERATION CONCEPTS STUDIES PROJECT

Page

DESCRIPTIONS . . . . . . . . . . . . . . 27

3.6 MILESTONES AND ACCOMPLISHMENTS . . . . . . . . . . . 33

3.6.1 Milestones. . . . . . . . . . . . . . . . . 33

3.6.2 Accomplishments.................... 33

4.0 PROJECT SUMMARIES . . . . . . . . . . . . . . . . 37

4.1 RESERVOIR STABILITY STUDIES

4.1.1a Thermal Flow Analys is of Porous Rock

Reservoirs.............. . 39

4.1.1b Thermomechanical Modeling of Porous Rock Reservoirs............... 47

4.1.1C Air-Water-Rock Interaction in CAES Reservoirs. . 51

4.1.1d Effects of Air Ventilation on Porous Rock. . . . 65

4.1.1e Thermomechanical Properties of Porous Rock. . . 73

4.1.1f Moist Air Flow Tests ........... 81

4.1.1g Design and Construction of Porous Media Flow Facility. . . . . . . . . . . 85

4.1.1h Field Studies in Porous Rock Reservoirs. . . . . 91

4.1.2a Numerical Studies of CAES Hard Rock Caverns. . . 97

4.1.2b Laboratory Studies of CAES Hard Rock Caverns . . 105

4.1.3a Experimental Studies of Domal Rock Salt. . . . . 113

4.1.3b Field Studies of Salt Cavities........ 123

4.2 SECOND-GENERATION CONCEPTS STUDIES

4.2.1 Feasibility Study of CAES Augmentation by FBC. . 127

4.2.2a Preconceptual Design of CAES/TES Systems . . . 135

4.2.2b Engineering Study of Adiabatic CAES using Hard Rock Caverns ............. . 139

4.2.2c Engineering Study of Adiabatic CAES using Aquifers for Air Storage . . . . . . . . 149

4.2.3 Feasibility of Coal Gasification and CAES (CAES/CG). . . . . . . . . . . 151

4.2.4 Second-Generation CAES Equipment Evaluation. . 153 
4.2.5 Second-Generation Concepts Analysis and support ............... . 155

4.2.6 Economic Assessment of Second-Generation Concepts. . . . . . . . . . . . 157

4.2.7 Thermal Energy Storage Test Facility. . . . . 161

4.2.8 Advanced Storage Concepts Evaluation and Technical Assistance. ......... 163

4.2.9 Application and Design Studies of CAES for Solar Energy Applications . . . . . . . . 
$\checkmark$ 


\section{FIGURES}

Page

A. Compressed Air Energy Storage Technology Program Work

Structure Outline. . . . . . . . . . . . . . . vi

B. Compressed Air Energy Storage Technology Program

Milestones...................... . vii

1. Compressed Air Energy Storage Technology Program Work

Structure Outline. . . . . . . . . . . . . . . . . 3

2. Compressed Air Energy Storage Technology Program Functional

Organization . . . . . . . . . . . . . . . . . . . . .

3. Compressed Air Energy Storage Technology Program Schedule Diagram. . . . . . . . . . . . . . . . . . . . . .

4. Compressed Air Energy Storage Technology Program

Milestones . . . . . . . . . . . . . . . . . .

5. Compressed Air Energy Storage Technology Program Funding

Requirements...................... 8

6. Milestones for Reservoir Stability Studies . . . . . . . 22

7. Approach Used in Second-Generation Concepts Studies. . . . . 28

8. Milestones for Second-Generation Concepts Studies. . . . . . 34

9. Effect of WelTbore Heat Transfer on Thermal Energy

Recovery . . . . . . . . . . . . . . . . . . .

10. Functional Structure of Porous Media Laboratory

Studies. . . . . . . . . . . . . . . . . . .

11. Changes in Gas Permeability at Elevated Temperatures

from Autoclave Experiments . . . . . . . . . . . . .

12. Changes in Permeability of Sandstone as a Function

of Temperature................... . . 60

13. Simultaneous Fluid-Flow/Stress-Strain Experiments. . . . . . 61

14. Viscosity Versus Temperature Curve Required to

Eliminate Permeability Reduction with Temperature

Increase . . . . . . . . . . . . . . . . . 
Page

15. Young's Modulus Versus Effective Confining Pressure for Three Temperatures. Error bars are one standard deviation or the range where only two test repeats are available.....................

16. Poisson's Ratio Versus Effective Confining Pressure for Three Temperatures. Error bars mean the same as in Figure 15. . . . . . . . . . . . . . . . .

17. Mohr Failure Envelopes for Three Temperatures. The semicircle represents states of stress for an operating porous medium CAES reservoir... . . . . . . . . . .

18. Isometric View of Porous Media Flow Facility's Test Stand. . . . . . . . . . . . . . . . . .

19. Schematic of Porous Media Flow Facility Layout........

20. Temperature Contours $\left({ }^{\circ} \mathrm{C}\right)$ Around CAES Cavern for Different Operational Cycles . . . . . . . . . . .

21. Temperatures $\left({ }^{\circ} \mathrm{C}\right)$ into Cavern Wall ........... 100

22. Temperatures $\left({ }^{\circ} \mathrm{C}\right)$ into Cavern Wall ........... 100

23. Principal Stress Trajectories Around CAES Cavern for Different Operational Cycles . . . . . . . . . . 101

24. Vertical Stress into Cavern Wall . . . . . . . . . 102

25. Vertical Stress into Cavern Wall . . . . . . . . . 102

26. Mohr Failure Envelopes for Dry and Saturated Kasota Dolomite. . . . . . . . . . . .... 108

27. Plots of Differential Axial Stress Versus Volumetric, Axial, and Lateral Strain............ 108

28. Variation of Compressive Strength of Sykesville Gneiss with Foliation Angle.

29. Acoustic Emissions for Cyclic Test of Salt . . . . . . . 115

30. Cyclic Uniaxial Test on Jefferson Island Dome Salt . . . . 115

31. Typical Cycle, Salt Stress-Strain Versus Time. . . . . . . 116 
32. Strain and Temperature for Cyclic Thermal Loading and Constant Axial Stress on Salt. ............

33. Index Tension Test ............. . 118

34. In-Situ Test Beneath Salt Pillar, $-418 \mathrm{~m}(-1370 \mathrm{ft}) . . . . .120$

35. Two-Stage Cycle Configuration. . . . . . . . . . 144

36. Inlet Temperature of Second-Stage Compressor Effects on ACAES Cycle Performance for Varied Storage Pressures................. 145

37. Required Combined Compressor Train Input Power to Deliver $850^{\circ}$ Air to Both TES\# 1 and \#2. .......... 146 
1

. 


\section{$\underline{\text { TABLES }}$}

Page

1. Outline of Reservoir Stability Studies. . . . . . . . 13

2. Outline of Second-Generation Concepts Studies . . . . . . 29

3. Initial Results of Corrosion Tests. ........... 53

4. Test Matrix ............... . . . 55

5. Changes in Elastic Constants Due to Cyclic Loading. . . . . . 79

6. Properties of a Sampling of Possible Storage Media. . . . . . 143 


\subsection{COMPRESSED AIR ENERGY STORAGE TECHNOLOGY PROGRAM}

\subsection{BACKGROUND}

Compressed air energy storage (CAES) is a technique that transfers energy from off-peak to peak demand time for electric utility systems. It incorporates modified state-of-the-art gas turbines and underground reservoirs---aquifers, salt cavities or mined hard rock caverns. The compressor and turbine sections of the gas turbine are alternately coupled to a motor/generator for operation during different time periods. During nighttime and weekend off-peak periods, base load plants not using petroleum fuels provide energy to compress air which is stored in the underground reservoirs. During the subsequent daytime peak-load periods the compressed air is withdrawn from storage, mixed with fuel, burned, and expanded through the turbines to generate peak power. Because the turbine is not required to drive a compressor, this concept reduces peaking plant consumption of petroleum fuel by more than 60 percent. Some second-generation CAES concepts do not require any petroleum fuels at a11.

\subsection{PURPOSE}

Studies have shown that the CAES concept is technically feasible and, for utilities with the proper power generation mix, economically viable. Compressed air energy storage systems offer several advantages over conventional systems used by utilities for meeting peak load requirements. Energy storage offers a degree of flexibility and control in system operation (e.g., frequency stabilization). It can be considered as a spinning reserve. It can be started rapidly, and is thus available as supplemental generation in times of emergency. Replacement of current gas turbine peaking plants by CAES plants could result in annual savings of more than 100 million barrels of oil. The net annual oil saving would be greater in the future due to increased power generation. Compressed air energy storage plants are not limited to the same degree of siting 
difficulties faced by conventional pumped hydro plants. Finally, a welldesigned CAES plant should have a smaller adverse impact on the environment, in terms of emissions, than a conventional gas turbine peaking plant.

\subsection{RATIONALE}

In view of the concept's potential benefits, the Department of Energy has undertaken a comprehensive research and development program to accelerate commercialization of this technology. For conventional CAES systems, a key question is related to long-term cavern stability. To provide the utilities with a high degree of confidence in the CAES concept, it is necessary to pursue a comprehensive technology research and development program on guidelines for design of CAES reservoirs.

A key question to CAES technology commercialization is the dependence of CAES plants on petroleum fuels. The technology dependence on petroleum fuels could become a major barrier to large-scale implementation of CAES technology. Thus, it is necessary to identify and examine second generation CAES concepts.

\subsection{GOALS}

The CAES Technology Program is charged with promoting commercialization of CAES technology for electric utility applications. The primary motivation is the annual conservation of more than $100 \mathrm{million}$ barrels of oil. This translates into two major program goals:

- Determine long-term reservoir stability criteria for CAES operating conditions

- Identify, determine feasibility of, and develop second-generation CAES concepts that minimize the need for, or do not require, petroleum fuels for firing of the CAES plant turbines. 


\subsection{OBJECTIVES}

In response to the goals and needs of the CAES Technology Program, two major research and development elements were formulated. These are the Reservoir Stability Studies and Second-Generation Concepts Studies. The primary objectives of the two major program elements are as follows.

- Reservoir Stability Studies

Develop stability criteria for large underground reservoirs used for compressed air storage

- Second-Generation Concepts Studies

Develop advanced CAES technologies that require little or no petroleum fuels for operation.

\subsection{PROGRAM STRUCTURE}

The program is organized into elements and subelements as shown in Figure 1. In support of the two major program thrusts, Reservoir Stability

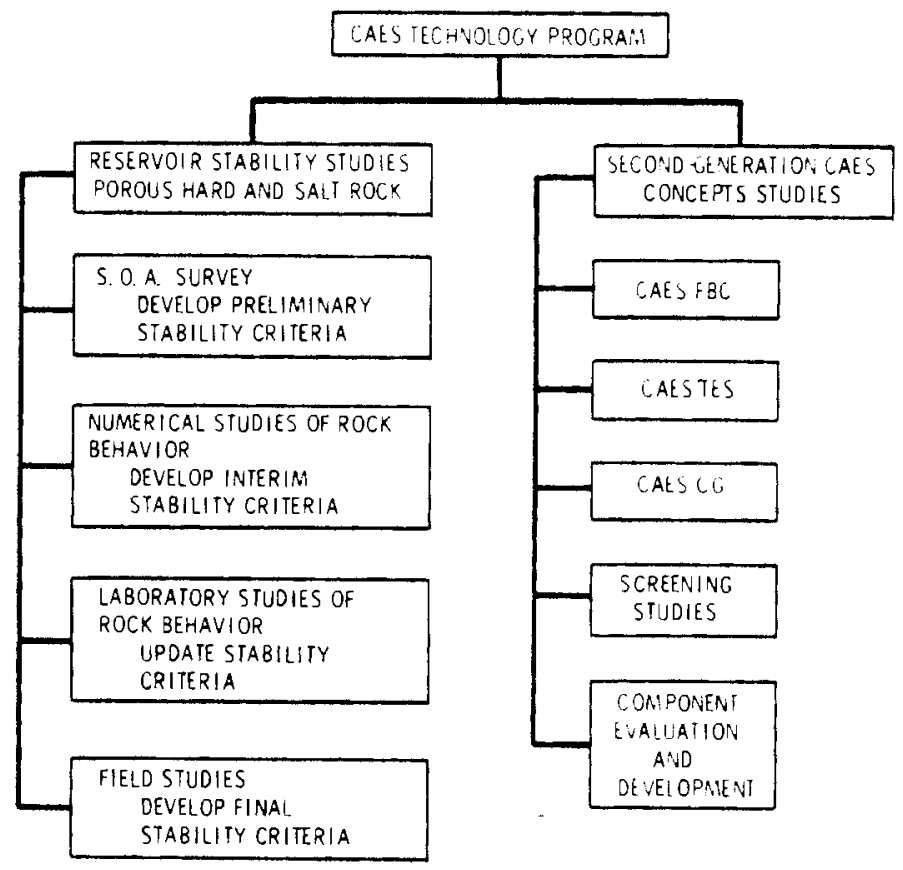

FIGURE 1. Compressed Air Energy Storage Technology Program Work Structure Outline 
Studies and Second-Generation Concepts Studies have been established. Functionally, PNL's charge as the lead laboratory is to provide program planning and management. In addition, PNL scientists and engineers are involved in a number of technical studies in support of the program. The functional program organization is shown in Figure 2.

The emphasis in the early phase of the program is on the Reservoir Stability Studies. In FY-1982, the emphasis will shift to the SecondGeneration Concepts Studies. This is shown in the schedule diagram in Figure 3. This figure also indicates the long-range planning in the program and the interrelationships between the various projects within the program.

\subsection{MAJOR PROGRAM MILESTONES}

To achieve the established objectives and to measure progress, a number of major milestones have been established for this program. These milestones are shown in Figure 4 . The most critical are the completion of reservoir stability studies in FY-1982 and planned initiation of second-generation concept testing in FY-1981.

\subsection{RESOURCE REQUIREMENTS}

To achieve the program objectives, expenditures of up to $\$ 25.4$ million may be required for the period FY-1979 to FY-1984. Figure 5 shows the annual funding requirements by the two major program elements. The Reservoir Stability Studies are winding down and are to be virtually completed in FY-1980. The Second-Generation Concepts Studies are scheduled to be accelerated in FY-1982. It should be noted, however, that there is a large degree of uncertainty in this part of the program since the technology development programs remain to be identified. This should occur in FY-1981. 


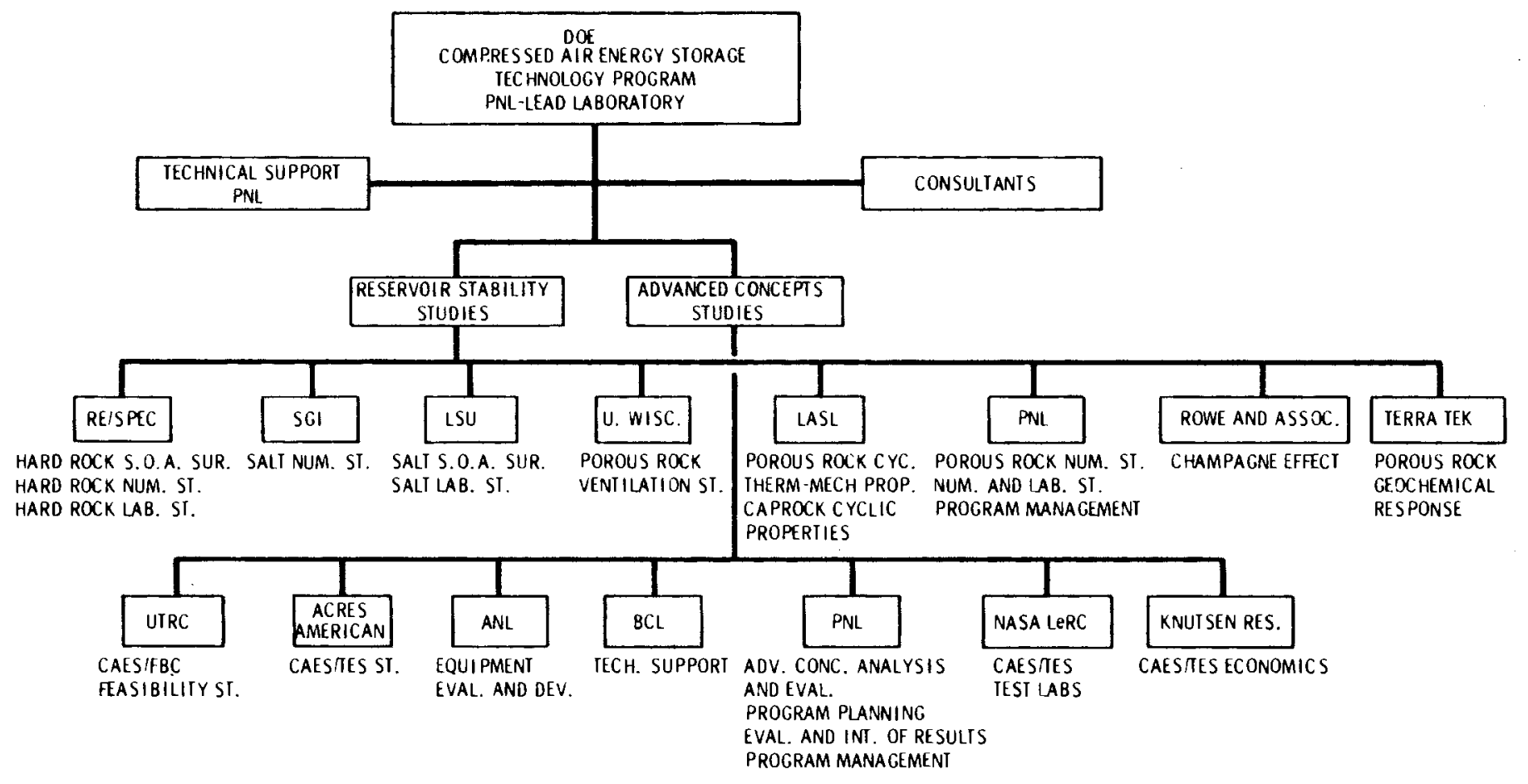

FIGURE 2. Compressed Air Energy Storage Technology Program Functional Organization 


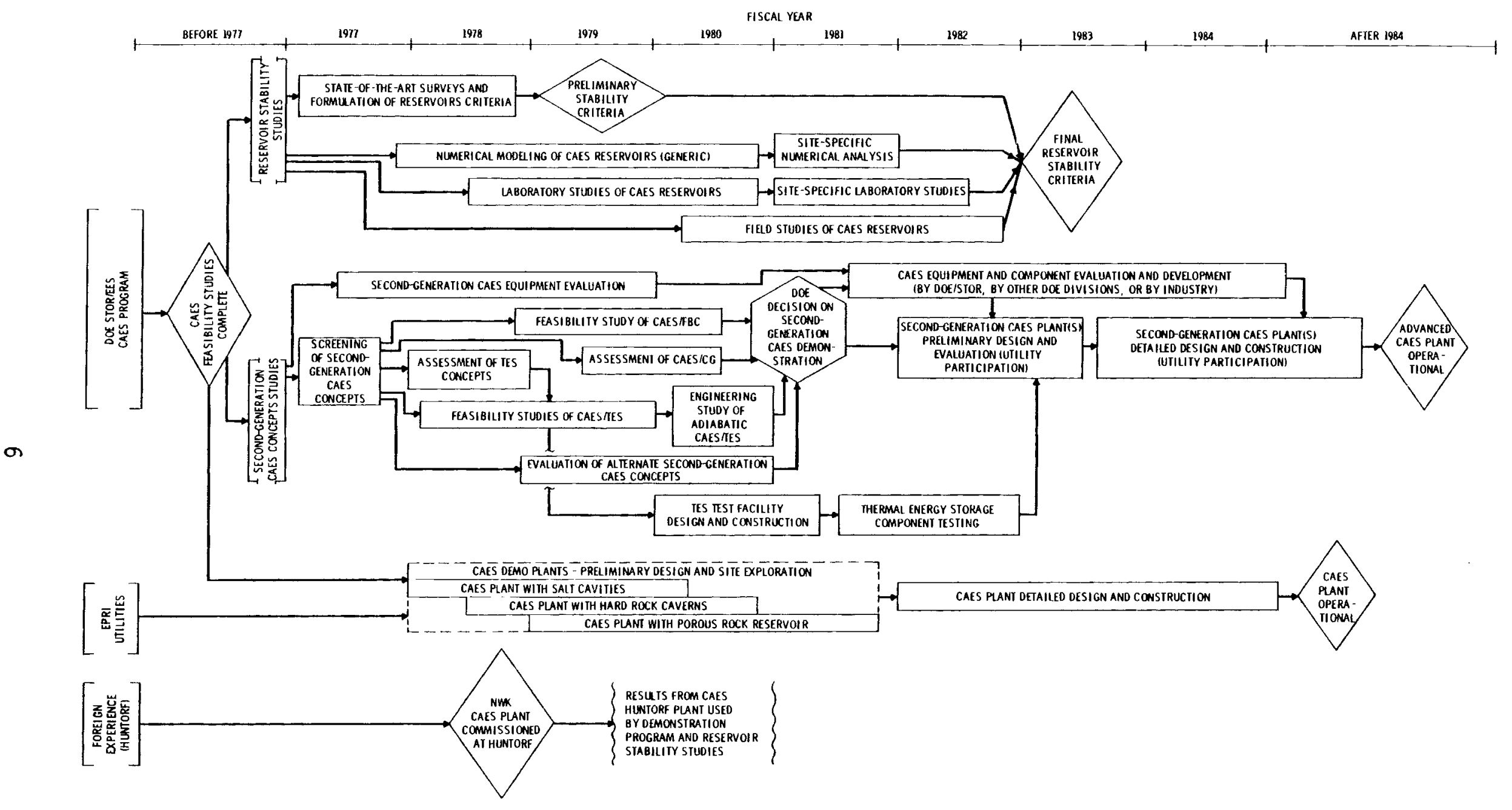

FIGURE 3. Compressed Air Energy Storage Technology Program Schedule Diagram 


\begin{tabular}{|c|c|c|c|c|c|c|c|}
\hline MILESTONE IACTIVITY FISCAL YEAR & 1979 & 1980 & 1981 & 1982 & 1983 & 1984 & $\begin{array}{c}\text { AFTER } \\
1984\end{array}$ \\
\hline \multicolumn{8}{|l|}{ A. RESERVOIR STABILITY STUDIES } \\
\hline \multicolumn{8}{|l|}{ 1. STATE-OF-THE-ART SURVEY } \\
\hline \multicolumn{8}{|l|}{ 2. NUMERI CAL STUDIES } \\
\hline \multicolumn{8}{|l|}{ 3. LABORATORY STUDIES } \\
\hline \multicolumn{8}{|l|}{ 4. FIELD STUDIES } \\
\hline \multicolumn{8}{|l|}{ 5. STABILITY CRITERIA } \\
\hline \multicolumn{8}{|l|}{ B. SECONOGENERATION CONCEPTS STUDIES } \\
\hline \multicolumn{8}{|l|}{ 1. SECONDGENERATION CONCEPT EVALUATION } \\
\hline \multicolumn{8}{|l|}{ 2. COMPONENT EVALUATION AND DEVELOPMENT } \\
\hline 3. SECOND-GENERATION CONCEPT TESTING & & & $\Delta$ & & & & 12 \\
\hline
\end{tabular}

$\nabla$ initiate activity

$\triangle$ MILESTONE

1. COMPLETE S-O-A SURVEY

2. COMPLETE NUMERICAL STUDIES

3. - COMPLETE LABORATORY STUDIES

4 - COMPLETE FIELD STUDIES

今. EStablish PRELIMINARY Stability CRITERIA

6. - ESTABLISH FINAL STABILITI CRITERIA

1) - COMPLETE SECOND-GENERATION CAES FEASIBILITY STUDY

8 DOE DECISION TO PROCEED ON DEVELOPMENT OF SECONDGENERATION TECHNOLOGIES

9. - COMPLETE COMPONENT EVALUATI ON

10. - COMPLete COMPONENT DeVElopment

11. - Initiate seconogeneration deVElopment PRoject

12. BEGIN TESTING OF SECONO-GENERATION PLANT

FIGURE 4. Compressed Air Energy Storage Technology Program Milestones 


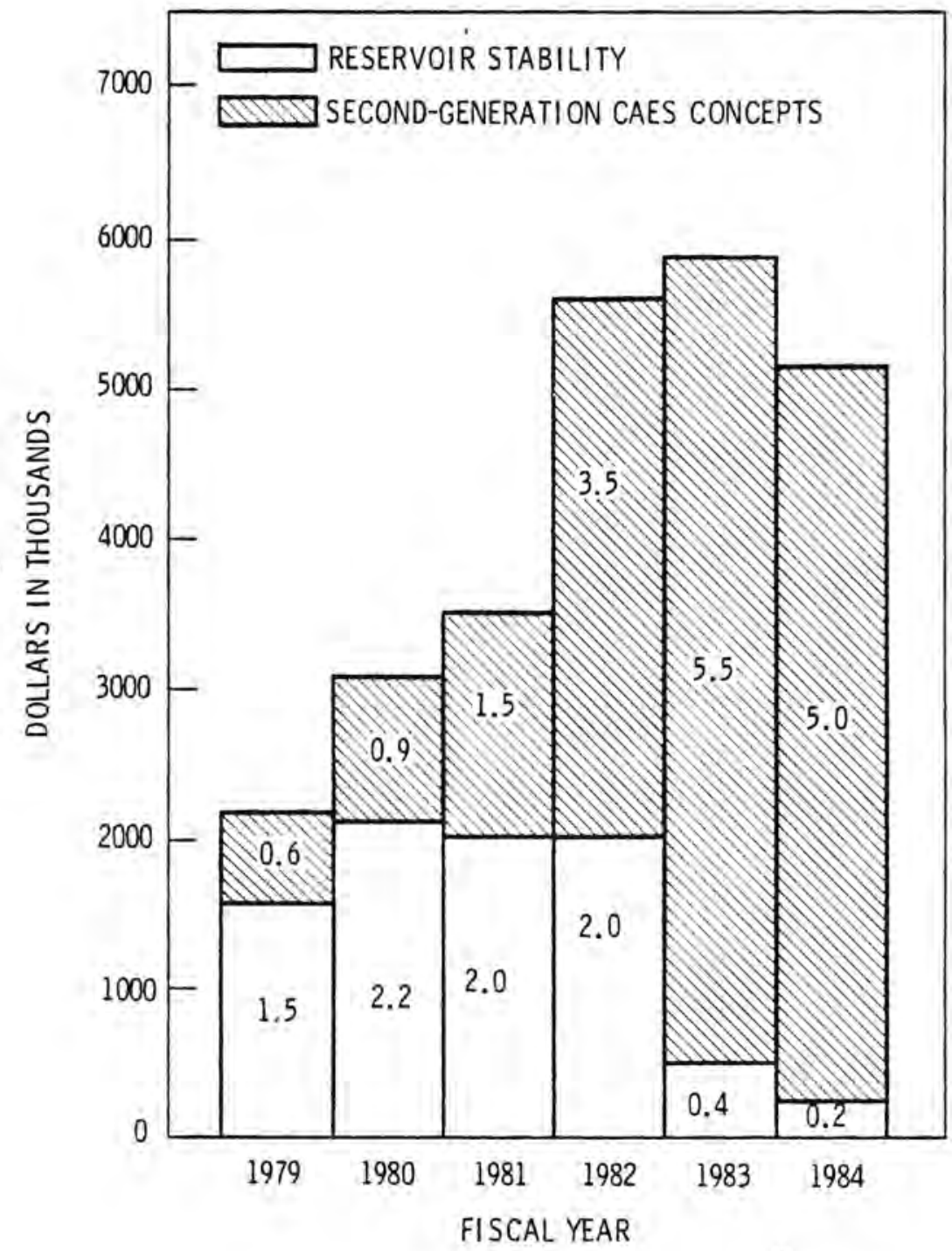

FIGURE 5. Compressed Air Energy Storage Technology Program Funding Requirements 


\subsection{CAES RESERVOIR STABILITY STUDIES}

\subsection{INTRODUCTION}

The integral part of the CAES concept is a large underground cavern used as the pressurized air container. For a nominal design, air at pressures between $5 \mathrm{MPa}(50 \mathrm{~atm})$ and $10 \mathrm{MPa}(100 \mathrm{~atm})$ is to be stored in the underground reservoirs and cycled on a daily basis. The reservoirs may be operated in either an uncompensated (constant volume) or compensated (constant pressure) mode where compensation is accomplished with water or brine. Three broad classes of rock have been identified as candidate hosts for CAES reservoirs: hard rock, porous rock, and salt.

The type of host rock is an important factor in the choice of modes for CAES operation. Excavation costs in hard rock nearly exclude operation of an uncompensated storage system. Operation of a compensated system requires relatively low storage temperatures (less than $\sim 100^{\circ} \mathrm{C}$ ) to avoid boiling and large vapor plumes when warm water reaches the surface.

Storage in salt (primarily domal) can be either compensated or uncompensated, al though uncompensated is more acceptable because of brine storage problems at the surface and concerns about control of solution, precipitation and erosion of the salt. The only operational CAES peaking power plant, at Huntorf in West Germany, uses an uncompensated salt cavity. Compressed air energy storage in salt is also generally restricted to lower temperature, less than $80^{\circ} \mathrm{C}$, because creep closure of the cavern is greatly accelerated at higher temperatures. Compressed air energy storage in porous media operates somewhere between a compensated and an uncompensated mode. No major structural problems have been identified with storage of air in porous media at less than $150^{\circ} \mathrm{C}$. Deleterious temperature effects such as rock matrix disaggregation and other geochemical effects, could restrict air storage temperatures to less than $300^{\circ} \mathrm{C}$. However, the upper temperature limit for stable reservoir operation remains to be resolved. 
Storage of natural gas and oil in underground reservoirs has been practiced for nearly 50 years. In most instances, this storage has involved seasonal cycling of gas and oil with low mass flow rates and at low temperatures relative to potential adiabatic CAES reservoir operation. Compressed air energy storage reservoirs will be subjected to daily cycling of air with attendant temperature, pressure, and humidity fluctuations. The CAES reservoirs must remain stable and operational under these conditions over periods of 30 to 50 years. Thus, while previous gas storage experience is valuable, virtually no data exist for CAES operating conditions.

The resolution of above issues could substantially improve the commercial viability of CAES. The Reservoir Stability Studies were established to resolve those issues.

\subsection{GOALS}

The goal of the Reservoir Stability Studies is to establish criteria for long-term stability of underground CAES reservoirs. These criteria are intended to be general design tools and aids that utilities and architect-engineer firms may use to evaluate reservoir stability at candidate CAES sites.

Those familiar with geotechnical engineering will agree that the determination of quantitative stability criteria for underground reservoirs is a challenging goal; a goal that is unattainable for some geotechnical issues. Nonetheless it was reasoned that pursuit of this goal would require facing the "tough" issues which would have to be addressed by those evaluating sites and designing CAES reservoirs.

Whenever possible the reservoir stability studies have been directed to meet the needs identified by utilities participating in the CAES DOE/EPRI Demonstration Program who are endeavoring to incorporate CAES into their generating system. 


\subsection{OBJECTIVES}

The objectives of the reservoir stability studies are:

- Complete investigative numerical and laboratory studies in hard rock, porous rock, and salt necessary to develop reservoir stability criteria

- Complete field studies directed toward confirmation of reservoir stability criteria.

Successful completion of the objectives should permit the establishment of reservoir stability criteria.

\subsection{STRATEGY}

Early in the program a strategy was developed for reaching our objectives and establishing reservoir stability criteria. It was recognized that a significant amount of research would be required because of the unusual and unique operating conditions and rock behavior encountered in each type of CAES reservoir. The program strategy developed had four major activities for CAES in each rock type.

- State-of-the-Art Survey: To establish preliminary reservoir stability criteria and identify areas requiring research and development.

- Numerical Modeling: To parametrically evaluate the response and stability of CAES reservoirs to a wide variety of CAES operating and geotechnical conditions. These results will be used to guide activities in other phases of the program.

- Laboratory Testing: To examine issues not presently amenable or appropriate to numerical modeling, provide data for use in numerical models, and investigate fundamental rock mechanics, thermal and fluid, and geochemical phenomena as appropriate to CAES.

- Field Studies: To corroborate numerical modeling and laboratory analyses to provide accurate estimates of reservoir response to CAES conditions, to examine geotechnical issues not amenable 
to evaluation with numerical modeling or laboratory testing, and to verify the existing reservoir stability criteria and amend as necessary.

This strategy was designed to meet the goal of the Reservoir Stability Studies and to interface with other CAES related activities being carried on by DOE, EPRI, and private concerns. Figure 3, presented earlier, highlights the scheduled reservoir stability activities and how they relate to scheduled activities by other groups. Special efforts were made to schedule activities to coordinate with the DOE/EPRI and utility sponsored CAES Demonstration Studies.

\subsection{RESERVOIR STABILITY STUDIES PROJECT DESCRIPTIONS}

Summaries of project scope and progress are presented below with short preliminary comments giving perspective to project reports. More detailed summaries are presented in Chapter 4. Table 1 provides an outline of the Reservoir Stability Studies Program.

\subsubsection{Porous Media Studies}

Natural gas has been stored in porous rock formations for more than 50 years and the conditions required for natural gas storage are similar to those for CAES. However, CAES requires daily cycling, as compared to annual cycling for natural gas. Further, air has at least twice the viscosity of natural gas, and air may have to be stored at elevated temperatures. These requirements result in a large number of unknowns regarding CAES in porous rock reservoirs.

Some of the concerns related to CAES porous media reservoir stability that are being addressed by numerical, laboratory, and field studies in the Reservoir Stability Studies include:

- low frequency fatigue caused by cyclic pressure, temperature, and humidity conditions on porous media and caprock

- reservoir material properties at nonambient conditions 


\section{TABLE 1. Outline of Reservoir Stability Studies}

\section{Title}

Studies

Thermal-Flow Analysis of Porous

Rock Reservoirs

Thermomechanical Modeling of Porous Rock Reservoirs

Air-Water-Rock Interaction in CAES Reservoirs PN

Effects of Air Ventilation of Porous Rock

Thermomechanical Properties of Porous Rock

Moist Air Flow Tests

Design and Construction of Porous Media

Flow Facility

\section{Contractor}

PNL

PIIL

U Wisc-Mi lw.

LASL

Terra Tek

PAL and

numerous vendors

Pinl and contractors

to be decided

$\mathrm{Re} / \mathrm{Spec}$ Inc.

$\mathrm{Re} / \mathrm{Spec}$ Inc.

Re/Spec Inc.

\section{Serata Geomechanics}

Louisiana St. University

PNL, Morton Salt

Co, and contractors

to be decided

Funding Level

(dollars in thousands) Status

$85^{\star}$

$55^{\star}$

$85^{\star}$

$235^{\star \star}$

$133^{\star \star}$

75*

$275^{\star}$

297*

$35^{\star \star \star}$

$276^{\star \star}$

$318^{\star \star}$

$171 * \star$

324 *

$225^{\star}$
On schedule

On schedule

on schedule

on schedule

On schedule

on schedule

one month behind schedule

on schedule

Completed

On schedule

On schedule

On schedule

on schedule

on schedule

*FY-80, if fully funded

$\star \star T o t a l$ contracts if fully funded in FY-80

$\star \star \star F Y-79$ 
- effects of reservoir morphology, anisotropy, and inhomogeneity

- response of wellbore casing and cementation materials

- wellbore desaturation and air-water interface movement

- the potential for geochemical reactions

- the generation and transport of fine particulate matter.

- Thermal-Flow Analys is of Porous Rock Reservoirs Principal Investigator - L. E. Wiles, PNL

The objective of this modeling effort is to characterize the fluidthermal behavior of a porous media reservoir. Accomplishments to date include one-dimensional radial dry and wet fluid/thermal models and two-dimensional models. Results were obtained for two-dimensional modeling of warm air injection into an axisymmetric but anisotropic reservoir. Topics investigated parametrically include, wellbore heat transfer, completion interval, and permeability anisotropy. Work is underway on a water coning model to determine vertical water movement during charge and discharge cycles. A coordinated effort will focus on a bubble development mode1. These two studies will provide the basis for a twodimensional fluid/thermal flow model for wet reservoirs.

- Thermomechanical Modeling of Porous Rock Reservoirs Principal Investigator - J. R. Friley, PNL

The objective of this task is to characterize the thermomechanical response of porous media reservoirs to cyclic thermal and pressure loads. Input from thermal flow modeling was utilized with finite element structural analysis techniques to determine poroelastic and thermoelastic response of a generic porous media reservoir. Cracking of caprock was also examined. Thermomechanical test data and failure models are being incorporated into the analysis to evaluate stress levels at temperature and safety factors. In addition stress levels near the wellbore are being examined. 
- Air-Water-Rock Interaction in CAES Reservoirs

Principal Investigator - J. A. Stottlemyre, PNL

This experimental effort is directed towards determining geochemical and microstructural response of porous media to hot, humid air. Permeability, porosity and friability are the properties of chief concern in measurements to date. Autoclave studies have been performed at high temperature and controlled humidity but without flow and sample confinement. Results indicate a need for flow and confinement to determine CAES porous media response. Early FY-1980 work concentrated on establishment of statistical significance of early results and characterizing porous media thermal properties. Construction of the flow facility, to be completed near midyear, will allow initiation of tests on confined specimens at elevated temperature to determine the response of porous media to the flow of humid air, and study desaturation rates.

- Effects of Air Ventilation on Porous Rock

Principal Investigator - H. J. Pincus, U. of Wiscons in-Milwaukee

The objective of this effort is to examine the effect of cyclic dry air ventilation at confined moderate temperature conditions on the permeability, structure and strength of porous media. A large data base acquired to date indicates trends in some rock types but no overriding phenomenon appears to be operating. In many cases, changes in the porous media are masked by material variability. A minor trend towards increased permeability in the dry air has been noted. Testing plans are now concentrated on an intensive study of a typical downhole sandstone core type to quantify the significance of this trend.

- Thermomechanical Properties of Porous Rock Principal Investigator - J. Blacic, LASL

This task is an experimental effort designed to determine the elastic and strength properties of aquifer and caprock materials under CAES operating conditions. Triaxial testing to determine failure envelopes and elastic constants at temperature and after stress cycling have been performed for sandstone from the Galesville formation. Testing for typical porous media specimens is planned along with a series of strength 
determinations for selected downhole caprock samples. Structural modeling will make direct application of this work but criteria based on strength or fatigue response may be obtained from the results.

- Moist Air flow Tests Principal Investigator - C. Cooley, Terra Tek, Inc.

This experimental study is an extension of autoclave experiments that utilize available time on existing equipment at Terra Tek. Moderate temperature tests under hydrostatic loading will allow moist air flow through samples to study the sensitivity of typical reservoir rocks to hydrolytic weakening and particulate generation phenomena. These tests are interim studies that will allow screening of the phenomena and simplification of test matrices in the flow facility. Early results of this effort have duplicated trends observed in other studies. Testing is now being performed to isolate phenomena causing permeability reduction at elevated temperatures.

- Design and Construction of Porous Media Flow Facility Principal Investigator - M. A. McKinnon, PNL

This is an equipment development task whose goal is to create an operational facility that will allow full simulation of CAES environmental conditions. Previous experimental work with parts of the environment simulated indicate that coupling between phenomena will be important for CAES porous media response determination. Facility capabilities include triaxial loading with variable load and structural properties measurement, CAES temperature range simulation and cyclic flow of controlled humidity hot air through samples. Design includes add-on capability for two more cells and ability to supplement experimental range with a liquid loop. Desaturation, permeability and porosity change, structural and thermal response are measurable. Procurement and finalization of detail design is completed and construction has been initiated. Startup is scheduled for the third quarter of FY-1980. 
- Field Studies in Porous Rock Reservoirs

Principal Investigators - R. D. Allen and P. J. Gutknecht, PNL

The goal of this task is to design and perform field studies in support of CAES reservoir stability efforts in porous media. A survey of existing literature related to field studies performance of aquifer CAES was completed. From this and inputs from other researchers a field studies plan was developed. Based on this plan, numerous sites were reviewed for potential studies. A site was selected and acquisition and confirmatory efforts are anticipated in the second half of FY-1980.

\subsubsection{Hard Rock Studies}

Hard rock caverns were first used for compressed air storage in 1916, in Norway. Since then there have been many instances of oil, gas, and air storage in excavated hard rock chambers. In general, the performance of these caverns has been satisfactory. However, a number of questions arise when hard rock caverns are used for CAES plants.

Because of the large difference in volume requirements between compensated and uncompensated caverns, current economics dictate that CAES plants utilize water-compensated hard rock caverns. As a result, pressure cycling will be minimal and the program studies will address hard rock caverns that involve daily cycling of only temperature and cavern wall wetting.

Some of the concerns related to hard rock CAES cavern stability that are being or will be addressed by numerical and laboratory studies include:

- cavern geometry and size

- effects of temperature loading rates

- low frequency fatigue caused by cyclic temperature and wetting conditions

- air penetration of hard rock mass

- hard rock properties at nonambient conditions

- residual strength of hard rock after failure

- weathering (geochemistry) of hard rocks at CAES conditions

- excavation techniques. 
- Numerical Studies of CAES Hard Rock Caverns

Principal Investigator - A. F. Fossum, Re/Spec Inc.

Compensated hard rock caverns are being examined in this study to determine geological constraints on cavern sizing, spacing and shapes, and to determine performance of the opening under alternate wet-dry, warm-cool cycles. Air leakage and water in-flow due to jointed systems is also under scrutiny. Results of initial study include the transient stresses in the cavern wall due to cyclic wetting with cool water. Calibration of numerical analysis tools is being performed by evaluation and analys is of an operational compressed air storage cavern at Trollhatten, Sweden. Supplementary studies of different rock types are planned. These and later analyses will result in formulation of stability criteria.

- Laboratory Studies of CAES Hard Rock Caverns

Principal Investigator - A. F. Fossum, Re/Spec Inc.

Laboratory studies in hard rock are required to fill voids in the existing rock mechanics 1 iterature with respect to cyclic performance of hard rock and properties at CAES operating temperatures. Conventional and fatigue testing is underway for a series of CAES candidate hard rocks. Testing is being performed on dry and water saturated specimens of both intact and jointed hard rock. Temperatures of up to $150^{\circ} \mathrm{C}$ are being used in the study. Rock types for which data have been gathered include igneous intrusive, metamorphic, and both chemical and clastic sedimentary. Early studies indicate that water has a marked influence on rock response and strength as does joint angle relative to the principle stresses. This study will result in expansion of the data base to cover knowledge essential to CAES criteria, and will provide input for numerical studies.

Additional efforts have been initiated in hard rock numerical and laboratory simulation of the "champagne effect". Numerical studies are being carried out by Rowe and Associates (through PNL) while physical modeling studies are being performed by Dr. Philip Thompson of Rensselaer Polytechnic under separate contract to the Department of Energy (DOE). Because these studies have only recently been initiated no summaries will be presented in this annual report. Field studies in hard rock 
are not planned because of the expense of such studies and because many issues identified for investigation are being addressed by other major DOE and foreign government projects.

\subsubsection{Salt Studies}

Storage of hydrocarbons in salt dome caverns has been practiced in the U.S. Gulf Coast region for more than 25 years. However, this kind of storage has involved mainly liquids and relatively slowly varying pressure loadings. Salt caverns used in CAES plants will undergo daily cycling of pressure, temperature, and humidity. Possible deleterious effects due to cyclic loadings must be identified and controlled so that the CAES caverns remain stable and functional over 30 to 50 year periods. Some of the concerns related to CAES salt cavern stability, being addressed by numerical, laboratory, and field studies include:

- cavern geometry and size

- long-term creep and creep rupture of rock salt

- effects of pressure and temperature loading rates

- low frequency fatigue caused by cyclic pressure, temperature and wetting conditions

- air penetration of salt fabric

- cavern monitoring methods

- salt properties at nonambient conditions.

- Numerical Studies of CAES Salt Caverns Principal Investigator - S. Serata, Serata Geomechanics, Inc.

This project is directed at determining the response of salt caverns to a wide range of siting and CAES operational conditions. Isothermal modeling of salt cavern response to CAES loadings was completed in May $F Y-1979$. The bulk of the progress in that effort was presented in the FY-1978 annual report. Therefore, no discussion on that effort will be presented here. Work on nonisothermal modeling of salt cavern response to CAES has only recently been initiated. 
- Experimental Studies of Domal Rock Salt

Principal Investigator - R. L. Thoms, LSU

Preliminary laboratory work has been directed at determining the behavior and permeability of salt from various sites (including Huntorf) under cyclic loads. Salt displays at least three distinct behavior patterns depending on temperature, load, loading rate, and strain rate. Therefore, the testing of salt at low fatigue rates provides vital data on the time dependent behavior of salt. In addition to the laboratory testing, bench scale testing in a pillar of a salt mine is also planned. These tests will provide some limited data on in situ salt response to CAES loadings, in particular the permeability near a CAES cavity and the effect of neighboring cavities on cavern closure. Advanced studies will focus on surficial effects of cyclic pressurization with humid air and on further bench scale tests. Preliminary results indicate that strain is bracketed to a small range for large stress cycling. The effect of thermal cycling is clearly evidenced by dramatic increases in strain rate at elevated temperatures. Acoustic emissions (AE) appear to conform directly to strain offering the possibility of using $A E$ as a monitoring tool for cavern instability. In-situ cyclic pressurization of a mine bore hole with air has been initiated.

- Field Studies of Salt Cavities

Principal Investigator - J. J. Jacobson, PNL

A preliminary survey of other salt field study activities being conducted by the Office of Nuclear Waste Isolation, the Strategic Petroleum Reserve Program, and the Solution Mining Research Institute indicated that CAES field study needs were not being met within present studies. The present concept of field studies in salt would be reduced scale testing of a 10 to $100 \mathrm{~m}^{3}$ salt cavity excavated from a salt dome in the Gulf Coast region. At present a preliminary plan has been developed and lease negotiations are being carried out with Morton Salt Company for use of a solution mined cavity at Grand Saline, Texas. Of special interest are the rates of cavern closure, the surficial effects and secondary permeability of the salt rock under CAES conditions. As with 
all other reduced scale field studies, dimensional analysis and determination of scaling effects are addressed before the test plan is completed. Numerical and laboratory analyses will be conducted apriori to predict test performance. PNL will administer and direct this effort, with major technical operations assumed by a qualified subcontractor.

\subsection{MILESTONES AND ACCOMPLISHMENTS}

\subsubsection{Milestones}

The major efforts in reservoir stability are directed toward the milestones shown in Figure 6 . The basic strategy outlined earlier is being followed by studies in each host rock type. The scheduling differs depending on how much of present day knowledge is amenable to CAES reservoirs and the scope of effort necessary to fulfill our goals.

The major milestones encountered in this reporting period include:

- Complete State-of-the-Art Survey in Hard Rock (May 1979)

- Complete Preliminary Hard Rock CAES Reservoir Stability Criteria (May 1979)

- Complete Field Study Plan for CAES in Aquifers (March 1980)

- Complete Field Study Plan for CAES in Salt (March 1980).

Three of four reports have been received from the contractor responsible for the State-of-the-Art Survey in hard rock. Reports have been issued on geotechnical issues, preliminary stability criteria for CAES in hard rock, and preliminary stability criteria for UPHS in hard rock. The only remaining report deals with a compendium of thermal, chemical, and mechanical properties of hard rock required for simulation of CAES reservoir response to CAES conditions. The Preliminary Hard Rock CAES Reservoir Stability Criteria report was received in April 1979, ahead of schedule. The Field Study Plans for CAES in both aquifers and salt were received in January 1980, ahead of schedule. 


\begin{tabular}{|c|c|c|c|c|c|c|}
\hline MILESTONE/ACTIVITY & 1978 & 1979 & 1980 & 1981 & 1982 & 1983 \\
\hline \multicolumn{7}{|l|}{ A. AQUIFERS } \\
\hline 1. STATE-OF-THE ART SURVEY & $\frac{11}{7}$ & & & 2 & 3 & \\
\hline 2. NUMERICAL MODELING & $\frac{1}{7}$ & & & 4 & 5 & \\
\hline 4. FIELD TESTING & & & 6 & & & \\
\hline \multicolumn{7}{|l|}{ B. HARD ROCK CAVERNS } \\
\hline 1. STATE-OF-THE-ART SURVEY & & 2 & & & & \\
\hline 2. NUMERICAL MODELING & & & & & 3 & \\
\hline 3. LABORATORY TESTING & & $y$ & & 4 & 5 & \\
\hline \multicolumn{7}{|l|}{ C. SALT CAVERNS } \\
\hline 1. STATE-OF-THE-ART SURVEY & & & & & & \\
\hline 2. NUMERICAL MODELING & V & & & & & \\
\hline 3. LABORATORY TESTING & & & & 4. & & \\
\hline 4. FIELD TESTING & & & 6 & & & 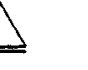 \\
\hline D. STABILITY CRITERIA & & 8 & & & & 9 \\
\hline & & & & & & \\
\hline
\end{tabular}

$\nabla$ BegINACTIVITY

$\triangle$ MILESTONE

$\triangle$ ACTIVITY BAR

1 COMPlete STATE-OF-THE-ART REVIEW

2 COMPLETE GENERIC NUMERICAL STUDIES

3 COMPLETE NUMERICAL STUDIES - SITE SPECIFIC AND FIELD STUDIES SUPPORT

4 COMPLETE GENERIC LABORATORY STUDIES

5 COMPLETE LABORATORY STUDIES - SITE SPECIFIC AND FIELD STUDIES SUUPPORT

6 PRELIMINARY FIELD STUDIES PROGRAM PLAN AND SITE SELECTION

A COMPLETE FIELD STUDIES

8 REPORT ON PRELIMINARY RESERVOIR STABILITY CRITERIA

9 REPORT ON FINAL RESERVOIR STABILITY CRITER IA

FIGURE 6. Milestones for Reservoir Stability Studies 
No major obstacles are apparent that would impair meeting subsequent milestones leading to development of reservoir stability criteria.

\subsubsection{Accomplishments}

Additional accomplishments during this reporting period include:

- Completed initial laboratory studies of air-water-rock interactions

- Completed numerical studies of moisture effects on air storage in porous rock

- Completed a two-dimensional study of CAES in a porous rock reservoir

- Completed design of a flow facility for laboratory studies of porous rock.

Citations for reports in these areas are given in Section C of the Summary. 


\subsection{SECOND-GENERATION CAES CONCEPTS STUDIES}

\subsection{INTRODUCTION}

The CAES plant at Huntorf and the conventional CAES plants currently being considered by electric utilities require firing of the turbine with petroleum fuels. Depending on the extent to which their output would replace gas and oil-fired power generation, petroleum fuel consumption can be reduced by more than 60 percent. (a) The CAES concept's dependence on petroleum fuels could become a major barrier to its large-scale implementation by the utilities.

To overcome this barrier, a number of activities have been initiated by DOE's Second-Generation CAES Concepts Studies program at PNL. These activities range from examining concepts that replace petroleum fuels with coal to those that use thermal energy storage and those that integrate CAES with solar energy. A coarse screening of the various ideas has resulted in emphasizing three of the most promising concepts for utility applications. These are 1) a CAES system with a coal-fired fluidized bed combustion process, 2) a CAES system with a coal-fired low Btu gasifier, and 3) a CAES system with various degrees of thermal energy storage. The limiting case of the last is an "adiabatic" CAES system that would have sufficient thermal energy storage capacity to eliminate the need for any fuel for the turbines.

\subsection{GOALS}

To ensure large-scale commercialization of CAES, the goal of the Second-Generation CAES Concepts Studies is to develop CAES concepts that use little or no petroleum fuels for operation. The ul timate goal of this study is to promote a full-scale demonstration of one or more of

\footnotetext{
(a) The Huntorf CAES plant required 5500 Btu of fuel per kilowatt hour (Btu/kWh) of electricity produced. Current conventional CAES plant designs require about $4000 \mathrm{Btu} / \mathrm{kWh}$. Simple cycle gas turbines used for peaking power require about 12,000 Btu/ $\mathrm{kWh}$.
} 
the advanced concepts. The demonstrations are to be joint ventures involving DOE and the electric industry, including EPRI.

It is difficult to establish cost goals for a CAES plant because of the complex interaction of the plant's capital costs with the fuel and storage charging power costs. Furthermore, CAES provides secondary benefits that are difficult to quantify and integrate into cost analyses.

Thus, the cost goals for advanced CAES concepts are almost exclusively reflections of the costs of the components that replace the petroleum fuel combustion in a conventional CAES plant. The turbomachinery and balance-of-plant must be, basically, off-the-shelf items.

With the above in mind and assuming that the general cost goal for advanced CAES plants is $\$ 60 / \mathrm{kWhr}$ (1980 dollars), the cost goal for the component that replaces the conventional combustor is $\$ 10 / \mathrm{kWhr}$. These costs are based upon preliminary estimates of maximum allowable costs that will permit the CAES concept to be economically competitive with alternatives.

\subsection{OBJECTIVES}

To develop advanced CAES technologies that require little or no petroleum fuels for operation, the following objectives have been established:

- Identify and screen second-generation CAES concepts that have potential for reduced consumption of petroleum fuels

- Establish feasibility of integrating thermal energy storage with CAES

- Establish feasibility of integrating coal-fired fluidized bed combustion with CAES

- Examine feasibility of integrating coal gasification systems with CAES

- Evaluate and develop advanced CAES equipment and components. 


\subsection{STRATEGY}

The basic strategy of Second-Generation Concept Studies is to examine all identified viable second-generation CAES concepts and perform preliminary technical and economic screening to select those that show the most promise. The next step is to perform preliminary engineering design and detailed technical and economic analyses to realistically assess the viability of these concepts. When the detailed analyses are complete, the selected second-generation CAES concepts are to be screened for relative comparison with each other and with other energy storage concepts. Following the screening process, reports and recommendations are to be made to DOE. The decisions reached by DOE on the basis of these recommendations are to be used for establishing an equipment development program and/or full-scale development/demonstration programs for one or more of the concepts. The approach is outlined schematically in Figure 7.

\subsection{SECOND-GENERATION CONCEPTS STUDIES PROJECT DESCRIPTIONS}

The following project descriptions are made according to type of activity. The project outline is shown in Table 2.

- Feasibility Study of CAES Augmentation by FBC

Principal Investigator - A. J. Giramonti, UTRC

The objectives of this task are to review and assess the state-of-theart of coal-fired fluidized bed (FBC) technology, to perform preliminary screening analysis to identify the system with the greatest potential for the near term application with CAES, to develop a preconceptual system design and to project the potential market available to a CAES/FBC system. The task was subcontracted during FY-1979 and is scheduled to be completed in mid FY-1980. Supplementary work is being planned that includes transient operation and load following, and study of required equipment development for CAES applications. 


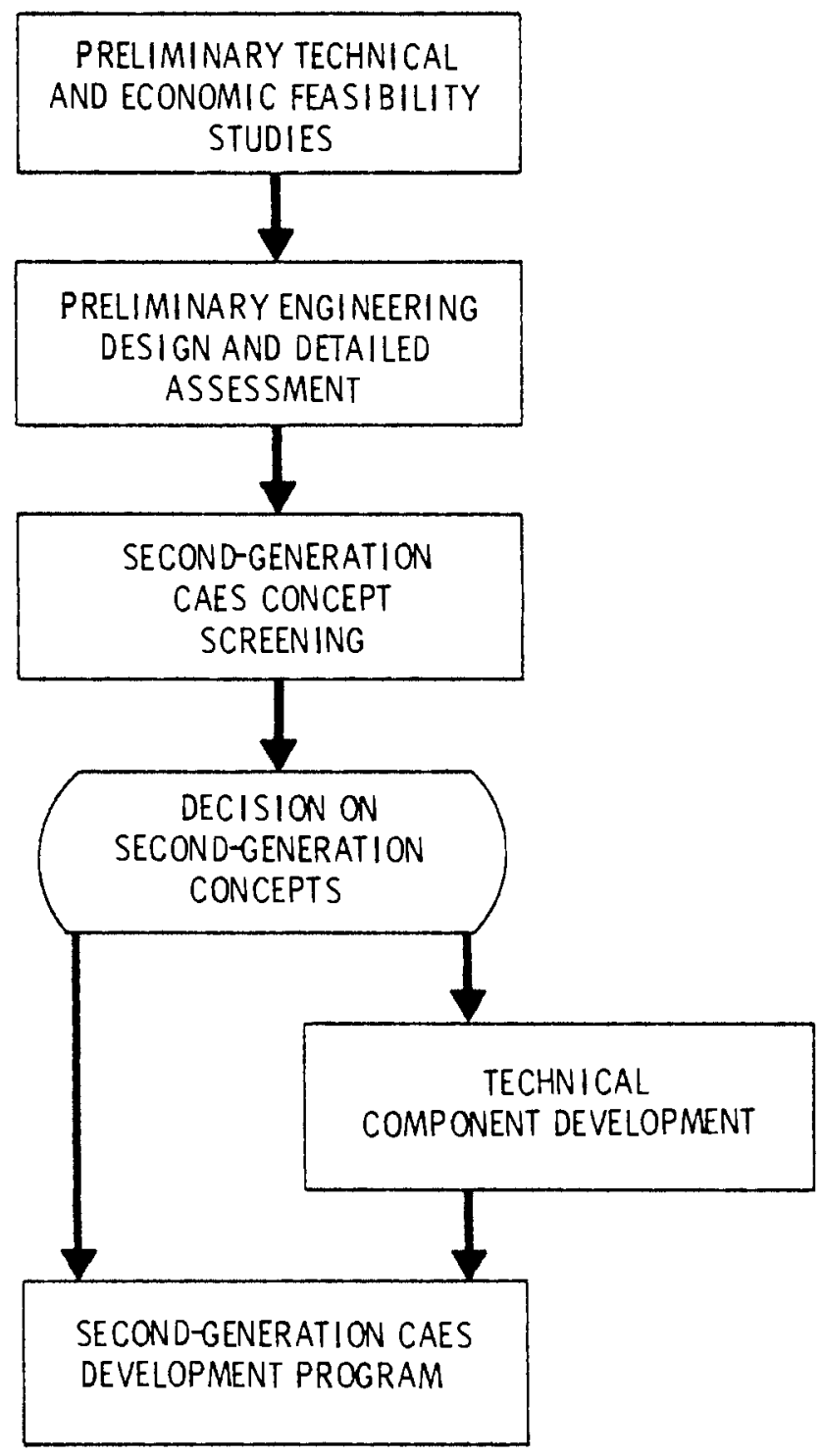

FIGURE 7. Approach Used in Second-Generation Concepts Studies 
TABLE 2. Outline of Second-Generation Concepts Studies

Title

Feasibility Study of CAES Augmentation by $\mathrm{FBC}$

Preconceptual Desion of CAES/TES Systems

Enqineerina Study of Adiabatic CAES using Hard Rock Caverns

Enaineering Study of Adiabatic CAES using Aquifers for Air Storage

Feasibility of Coal rasification and CAES (CAES/CG)

Second-reneration CAES Equipment Evaluation

Second-fieneration Concepts Analys is and Support

Economic Assessment of Second-

Generation Concepts

Thermal Energy Storage Test Facility

Advanced Storage Concepts Evaluation and Technical Assistance (ILA)

Application and Desian Studies of Compressed Air Enercy Storane for Solar Applications

*FY-1980 only

**Total contract

\section{Contractor}

United Technoloaies

Research Center

PNL

Acres American Inc.

Saraent and Lundy

PNI

PNL

PNL

$\mathrm{BCL}$

MIT

\section{Funding Level}

$\$ 27 !, 000^{\star \star}$

$50,000^{\star}$

$250,000^{\star \star}$

$20,000^{*}$

$55,000^{\star}$

$45,000^{\star}$

$9 \AA, 000^{\star \star}$

$150,000^{\star \star}$
On schedule

Planned

On schedule

Completed

On schedule

On schedule

On schedule

Planned

On schedule

lanned

On schedule 
- Preconceptual Design of CAES/TES Systems

\section{Principal Investigator - M. K. Drost, PNL}

The activity consists of developing a first cut design of several TES concepts so that a preliminary cost estimate can be made. The results of the cost analysis will be used with the CYCLOPS code to develop an optimized TES and CAES cycle arrangement. The optimized TES and cycle arrangements will be compared, and conclusions about the relative attractiveness of each TES concept can be reached. The results will be summarized in a final report with recommendations to DOE on the next step in the development of this technology. This task will include surface and subsurface TES beds and also the use of aquifers as TES devices.

- Engineering Study of Adiabatic CAES using Hard Rock Caverns Principal Investigator - M. J. Hobson, Acres American, Inc.

The activity in this project consists of engineering design and cost studies of adiabatic CAES systems with thermal energy storage using hard rock caverns for air storage. Wherever possible, information and experience gained from the Potomac Electric Power Company (hard rock) will be used by the subcontractors. The CAES systems design and the economic systems analyses will be based upon those developed in the PEPCO study. PNL prepared the statements-of-work, issued subcontracts and is monitoring this task.

- Engineering Study of Adiabatic CAES Using Aquifers for Air Storage Principal Investigator - under negotiation with Sargent and Lundy

PNL is currently negotiating with Sargent and Lundy to perform an engineering design study of an adiabatic CAES plant using aquifers for air and thermal energy storage. This project is to dovetail with the current Public Service of Indiana study of CAES with aquifers. PNL will let the subcontract and monitor the study.

- Feasibility of Coal Gasification and CAES (CAES/CG)

This task is a continuation of work initiated in FY-1979 to determine the feasibility of the concept of coal gasification integrated with 
CAES (CAES/CG) and to establish if any research and development is required. Efforts in FY-1979 included examination of all available CAES/CG information and specific CG research that is pertinent to CAES applications. A survey report is being prepared and will be completed in FY-1980.

- Second-Generation CAES Equipment Evaluation

Principal Investigator - To be determined

This task is a study of the technical limitations of the available turbomachinery for advanced CAES plants. This work was initiated at Argonne National Laboratory in FY-1978 but has been halted in FY1980 pending results of engineering studies of advanced CAES concepts. Its goal is to identify the ranges of temperature, pressure, etc. that off-the-shelf equipment can provide for advanced CAES concepts. A request for proposal (RFP) is planned, when studies of advanced CAES concepts are completed, that will examine the results of the engineering studies and explore the development requirements and costs of developing equipment for advanced CAES plants.

- Second-Generation Concepts Analys is and Support

Principal Investigator - F. R. Zaloudek, PNL

The activities scheduled for this task are directed at providing integration of all in-house and subcontracted tasks in the SecondGeneration Concepts Studies. Their purpose is to develop the documentation that could be used in making recommendations to DOE/STOR on development of second-generation CAES concepts. Major activities in this task include the following:

- Acquire, compile and integrate data on all projects related to advanced CAES systems. Develop a screening technique and prepare recommendations to DOE/STOR on which of the second-generation CAES concepts DOE should continue into the development/demonstration phase.

- Modify and use the CYCLOPS code to permit preliminary technical and economic screening analysis of the various advanced CAES alternatives. The code will also be used to support all other related studies that require cycle analysis. 
- Screen and evaluate new concepts and new ideas for CAES. This includes evaluation of unsolicited proposals and development of new applications.

- Economic Assessment of Second-Generation Concepts Principal Investigator - R. W. Reilly, PNL

In this task, the goal is to provide economic analysis support to the Second-Generation Concepts Studies project. The intent is to lay the groundwork for a comprehensive report, to be made to DOE early in FY-1981, which will identify the second-generation CAES concepts meriting further research and/or development.

The project is composed of two main tasks. The first develops the methodology and background data for analys is of advanced CAES system designs, and then provides such analys is for systems presently under study or development. The second compares the economics of the most promising of these advanced CAES systems to competing near-term technologies.

- Thermal Energy Storage Test Facility

An experimental thermal energy storage (TES) test facility has been identified as a necessary element of the CAES/TES studies. DOE's Division of Electric Energy Storage asked NASA-Lewis to become the lead laboratory to develop a thermal energy storage test facility in FY-1979. However, NASA is relinquishing all DOE TES programs and the responsibility for this project has been assumed by PNL.

The objective of this task is to build an experimental TES test facility, develop the technology and evaluate the economics for integrating sensible heat, packed bed, thermal energy storage with CAES.

- Advanced Storage Concepts Evaluation and Technical Assistance (ILA) Project Manager - W. A. Moore, BCL

Under this project, Battelle Columbus Laboratories ( $B C L$ ) assists the Division of Energy Storage Systems in evaluating several advanced 
mechanical storage concepts, in planning and formulating R\&D strategies, and in preparation of multiyear program plans and program approval documents .

- Application and Design Studies of Compressed Air Energy Storage for Solar Energy Applications Project Manager - G. T. FTynn, MIT

The objective of this study was to investigate advanced nonfired CAES concepts with particular attention given to solar applications. The basis for the nonfired CAES system was the adiabatic cycle.

\subsection{MILESTONES AND ACCOMPLISHMENTS}

\subsubsection{Milestones}

The milestones for the Second-Generation Concepts Studies are shown in Figure 8 . The critical item is the decision to be made in FY-1981 with respect to what second-generation technologies should be promoted into the component and concept technological development phase. Preceeding that decision are the various studies on integration of thermal energy storage, coal gasification, and coal-fired fluidized bed combustion with CAES. Most of the studies are progressing on schedule. The coal-fired fluidized bed combustion and coal gasification studies are to be completed in FY-1980. The first of the thermal energy storage/CAES studies is to be completed in FY-1980 and a second early in FY-1981. These studies will provide the primary information for decisions on the future activities in the Second-Generation Concepts Studies project.

\subsubsection{Accomplishments}

Major accomplishments in the Second-Generation Concepts Studies for the reporting period were as follows:

- Completed report of the study of CAES/TES and CAES/solar systems (Applications and Design Studies of CAES for Solar Applications, $G$. T. Flynn and J. L. Nash-Webber, Massachusetts Institute of Technology, MIT CAES-7, September 1979) 


\begin{tabular}{|c|c|c|c|c|c|c|c|}
\hline ACTIVITY/MILESTONE & 1979 & 1980 & 1981 & 1982 & 1983 & 1984 & AFTER 1984 \\
\hline $\begin{array}{l}\text { A. SECONO-GENERATION CONCEPT EVALUATION } \\
\text { 1. CAES / TES } \\
\text { 2. CAES / FBC } \\
\text { 3. CAES/CG } \\
\text { 4. OTHER ADVANCED CONCEPTS } \\
\text { B. COMPONENT EVALUATION AND DEVELOPMENT } \\
\text { 1. DEFINITION / PROCUREMENT } \\
\text { 2. DEVELOPMENT / TESTING } \\
\text { C. TECHNOLOGY DEVELOPMENT } \\
\text { 1. PRELIMINARY DESIGN AND EVALUATION } \\
\text { 2. DETAILED DESIGN AND CONSTRUCTION } \\
\text { 3. OPERATION AND TESTING }\end{array}$ & & $\frac{2}{3}$ & $\frac{14}{(4)}$ & 5 & $\frac{8}{8}$ & & $\frac{9}{7 / 0}$ \\
\hline
\end{tabular}

$\begin{array}{ll}\searrow & \text { BEGIN ACTIVITY } \\ \triangle & \text { MILESTONE } \\ \bigcirc & \text { DOE DECISION } \\ \searrow & \text { TECHNOLOGY READINESS } \\ - & \text { ACTIVITY BAR }\end{array}$

1. ESTABLISH FEASIBILITY OF CAES / TES
$\hat{2}$ ESTABLISH FEASIBILITY OF CAES / FBC

3. ESTABLISH FEASIBILITY OF CAES/CG

(4) DOE DECISION - SELECT CONCEPT FOR DEVELOPMENT PROGRAM

5 COMPLETE FEASIBILITY STUDIES OF OTHER ADVANCED CONCEPTS

6 COMPLEE COMPONENT EVALUATION

A COMPLETE COMPONENT DEVELOPMENT

B COMPLETE PRELIMINARY PLANT DESIGN AND EVALLATION

9 COMPLETE DETAILED PLANT DESIGN AND BEGIN CONSTRUCTION

10 BEgIN TESTING OF SECOND-genERATION PLANT

FIGURE 8. Milestones for Second-Generation Concepts Studies 
- Completed report on the economics of CAES/TES system (The Economics of CAES Employing Thermal Energy Storage, S. C. Schul te and R. W. Reil1y, PNL-3191, November 1979)

- Selected preferred coal-fired fluidized bed combustor system for CAES (Technical and Economic Assessment of FBC Augmented CAES Systems, R. D. Lessard, United Technologies Research Center, Progress Reports 3 and 4, December 1979)

- Initiated engineering design studies of adiabatic CAES plants (Conceptual Design and Engineering Studies of Adiabatic CAES, Acres American, Inc., awarded September 1979)

- Initiated activity on design of thermal energy storage test facility for CAES

- Evaluated novel CAES concepts, e.g., a two-task, closed-loop low pressure ratio system (Advanced CAES Concepts Studies, R. T. Allemann and M. K. Drost, PNL, 1979 Contractors Review, August 1979)

- Evaluated adiabatic CAES cycles using aquifers for air and thermal storage (M. K. Drost, PNL report to be published).

The above accomplishments are elements of projects that were performed either partially or totally during the reporting period. 
- 1 


\subsection{PROGRESS SUMMARIES}

In this section detailed discussions are given of the individual projects that comprised the Reservoir Stability Studies and SecondGeneration CAES Concepts Studies during this reporting period. Topics discussed are organized according to:

- Project Objectives

- Project Tasks

- Technical Progress

- Technical Problems

- Publications. 
. 


\subsection{1a Thermal-Flow Analys is of Porous Rock Reservoirs}

L. E. Wiles and R. A. McCann

Pacific Northwest Laboratory

\section{OBJECTIVES}

The fundamental objectives of the numerical analysis of the fluid/thermal behavior of porous media reservoirs for CAES are:

- characterize the fundamental response of the reservoir to CAES loading conditions

- define the sensitivity of reservoir performance to variations in reservoir parameters

- provide performance data to the parallel efforts of structural analysis, geochemical evaluations and field studies

- develop tools for site evaluations for field studies and commercial CAES facilities.

\section{TASKS}

Efforts towards the above objectives were initiated in FY-1977. Two tasks were defined for the reporting period covered by this review (Apri1 1, 1979 to Apri1 1, 1980).

Task 1. Analysis of Single-Phase (Dry Air) Nonisothermal Flow in a TwoDimensional CAES Reservoir

Use a computer code that models single-phase (dry air) nonisothermal flow in a two-dimensional $(r-z)$ reservoir to evaluate parameters that enter the model by virtue of inclusion of the vertical dimension.

Task 2. Analysis of Two-Phase (Air-Water) Isothermal Flow in a TwoDimensional CAES Reservoir

Develop a computer code that models two-phase (air-water) isothermal flow in a two-dimensional $(r-z$, or $x-y)$ reservoir to evaluate the potential for water coning and the time required to develop the air storage bubble. 


\section{TECHNICAL PROGRESS}

Task 1. Analysis of Single-Phase (Dry Air) Nonisothermal Flow in a TwoDimensional $(r-z)$ Reservoir

The analysis was performed by establishing a set of reference conditions for the reservoir geometry, material properties, and operating conditions. In general, single parameters were then varied over a range of conditions to determine the sensitivity of reservoir response. The model used in this analysis uses a finite difference method to solve the equations for conservation of mass, momentum, and energy in the belowground system. The significant assumptions are:

- the region of interest is free of water, and

- the performance of the reservoir is represented by the performance of a single well.

Conditions examined with the model related to either the wellbore heat transfer between the earth's surface and the reservoir or to the effect on the pressure and temperature response in the porous zone due to vertical flow perturbations in that region.

The wellbore heat transfer was evaluated with respect to insulation, preheating (bubble development using heated air), air storage volume and porous zone depth. The responses that were of primary concern were the effect of the heat transfer on thermal energy recovery and therma 1 cycling in the wellbore.

The results relating to thermal energy recovery are shown in Figure 9. The previous one-dimensional studies implied that there were no wellbore heat losses. Therefore, curve 7 (no wellbore heat loss) contrasts significantly with curve 1 (no wellbore insulation). Comparison of curves 1 and 4 (insulated wellbore) indicates the benefit of a moderate amount of wellbore insulation. Curves 2 and 5 indicate that the beneficial effects of preheating on thermal energy recovery are rapidly dissipated. The effect of air storage volume and reservoir depth are related to the air mass flow rate and, therefore, to the rate of thermal energy entering 


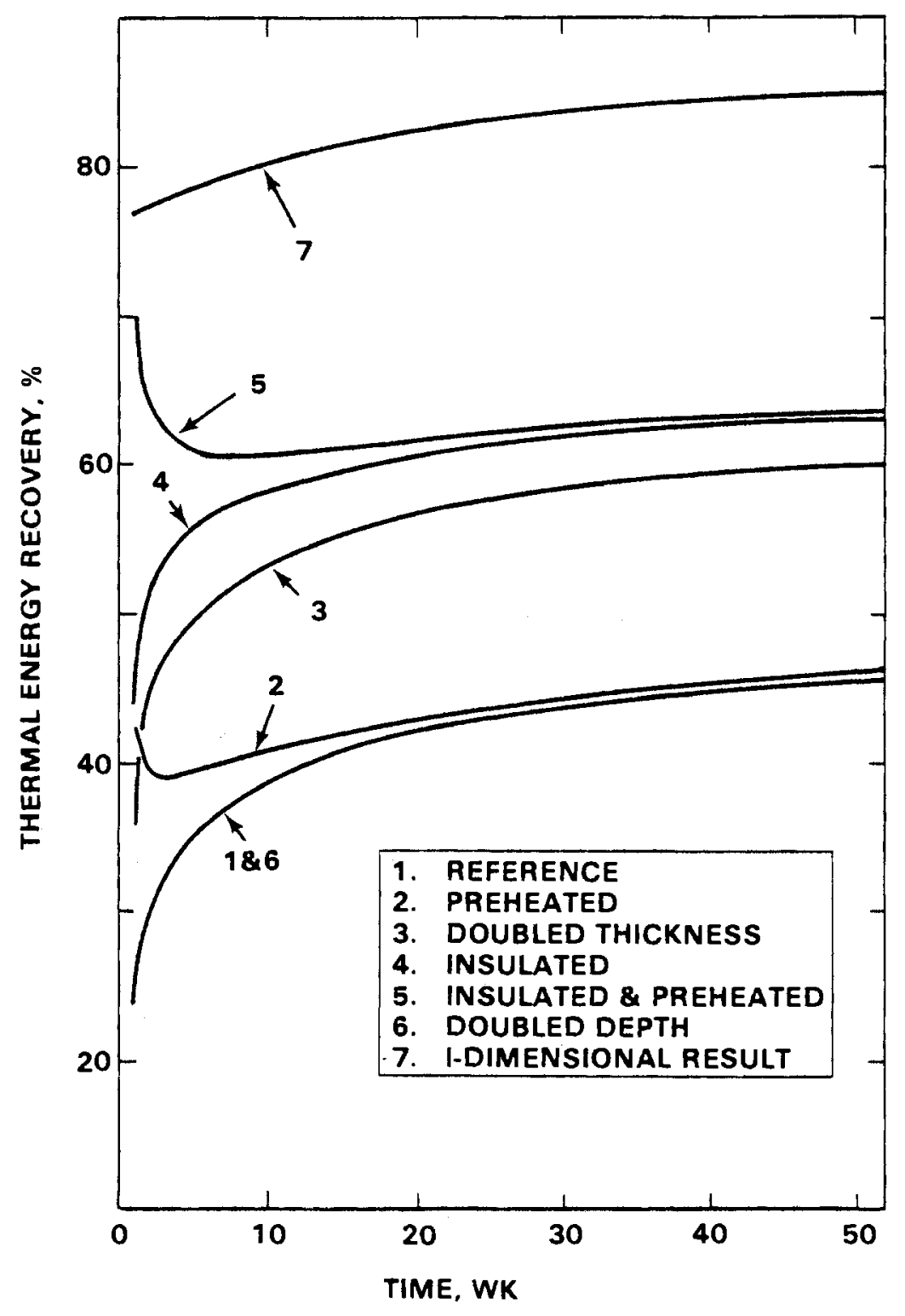

FIGURE 9. Effect of Wellbore Heat Transfer on Thermal Energy Recovery 
the underground system. This will affect the magnitude of the results compared to the reference conditions but the same characteristic behavior occurs, as seen by comparing curves 3 and 6 with curve 1 .

While wellbore heat transfer reduces thermal energy recovery, it reduces thermal cycling and temperatures at the porous zone. From a reservoir stability consideration, this might be an advantage. The high temperatures and greater extremes of thermal cycling are more pronounced near the surface which may pose special problems in casing design and well completion.

Within the porous zone, the parameters that were evaluated were the producing length and anisotropic and stratified permeability. The results of the analysis indicated that the reservoir response was most sensitive to the producing length and that a thin horizontal layer of low permeability would not significantly affect reservoir performance provided that the producing section of the wellbore extended through that layer. Reducing the producing length of the wellbore for a given air mass flow rate would result in a nearly linear increase in the pressure drop between the bulk of the reservoir and the wellbore. Therefore, operational efficiency is highest when the producing length is maximized.

Task 2. Analys is of Two-Phase (Air-Water), Isothermal Flow in a TwoDimensional CAES Reservoir

The development of a numerical computer model was initiated in FY1980 for the purpose of analyzing isothermal two-phase flow in the porous media reservoir with the inclusion of the effects of capillary pressure and relative permeability. Results obtained previously indicated that reservoir pressure losses and temperature distributions were highly sensitive to producing length. For reservoirs characterized by having a water saturated zone below the air storage zone, the producing length will have to be established in consideration of the potential for water coning, which may occur during a reservoir discharge cycle. Potentially adverse geochemical reactions may also occur due to the interaction of air and water, leading to degraded reservoir performance. 
Experience in natural gas storage indicates that the time required for bubble development may be on the order of years. A two-phase, two-dimensional model is necessary to predict bubble development times for various reservoir conditions. Such a model could be used to optimize the time required for bubble growth.

\section{Literature Survey}

An investigation of the open literature was carried out to provide a basis for developing the two-phase flow model. This investigation essentially touched upon two fundamental categories. The first was the physical description of how individual fluids and coexistent fluids behave in porous media. Of particular importance to the model were the relationships between relative permeability and fluid saturations, and capillary pressure and fluid saturations. A second area of literature review was the application of mathematical and numerical techniques to two-phase flow in the reservoir. At least four basic techniques are available for the numerical solution, with variations existing for each technique. Line successive over relaxation (LSOR) is an attractive computational technique that has been applied to simulation of coning in $0 i 1$ and gas reservoirs. The effectiveness of this technique is enhanced by the use of "additive corrections" which locally smears high continuity errors. The alternating direction implicit (ADI) method has also been applied to problems similar to those of interest here but it is not as flexible as other methods. The strongly implicit procedure (SIP) has been shown to be superior to the ADI method for multiphase reservoir problems including coning, particularly as the complexity increases. The fourth method, direct matrix inversion, is generally only suitable to specialized problems due to the necessity for computing, storing, and inverting a large coefficient matrix. The vertical equilibrium (VE) method, a technique applicable to all the above solution algorithms, provides for virtual elimination of computations in the vertical dimension by assuming that each fluid phase varies hydrostatically in the direction normal to the confining strata. The VE method will be evaluated for bubble development computation following the well coning studies. 
The LSOR technique with "additive corrections" was used for early computations of well coning. Weak coupling between pressures and saturations in this version of the model resulted in excessive numbers of iterations to convergence. Stronger coupling and faster convergence was achieved by replacing the liquid pressure with a functional relationship between gas pressure and liquid saturation. Although a substantial improvement in code efficiency was obtained, parametric examination of reservoir behavior is still very expensive. More effective methods of obtaining a solution will be examined if time and funds permit.

Verification and Parametric Studies

As the numerical model is developed, it will be tested against known analytic solutions for special test case problems and against solutions and experimental results presented in the literature. This analysis will serve the purpose of establishing the validity of the solutions obtained from the code.

A gravity drainage problem has been solved. A vertically uniform fluid distribution was set as the initial condition. The fluid was allowed to fall until equilibrium was reached. The capillary transition zone between a fully saturated region and an overlying region containing only residual water was satisfactorily predicted. Conditions simulating coning and bubble development have been computed but have not been carried out far enough to suggest the effectiveness of the code for performing a parametric study.

The parameters that are believed to be important to coning include mass flow rates, the length of the producing section of the wellbore relative to the thickness of the air storage zone, and the directional permeability. These parameters are most likely to effect the near-wellbore pressure response which would lead to coning. Another important factor may be the thickness of the saturated zone below the air storage zone. The parameters important to bubble development include the gas overpressure 
(difference between gas pressure and hydrostatic pressure), permeability, wellbore producing length, thickness between confining strata, and the ability to produce water from wells both inside and outside the bubble. With the deveiopment of an appropriate numerical tool, these parameters will be evaluated.

TECHNICAL PROBLEMS

No insurmountable problems are presently anticipated.

\section{PUBLICATIONS}

L. E. Wiles, The Effects of Water on Compressed Air Energy Storage in Porous Rock Reservoirs. PNL-2869, Pacific Northwest Laboratory, Richland, WA, March 1979 .

L. E. Wiles, Numerical Analysis of Temperature and Flow Effects in a Dry Two-Dimensional, Porous-Media Reservoir Used for Compressed Air Energy Storage. PNL-3047, Pacific Northwest Laboratory, Richland, WA, October 1979. 


\subsection{1b Thermomechanical Modeling of Porous Rock Reservoirs J. R. Friley \\ Pacific Northwest Laboratory}

\section{OBJECTIVE}

The objective of the structural analysis effort is to develop analysis capability for structural modeling of a porous rock CAES reservoir and to use this capability to model the behavior of a generic site well under typical operating conditions. While material property selection undoubtedly will strongly influence the structural behavior, it is felt that the salient response modes can at least be identified in this fashion.

\section{TASKS}

\section{Task 1}

This task involved the modification of an existing finite element computer program to treat the structural loading component due to pore pressure in a porous thermoelastic material. The modification treats structural response due to pore pressure by assuming that the two behavioral modes of fluid flow and mechanical response are uncoupled. In addition to pore pressure loading, in-situ effects and thermal loading capabilities were also required.

\section{Task 2}

In Task 2, 3, and 4, several modes of material response were to be investigated. Task 2 invoived assessing a Mohr Coulomb margin of safety for the sandstone of the porous zone.

Task 3

The objective of this task was to assess the magnitude and expanse of rock zones exhibiting tensile behavior. Such behavior if extensive, could result in leakage problems. 


\section{Task 4}

Under this task, fatigue stresses in the porous and caprock regions of the well will be investigated. Cyclic loading of temperature and pore pressure will induce cyclic (fatigue) stress levels. The magnitude and distribution of these stresses in the porous and caprock region are to be investigated.

\section{Task 5}

The stiffness of the overburden above the caprock will likely influence the resultant stress response of the reservoir. This task assesses this effect by investigating two models using caprock stiffnesses believed to bound the overburden stiffness expected to be present in most porous CAES sites.

Task 6

This task involves a code development effort to incorporate an axisymmetric shell element into the finite element computer code currently being used. The additional capability will allow more refined treatment of different well-completion techniques.

\section{TECHNICAL PROGRESS}

Task 1

An existing finite element code was selected for modifications dealing with thermo-poroelastic material behavior. The computer code is the ADINA program developed by Klaus Bathe, Massachusetts Institute of Technology. Modifications to treat these effects for two-dimensional axisymmetric models have been completed. A slight additional modification to treat orthotropic thermal expansion behavior is being incorporated at this time.

Task 2

A Mohr Coulomb failure envelope was used to assess the likelihood of rock damage in the porous zone. This Mohr Coulomb data was taken from thermomechanical tests performed on Galesville sandstone. Test 
conditions differed somewhat from nominal conditions of a porous CAES environment. Initial results, however, show that appreciable porous rock failure is unlikely. Work is currently underway to compare the porous rock response to Mohr Coulomb data more germane to anticipated porous CAES conditions.

Task 3

Most design procedures neglect any tensile load-bearing capacity of rock. If analytical modeling indicates an appreciable degree of rock under tensile stresses, then the potential for rock fracture or loosening of rock along pre-existing faults exists. Tensile stresses were observed to occur only in the caprock region of the models analyzed. The porous zone showed no tensile stress components. The response mode which caused these caprock tensile stresses to occur involved the thermal. strain behavior of the porous zone. The size of the porous zone experiencing elevated temperature was observed to be appreciably greater in diameter than the region of caprock which experienced high temperatures. Radial expansion of the porous zone stretched the central portion of the caprock causing tensile hoop stress to develop in the central caprock region. In addition, vertical growth of the central porous zone forced the caprock upward and induced a tensile flexure stress component on the top surface of the caprock. The magnitude of this flexure effect was seen to depend largely on stiffness of the overburden (See Task 5).

Task 4

Porous CAES sites will be subjected to cyclic structural loading due to the daily charge/discharge operation. This task involves the study of the cyclic components of stress due to fluctuations of pore pressure and temperature.

Fatigue stress effects were investigated by evaluating shear stress magnitudes for load cases corresponding to daily cyclic loading. This was done for various times during the first year of simulated site operation. The following trends were observed: 
- Fatigue stress levels tended to diminish with reservoir age and approach a steady state spatial distribution.

- This distribution of fatigue stresses was concentrated in the central region of the well model.

- Fatigue stresses were substantially greater in the porous zone than in the caprock.

Task 5

The effect of overburden stiffness on stress behavior was investigated by performing two sets of analyses which bracket this stiffness effect. The first set of analyses simulated overburden simply as a hydrostatic pressure loading, thus simulating no overburden shear stiffness. The second set of analyses restrained vertical motion of the top surface of the caprock (while allowing free radial motion) thus simulating large overburden stiffness. The primary difference in structural behavior between the two simulations was the tensile stress observed in the caprock. For the set of analyses simulating no overburden shear stiffness, flexure tensile stresses occurred on the top surface of the caprock. For the restrained caprock model, this flexure behavior was inhibited and tensile stresses were reduced.

\section{Task 6}

Development of finite element stiffness and thermal load matrices for an axisymmetric membrane shell element has been completed. Work is currently underway to add this element to the modified version of the ADINA computer program. Analyses addressing well completion configurations will be performed when this task is completed.

TECHNICAL PROBLEMS

None

PUBLICATIONS

J. R. Friley, Structural Analysis of Porous Rock Reservoirs Subjected to Conditions of Compressed Air Energy Storage. PNL-3231, Pacific Northwest Laboratory, Richland, WA, January 1980. 


\subsubsection{Air-Water-Rock Interaction in CAES Reservoirs}

J. A. Stottlemyre

Pacific Northwest Laboratory

\section{OBJECTIVE}

The objectives of this project are: 1) determine the potential for and magnitude of alterations in fluid and heat transport properties, load bearing capacities, and fluid chemistries for aquifer materials subjected to CAES or STES operating conditions, 2) develop generic design, operation, and maintenance criteria, and 3) for specific field site(s) generate data in support of environmenta 1 reporting and design and operation criteria development.

\section{TASKS}

Task 1. Criteria Development

The laboratory support project involves several component investigations which generally fall into the following stability categories: caprocks, storage rocks, and well materials (Figure 10). Studies are being funded at Pacific Northwest Laboratory, Los Alamos Scientific Laboratories (LASL), Terra Tek, Inc., and the University of Wisconsin at Milwaukee (UWM). The LASL, Terra Tek and UWM studies are reported independently and therefore are not expanded upon here. Technical output from these efforts are to be integrated into an evolving stability criteria document. The responsibility for this integration resides within Task 1 .

Task 2. Well Materials Investigations (PNL)

This task involves literature integration and laboratory scale experimentation of carbon steel casing corrosion and thermal fatigue and completion cement dehydration and thermal fatigue.

Task 3. Reservoir Storage Materials - Fluid Flow, Thermophysical, and Microstructural Properties Characterization (PNL, Terra Tek, UWM)

This task involves several components: 1) heated cyclical dry air flow experiments, 2) thermophysical property measurements, 3) autoclave 


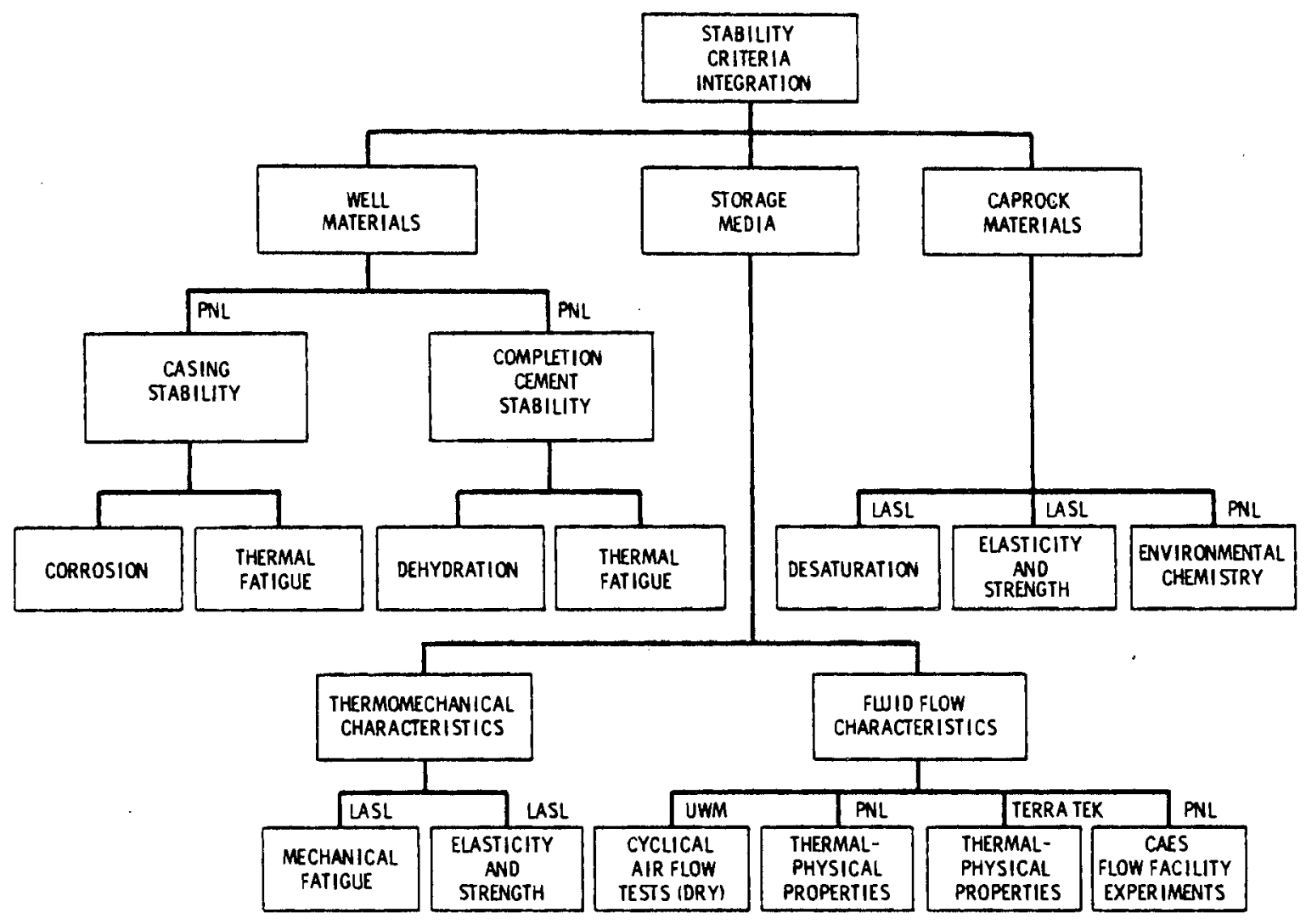

FIGURE 10. Functional Structure of Porous Media Laboratory Studies

geochemistry tests, and 4) simultaneous stress-strain, permeability, and fluid chemistry investigations. Desaturation and thermal fatigue testing is planned for late in the fiscal year.

TECHNICAL PROGRESS

Task 1. Criteria Development

Efforts have been limited to administrative and management aspects of PNL studies and external contracts. The most notable activities include: 1) development of a detailed experimental strategy for the Terra Tek study, 2) planning for and participating in a workshop designed to review CAES and Seasonal Thermal Energy Storage (STES) past and future laboratory efforts, 3) refocusing the LASL activities towards 
caprock investigations, 4) integrating CAES and STES support activities, and 5) developing a detailed test matrix for the CAES flow facility currently approaching completion.

Task 2. We11 Materials Investigations

Activity has centered on corrosion investigations with carbon steel casing samples exposed to anticipated CAES conditions. This work will be completed in April 1980 with a detailed topical report to follow. As such, progress reported herein is based on a post-test analys is of only 35 of the 114 samples tested. Some corrosion data are available in the literature for aerated steam environments and where appropriate, these data were correlated with the current test results for dry and humid compressed-air environments.

Initial results are listed in Table 3 for dry and humid air at $50^{\circ} \mathrm{C}, 175^{\circ} \mathrm{C}$ and $300^{\circ} \mathrm{C}$ and for three common casing materials. Corrosion rates in excess of $2.0 \mathrm{mil1s}$ per year have not been observed in the samples analyzed thus far. A trend towards enhanced corrosion rates

TABLE 3. Initial Results of Corrosion Tests

\begin{tabular}{|c|c|c|c|}
\hline \multirow[b]{2}{*}{ Material } & \multirow{2}{*}{$\begin{array}{c}\text { Test } \\
\text { Temperature } \\
{ }^{\circ} \mathrm{C} \\
\end{array}$} & \multicolumn{2}{|c|}{ Mils Per Year (MPY) } \\
\hline & & $0 \%$ Humidity & 100\% Humidity \\
\hline $\begin{array}{l}\text { A120 } \\
\text { H40 series } \\
\text { A53B }\end{array}$ & 50 & $\begin{array}{l}0.05 \\
0.16 \\
0.09\end{array}$ & $\begin{array}{l}0.29 \\
0.35 \\
0.31\end{array}$ \\
\hline $\begin{array}{l}\text { A120 } \\
\text { H40 series } \\
\text { A53B }\end{array}$ & 175 & $\begin{array}{l}0.89 \\
0.72 \\
0.20\end{array}$ & $\begin{array}{l}1.07 \\
0.97 \\
1.41\end{array}$ \\
\hline $\begin{array}{l}\text { A120 } \\
\text { H40 series } \\
\text { A53B }\end{array}$ & 300 & $\begin{array}{l}0.62 \\
0.85 \\
0.69\end{array}$ & $\begin{array}{l}1.59 \\
1.61 \\
1.48\end{array}$ \\
\hline
\end{tabular}


with increases in temperature and/or humidity has been observed. Of special interest is the general ease with which the corrosion scale (hematite) can be scraped from the $50^{\circ} \mathrm{C}$ samples as compared to the $175^{\circ} \mathrm{C}$ and $300^{\circ} \mathrm{C}$ samples. Since this scale is a potential source of particulates which might plug a porous reservoir rock, additional study of this phenomenon is warranted. In addition, the competence of the scale may dictate whether corrosion rates remain constant or decrease substantialiy with time due to protective scale formation.

The complete test matrix is listed in Table 4 . The experiments are performed in highly corrosive-resistant titanium autoclaves using $2.54 \mathrm{x}$ $2.54 \times 0.64 \mathrm{~cm}$ coupons of A120, H40, and A53B carbon steel casing materials. Corrosion scale exhibited patchy to complete coverage, reddish color, and was identified by $x$-ray diffraction to be the iron oxide (hematite). The rate of corrosion was determined based on metal weight loss subsequent to scale removal with a $500 \mathrm{ml} \mathrm{HCl}, 500 \mathrm{ml} \mathrm{H} 2 \mathrm{O}, 12.5 \mathrm{ml}$ formaldehyde solution. Noncorroded control samples were subjected to the same descaling and weighing procedures to permit weight loss corrections to be made. From the weight loss data and the surface area calculations, the corrosion rate in mils per year (mpy) is determined based on the following equation:

$$
C r=\frac{\left(5.26 \times 10^{5}\right) W}{A \rho t}
$$

where $\quad C r=$ corrosion rate (mpy)

$W=$ weight loss (gms)

$A=$ surface area $\left(i^{2}\right)$

$\rho=\operatorname{density}\left(\mathrm{gm} / \mathrm{cm}^{3}\right)$

$t=$ time $(h r)$.

The following activities are scheduled: analyze the remaining 79 samples, analyze the water at the bottom of the autoclave subsequent to a $100 \%$ humidity run, and expose samples to electron microscopy to determine the depth of corrosion and confirm the composition. Results will be available in a draft report scheduled for early June. 
TABLE 4. Test Matrix

\begin{tabular}{|c|c|c|c|c|}
\hline $\begin{array}{l}\text { Trail } \\
\text { No. } \\
\end{array}$ & Run No. & $\begin{array}{l}\text { Temperature } \\
{ }^{\circ} \mathrm{C} \\
\end{array}$ & $\begin{array}{c}\text { Humidity } \\
\% \\
\end{array}$ & $\begin{array}{l}\text { Duration } \\
\text { in Weeks } \\
\end{array}$ \\
\hline 1 & 9 & 50 & 0 & 1 \\
\hline 2 & 15 & 50 & 0 & 2 \\
\hline 3 & 5 & 50 & 50 & 1 \\
\hline 4 & 17 & 50 & 50 & 2 \\
\hline 5 & 1 & 50 & 100 & 1 \\
\hline 6 & 4 & 50 & 100 & 2 \\
\hline 7 & 10 & 175 & 0 & 1 \\
\hline 8 & 16 & 175 & 0 & 2 \\
\hline 9 & 2 & 175 & 50 & 1 \\
\hline 10 & 8 & 175 & 50 & 2 \\
\hline 11 & 13 & 175 & 100 & 1 \\
\hline 12 & 3 & 175 & 100 & 2 \\
\hline 13 & 14 & 300 & 0 & 1 \\
\hline 14 & 11 & 300 & 0 & 2 \\
\hline 15 & 18 & 300 & 50 & 1 \\
\hline 16 & 7 & 300 & 50 & 2 \\
\hline 17 & 6 & 300 & 100 & 1 \\
\hline 18 & 12 & 300 & 100 & 2 \\
\hline $19^{(a)}$ & 19 & 175 & 100 & 2 \\
\hline
\end{tabular}

(a) Sandstone core in contact with metal specimen 
Task 3. Reservoir Storage Materials - Fluid Flow, Thermophysical, and Microstructural Properties Characterization

\section{Thermophysical Properties Determination}

The objective of this effort is to determine the changes in thermal conductivity, specific heat capacity, and thermal expansion coefficient for porous materials as a function of temperature, confining pressure, and interstitial water saturation. The equipment purchased to measure the thermal properties of sandstones was delivered in August 1979 and consists of three types: 1) a drop calorimeter, 2) a dilatometer, and 3) a steady-state comparator conductivity device. The thermal properties that can be measured as a function of temperature are specific heat, linear thermal expansion, and thermal conductivity.

The equipment setup, shakedown and calibration procedures have been in progress during FY-1980. Each apparatus essentially utilizes a comparative technique in which thermal properties are measured relative to a well characterized standard. The following standards were used in equipment calibration and shakedown procedures: 1) NBS sapphire for specific heat measurements, 2) fused silica and alumina 1100 for thermal expansion measurements, and 3) pyroceram 9606 and fused silica for thermal conductivity measurements. During the remainder of FY-1980, the thermal properties of Galesville sandstone and Ottawa sand will be measured as a function of temperature.

\section{Air/Water/Rock Interactions Autoclave Study}

The air/water/rock interactions autoclave study was completed. A detailed discussion of the procedures, experimental equipment, experimental strategy, and preliminary conclusions were discussed in the 1978 CAES Annual Report. To briefly summarize this task, autoclave pressure vessels were used to react cores of Galesville sandstone in temperaturepressure-humidity environments anticipated for CAES. The three simulated environments were: 1) dry air, 2) heated, air-water vapor or nitrogenwater vapor mixtures, and 3) heated, compressed liquid water. The 
objective of the study is to determine how the mineralogical and physical characteristics of host rock formation are affected by environmental conditions imposed by CAES.

The physical properties of the rock of primary interest are permeability to gas and liquid water, apparent porosity, and friability (shear rupture modulus). Partial results of the experimental work are illustrated in Figures 11 through 13, in which changes in gas permeability, friability and apparent porosity are plotted as a function of temperature and humidity. The following observations and conclusions may be deduced from the experimental results:

- In a dry air environment, the Galesville sandstone appears to be quite stable at all temperatures tested $\left(50\right.$ to $\left.300^{\circ} \mathrm{C}\right)$.

- Property alterations are minimal for sandstone exposed to liquid or vapor phase water at temperatures less than $150^{\circ} \mathrm{C}$ over the two month test duration. Above $150^{\circ} \mathrm{C}$, the physical stability of the rock in a heated, liquid water environment may be questionable.

- Preliminary data indicated significant physical alterations in sandstones exposed to air-water vapor mixtures above $150^{\circ} \mathrm{C}$. However, these alterations were later proven to be the result of water condensing on the cooler roof of the autoclave and dripping onto the sample and, therefore, represent anomalous results. In later experiments, samples shielded from condensed water with gold foil exhibited reasonable stability at the higher temperatures. Note that in Figure 11 a distinction is made between measurements obtained from shielded and unshielded cores.

- The porosity and friability of all sandstone samples increased as a function of increased temperature, humidity, and/or time.

- Gas and liquid permeability changes were greater for samples exposed to the higher temperature and humidity conditions. Permeability changes appear to have been controlled by the degree of disaggregation of the surface of the sample. Dissolution of quartz cement is the 


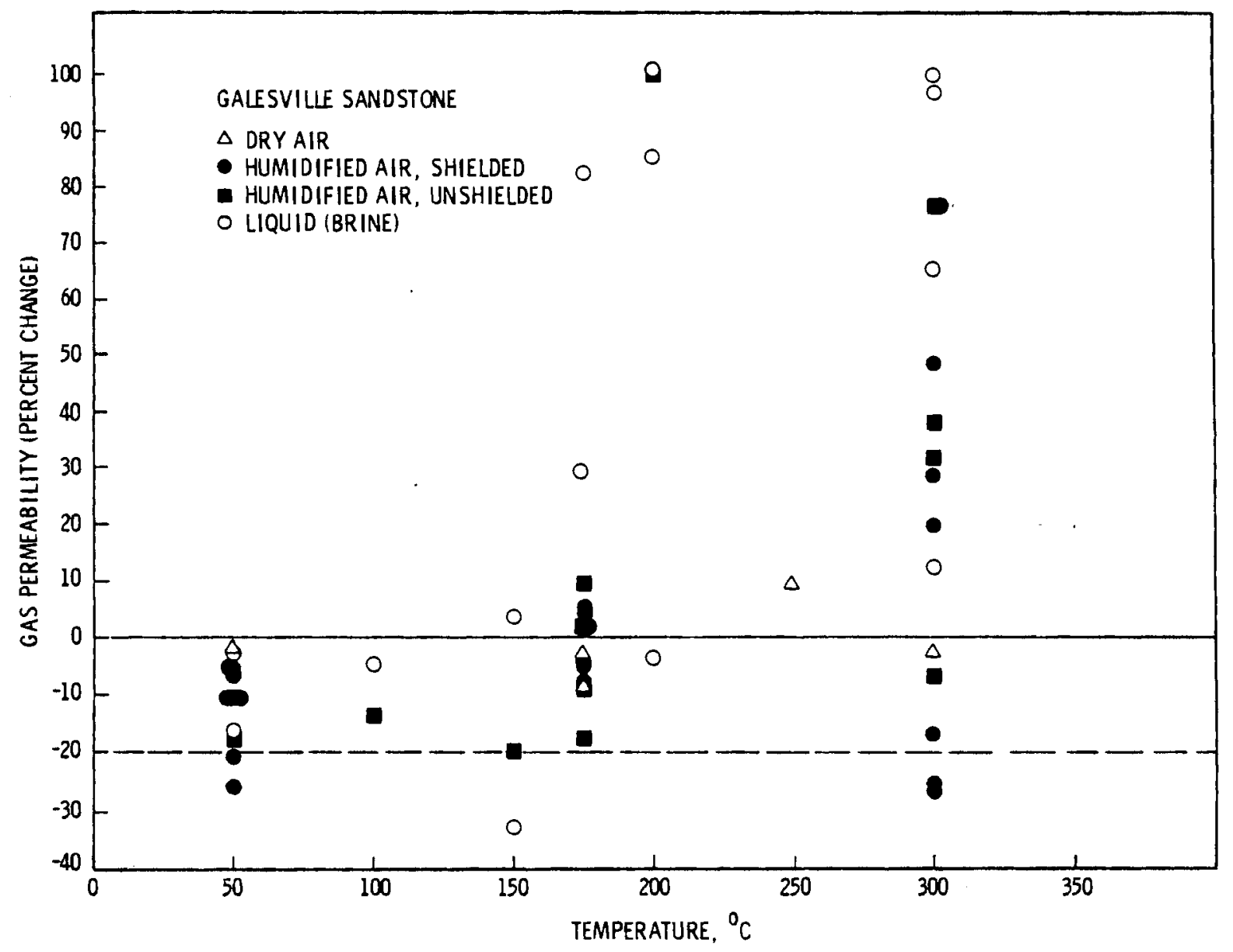

FIGURE 11. Changes in Gas Permeability at Elevated Temperatures from Autoclave Experiments

probable cause for the disaggregation of the sandstone. This disaggregation could result in increased rock permeability; however, it is possibie that dislodged particles may in some cases reduce the permeability by plugging the formation.

- Much of the scatter evident in the permeability resuits at high temperature is caused in part by the disaggregation of the surface of the cores. Disaggregation, especialiy for cores reacted in heated ground water (brine) often impedes accurate permeability 
measurements. It must be noted that under actual CAES conditions, such disaggregation may not occur since the rock will be exposed to a positive effective stress. Autoclave conditions are hydrostatic and the effective stress is zero.

- The chemical composition of the ground water (brine) monitored during experiments in which sandstone was reacted in liquid water indicates insignificant changes in the concentrations of the major cations $\mathrm{Na}, \mathrm{K}, \mathrm{Mg}$, and $\mathrm{Ca}$. The concentration of $\mathrm{Si}$ increases rapidly at first and then becomes nearly constant with time. The change in the concentration of $\mathrm{Si}$ is most likely the result of dissolution of amorphous silica and quartz in the sandstone. However, this chemical reaction was not definitive in petrographic analysis of reacted sandstone.

- Due to the limitations of the autoclave equipment, changes in rock physical properties may have been primarily caused by lack of confining stress on the sample.

- Sandstone may be suitable storage media for heated, humid air provided elevated temperature zones are relatively free of mobile liquid phase water. Future work in the CAES fluid flow facility which permits a much closer simulation of CAES reservoir conditions, should lend additional credibility to this conclusion.

\section{Flow Facility Experiments}

Since the CAES Flow Facility is not yet operational, activities under this task have been 1 imited to a review of the literature, theoretical development, and experimental strategy development. One issue that has been considered in detail involves the experimentally observed decrease in sand and sandstone permeability with increased temperature when liquid water is the interstitial fluid (Figure 12). No such degradation is observed with dry gas, mineral oil, or octanol. No data are available for humidified air. It is being suggested that evidence supporting CAES reservoir stability might be generated in two 


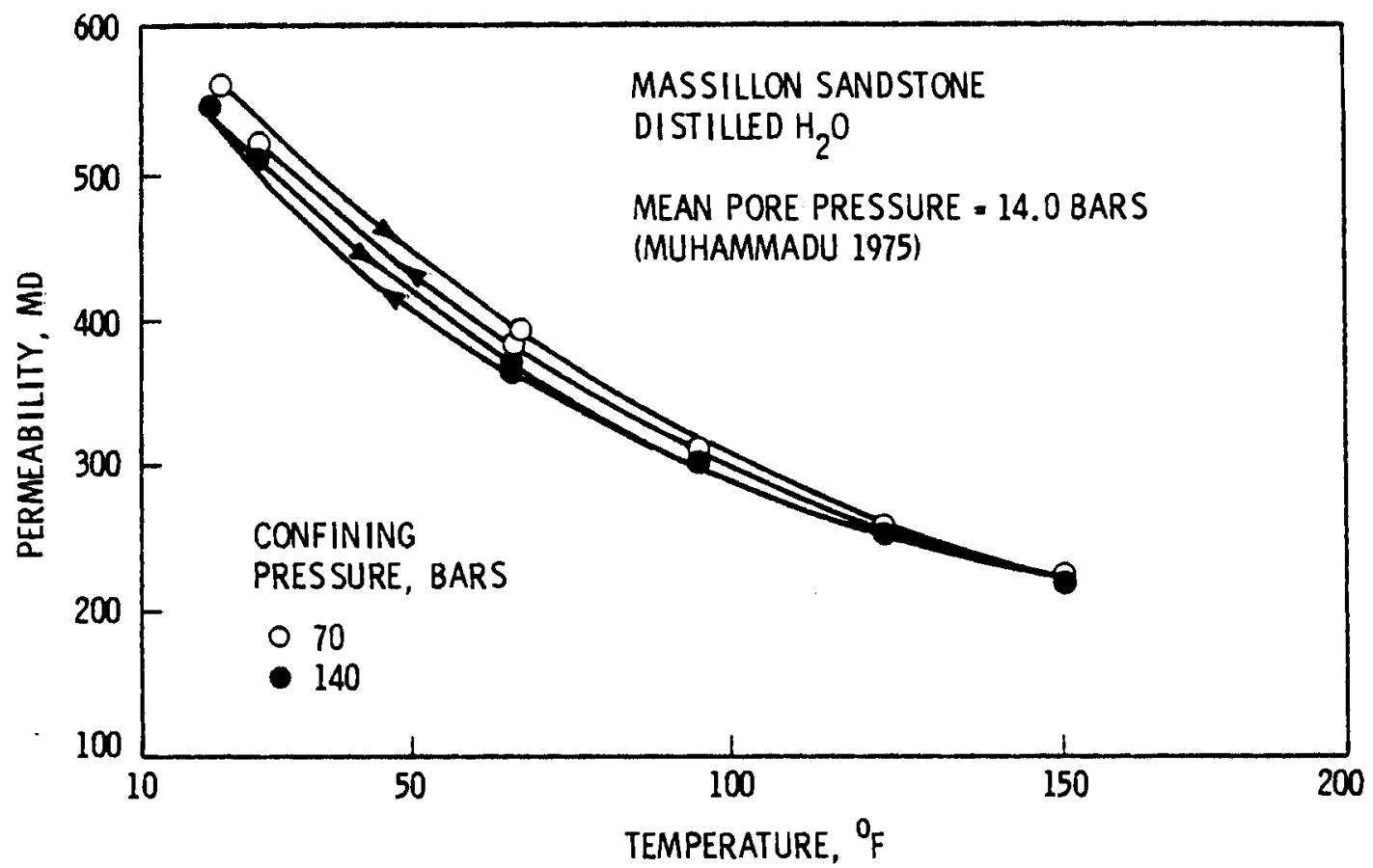

FIGURE 12. Changes in Permeability of Sandstone as a Function of Temperature

ways: 1) direct testing with humidified air, and 2) identifying the mechanism(s) responsible for the degradation in liquid water. The primary reason for the second approach is that if the cause is chemical weakening or pressure dissolution of the material, reaction rates may be substantially slower for humid air and therefore structural and fluid flow property changes might not be detected in 24-hour experiments.

All future experiments are to be conducted with the sample under a state of stress (Figure 13) similar to that anticipated for a representative CAES reservoir (confining pressure 100 to 300 bars, and pore fluid pressure 60 bars). Dry air, humid air, and liquid water are employed or working fluids. The monitoring temperatures span the range from 20 to $250^{\circ} \mathrm{C}$. Simultaneous monitoring of permeability, porosity, volumetric deformation, effluent chemistry, viscosity, and suspended load will be employed in addition to pre- and post-test analysis of mineralogy, microcracking, 


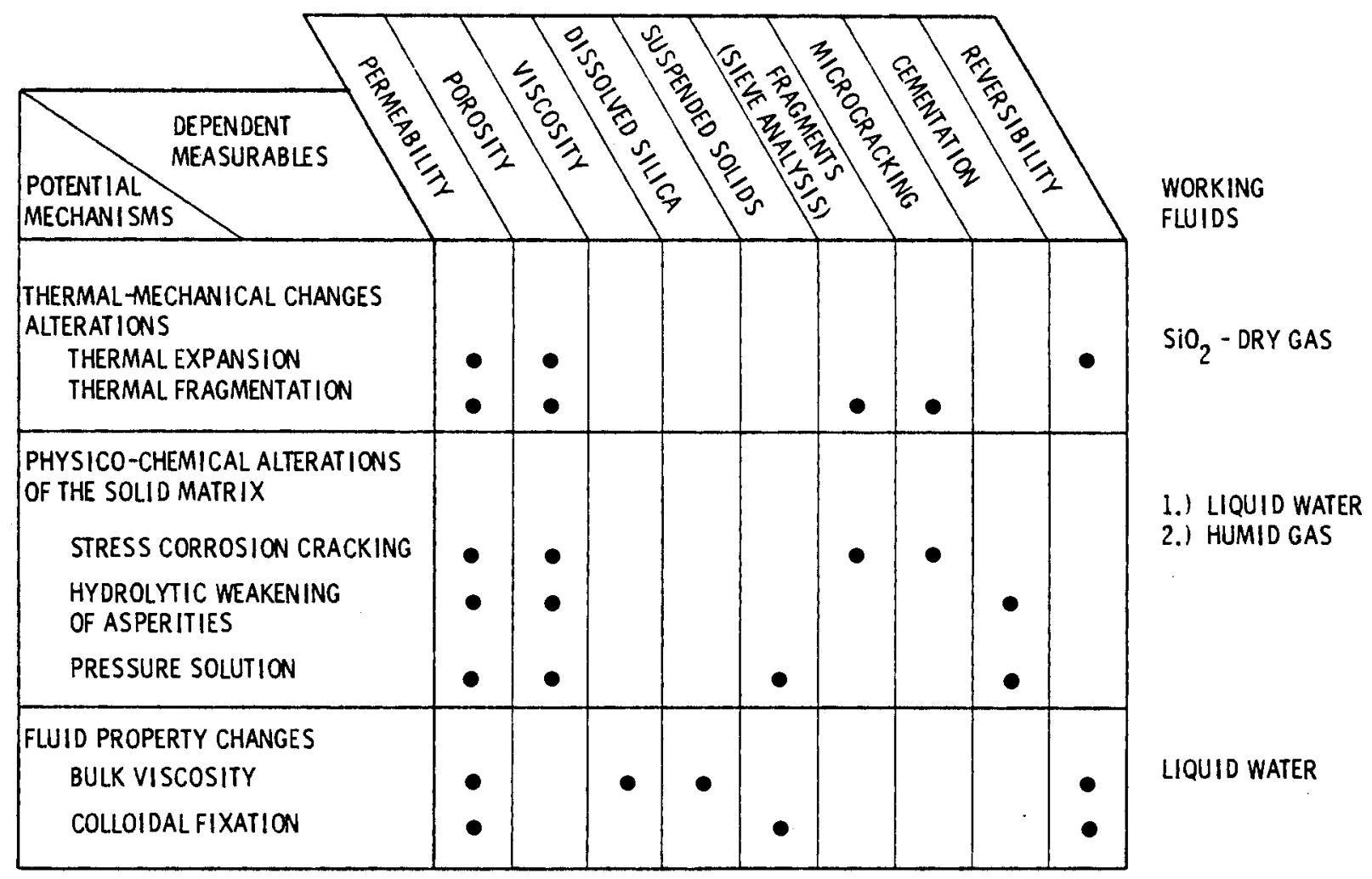

FIGURE 13. Simultaneous Fluid-Flow/Stress-Strain Experiments

and cementation. As shown in Figure 13, the primary objective is differentiating between thermomechanical alterations, chemical weakening, and fluid viscosity changes. If either thermomechanical or chemical weakening are indicated from the liquid water experiments, then similar probiems cannot be dismissed for a CAES humidified air environment. If, however, it is determined that temperature-induced increases in the concentration of dissolved and/or suspended silica results in anomalously high viscosity values compared to those for distilled water (Figure 14), it may be possible to conclude that intrinsic permeabilities are stable at temperatures approaching 200 to $250^{\circ} \mathrm{C}$ in both liquid water and humid air environments and that incorrect viscosity values have been used to compute the permeabilities (equation 2) in past investigations. 


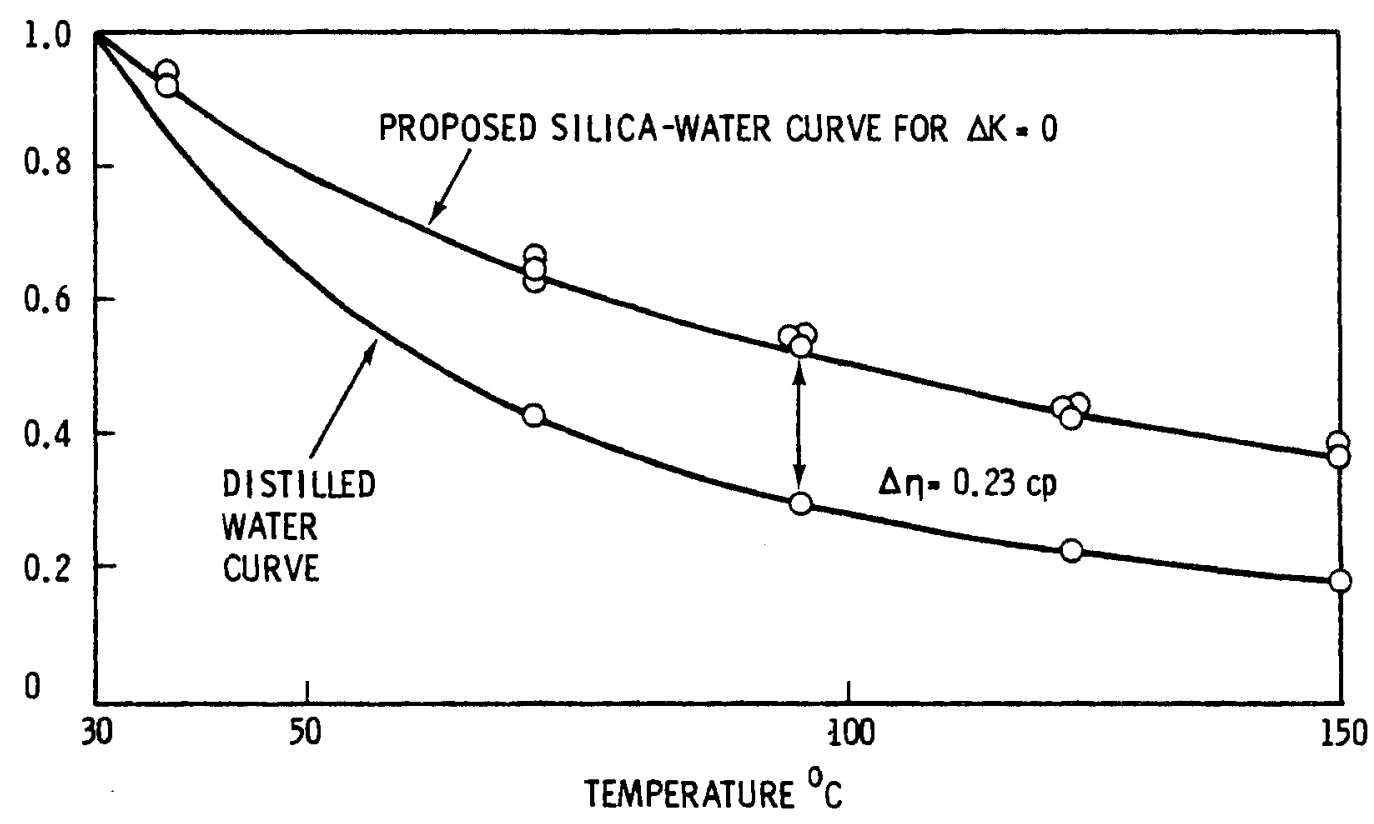

FIGURE 14. Viscosity Versus Temperature Curve Required to El iminate Permeability Reduction with Temperature Increase

$$
K=14.7 \times 10^{3} \frac{L H W}{\Delta \mathrm{pAp}}
$$

where: $\quad K=$ permeability $\left(\mathrm{md}, 10^{8} \mathrm{~cm} / \mathrm{sec}\right.$ )

$$
\begin{aligned}
\Delta p & =\text { pressure gradient (psi) } \\
w & =\text { flow rate }(\mathrm{gm} / \mathrm{sec}) \\
0 & =\text { density }\left(\mathrm{gm} / \mathrm{cm}^{3}\right) \\
L & =\text { core length }(\mathrm{cm}) \\
\mu & =\text { viscosity }(\mathrm{cp}) \\
A & =\text { cross-sectional area }\left(\mathrm{cm}^{2}\right) .
\end{aligned}
$$

The following experiments are planned at Terra Tek and PNL:

- Dry Gas Experiments. These experiments are designed to investigate thermomechanical permeability alterations, e.g., thermal expansion, thermal fragmentation, densification, and particulate plugging. 
- Humidified Air/Liquid Water Experiments. These experiments are designed to investigate the effects of chemical weakening of the sand matrix and fluid viscosity changes on the intrinsic permeability of the sand-water system.

- Enhance/Inhibit Experiments. These experiments are designed to investigate in greater depth any permeability alterations observed in the liquid water experiments. The main emphasis is on experimentation with an enhanced inhibited chemically reactive environment.

Aluminum Chloride Experiments. Aluminum chloride will be added to the pore fluid to enhance hydrolytic weakening.

Chlorotrimethylsilane Pretreatment. Distilled water saturated with silica at room temperature will permeate 0ttawa sand pretreated with $\mathrm{SiCl}\left(\mathrm{CH}_{3}\right)_{3}$. The pretreatment is intended to make the solid chemically nonreactive and yet identical in elasticity, strength, and thermal properties to that of untreated samples.

- Thermal Fatigue Experiments. The objective is to investigate the stability of quartzose sandstone under fluctuating temperature conditions.

TECHNICAL PROBLEMS

None

\section{PUBLICATIONS}

J. A. Stottlemyre, R. L. Erikson, and R. P. Smith, Potential Petrophysical and Chemical Property Alterations in a Compressed Air Energy Storage Porous Rock Reservoir. PNL-2974, Pacific Northwest Laboratory, Richland, WA, October 1979. 


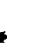

. 


\subsection{1d Effects of Air Ventilation on Porous Rock \\ H. J. Pincus \\ University of Wisconsin-Milwaukee}

OBJECTIVE

The objective of this project is to evaluate the effects of pressuretemperature cycling with compressed air on underground reservoir rocks and their associated caprocks. Effects of ventilation upon physical properties and microstructure have been determined. The results are intended to:

- contribute to development of site-qualification criteria

- identify geological parameters requiring field monitoring

- assist in developing monitoring systems for operating installations.

In the year ending September 30, 1979, operations were concentrated on ventilating 10 rock types and measuring changes in their properties. Funding was initially provided to process 126 specimens; over double that number were, in fact, processed.

Independent variables were air-temperature, mean flow-through air-pressure, pressure-drop across specimens, number of cycles, and rock type. Confining pressure was also varied to prevent bypassing. Dependent variables were Young's modulus, compressive strength, porosity, permeability, and specific heat; a small number of measurements were made of thermal conductivity and thermal expansion. Changes in microstructure were studied by optical diffraction analysis and by optical and electron microscopy. Relations among independent and dependent variables were sought.

During the current fiscal year the focus is on core samples of a single high-quality sandstone. It is planned to process at least 76 specimens; 112 specimens would yield more useful results.

Independent variables during the current year are air-temperature, number of cycles, and pressure-drop across specimens. Dependent variables are the same as those used last year. 
Tasks during the year ending September 30, 1979 were as follows:

- Task 1. Field work - determining local structure and collecting specimens

- Task 2. Compressed-air pressure-temperature cycling of specimens

- Task 3. Property testing

- Task 4. Optional experiments (thermal measurements, pre FY-1980 work, etc.)

- Task 5. Determination of changes in properties associated with Tasks 2 and 4

- Task 6. Analysis and interpretation of data from Tasks 1 through 5

- Task 7. Library work

- Task 8. Exchange of technical information with PNL

- Task 9. Report writing, administration.

Tasks during the current year are substantially the same as the above, with the following changes:

- Task 1. Block specimens from quarries are not being used for the basic text-matrix

- Task 4. At least two new "optional" experiments have been started (cyclic displacement of air-water interface; cyclic, radial flow effects around an axial hole)

- Task 8. Information has been furnished to PNL in connection with aquifer field studies in 1980 through 1981.

\section{TECHNICAL PROGRESS}

Task 1. Field Work

In the work ending September 30, 1979, five "levels" of each independent variable were used, as follows:

- Temperature: $20^{\circ}, 93^{\circ}, 121^{\circ}, 163^{\circ}, 200^{\circ} \mathrm{C}\left(68^{\circ}, 200^{\circ}, 250^{\circ}, 325^{\circ}\right.$, $395^{\circ} \mathrm{F}$ )

- Mean Flow-Through Pressure: $0.10,2.07,2.76,4.14,5.17 \mathrm{MPa}$ $(15,300,400,600,750$ psi) 
- Pressure-Drop: $0,0.28,0.55,0.83,1.10 \mathrm{MPa}(0,40,80,120,160$ psi)

- Number of Cycles: $0,500,1000,1500,2000$

- Rock Types: Five rock types in each of two test matrixes: 6 sandstones, 2 carbonates, 2 shales (or shaly sandstones).

Twenty five treatment-combinations were used, with up to four replications per treatment.

The results of this work were as follows:

- Young's modulus and compressive strength are much more affected by rock type than by the other independent variables.

- Within each rock type there are relatively few significant changes, with ventilation, in the mean and variance of Young's modulus and compressive strength. Out of 40 tests of significance, 8 were significant at the $5 \%$ level. More changes were detected in some sandstones than in any of the other rocks. Clean sandstones were the least affected.

- Where significant changes in Young's modulus and compressive strength were detected, mean values increased and variances decreased with ventilation.

- Permeabilities of three rock types were measured before and after ventilation. Permeabilities clearly increase with ventilation. Rocks with smaller original permeabilities undergo greater increases than rocks with larger original permeabilities.

- No significant changes in microstructure, porosity, or specific heat were detected.

- The best candidate for reservoir rock appears to be a medium-to coarse-grained, clean, we11-sorted quartz sandstone, with moderate cementation with silica. 
Task 2. Pressure-Temperature Cycling of Specimens

During the current year's work, the "levels" of the independent variables to be used are:

- Temperature: $50^{\circ}, 125^{\circ}, 200^{\circ} \mathrm{C}\left(122^{\circ}, 257^{\circ}, 392^{\circ} \mathrm{F}\right)$

- Number of cycles: $500,1500,2500$

- Pressure-drop: 0.5, 1.0 MPa (73, $145 \mathrm{psi})$; an additional level at $1.5 \mathrm{MPa}(218 \mathrm{psi})$ will be used, if feasible.

- Confining pressure will be constant at $4.14 \mathrm{MPa}$ (600 psi).

With two levels of pressure-drop there will be 18 treatment

combinations. With three levels there will be 27 treatment combinations. Using 4 samples per treatment-combination and adding one set of control specimens (unventilated), the total number would be 76 and 112 specimens for two and three levels of pressure-drop, respectively.

Cores obtained so far (Mt. Simon, $10 \mathrm{~cm}$ dia, from Indiana) have permeabilities too low to be representative of CAES reservoir rock. The search is continuing for additional cores. Should this prove fruitless, we could obtain cores by drilling horizontally in a St. Peter quarry; this would have the advantage of providing cores in which the flow would be parallel to the bedding.

Task 3. Property Testing

We have followed up on last year's work in several ways. For example, we have ventilated specimens of St. Peter at the 1, 2, 3, 4 levels for four independent variables: temperature, mean flow-through air-pressure, pressure-drop, and number of cycles. That is, the experimental matrixes used last year did not have treatment combinations where all four of these variables were at level 1, then at level 2, etc. (The experimental design for the current year does provide such combinations.)

The mean change in porosity in these experiments was a slight increase, which was not significant at the $5 \%$ level. (The probability of the mean change noted was $34 \%$.) The mean change in permeability in these experiments 
was an increase that was not significant at the $5 \%$ level. (The probability of the mean change noted was $10 \%$.). These data may also be studied in terms of ratios, as indicated below.

\begin{tabular}{|c|c|c|c|c|c|}
\hline \multicolumn{3}{|c|}{ Porosity } & \multicolumn{3}{|c|}{ Permeability } \\
\hline & & After (a) & & & After $^{(a)}$ \\
\hline Level & Number & Before & Level & Number & Before \\
\hline 1 & 4 & 1.02 & 1 & 3 & 1.84 \\
\hline 2 & 4 & 1.01 & 2 & 4 & 1.52 \\
\hline 3 & 3 & 1.02 & 3 & 4 & 1.08 \\
\hline 4 & 4 & 0.99 & 4 & 4 & 1.08 \\
\hline
\end{tabular}

(a) The mean for ventilated rocks divided by the mean for the same rocks unventiliated.

Each of these results is consistent with results obtained earlier.

Task 4. Optional Experiments

Prospective sites for field tests have been investigated as follows:

- Minnesota - Detailed subsurface data on the files of the Minnesota Geological Survey have been studied in the St. Paul office. Seven structures or areas in southeastern Minneosta have been considered. At least one of these looks promising. Another possible site has been ruled out because Minnesota does not allow storage of gas at depths of less than $500 \mathrm{ft}$. (Perhaps state law can be interpreted to mean that it was not intended to include air in this prohibition.) Maps and logs have been assembled by us for some of the structures studied, and are available for further evaluation.

- Wisconsin - The subsurface data in the files of the Wisconsin Geological and Natural History Survey are being organized and prepared for display by the Survey. It is very likely that southwestern Wisconsin has some prospects like those in southeastern Minnesota. 
- Indiana - On the recommendation of a geologist with the Illinois Geological Survey, a thesis on an area in northcentral Indiana has been studied. This area is probably fully utilized for gas storage at this time, but it would be well worth the effort to obtain detailed locations of current gas storage sites to see if there are any structures not being utilized.

Task 5. Determination of Properties Changes Associated with Tasks 2 and 4 Work is proceeding on two projects that were to be funded about January 1, 1980, as follows:

- Study of the effects of cyclically displacing the air-water interface along the axis of a cylindrical (NX-54mm) specimen. Construction of the equipment for this work is almost complete. (M.S. thes is in Civil Engineering - Pujol).

- Study of the effects of radial flow around an axiar hole in a cylindrical specimen. This is intended to shed light on the microstructural changes and changes in permeability around chargedischarge holes. Rough design of equipment has been completed. (M.S. thesis in Geological Sciences - Zakrzewski). Other thes is work:

- Two M.S. theses have been completed (Cutler 1979, Marshal1 1979). Results of these theses are summarized in the FY-1979 report.

- A third M.S. thesis (Gross) much like Marshall's but in a different area, is almost complete. Some of the results of this thesis appear in the FY-1979 report.

- An M.S. thesis (Hopper), about half complete, concentrates on effects of ventilation on thermal properties of rocks.

- An M.S. thesis (Swingen) is about to be undertaken, probably involving field work in Illinois with lab work like those of the earlier theses.

- An M.S. thesis (Vaticon) about to be undertaken will concentrate on the relationships among permeability, porosity, and microstructure. 
- A D. of Eng. thesis (Meiri) has been completed on finite-element analysis of displacement of the air-water interface at the edge of the air-bubble. (Advisor: Prof. G. Karadi).

Support for much of the work in progress comes from sources other than the DOE-PNL contract.

\section{TECHNICAL PROBLEMS}

The biggest need at present is for suitable amounts of and type of core for Task 2 in the preceeding section. We need this soon if we are to complete this phase of the work by September 30, 1980.

\section{PUBLICATIONS}

H. J. Pincus, "Geological Aspects of Storage of Compressed Air in Porous, Permeable Rocks," Proc. 3rd Int. Cong. of Engrg. Geol., Madrid, 1978, Sec. III, 2:107-116.

H. J. Pincus, "Measurement of Changes in Rock Fabrics," Proc. 4th Int. Cong., Int. Soc, Rock Mech., Vol I, pp. 265-271, 1979.

\section{Theses}

R. M. Cutler, Laboratory Studies of the Effects of Compressed Air Energy Storage on Selected Reservoir Rock and Caprock, University of WisconsinMilwaukee thesis, 1979 .

T. B. Marsha11, Compressed Air Storage in Paleozoic Sands tones of SouthEastern Minnesota, University of Wisconsin-Milwaukee thesis, 1979.

\section{Presentations}

H. J. Pincus, "Relationships Among Permeability, Porosity, Microstructure, and Other Physical Attributes of Rocks used for Storage of Compressed Air," International Geologic Congress, Paris, July 1980. (The written version of the paper will be submitted for pubiication in the December 1980 issue of the Bulletin of the International Association of Engineering Geology.) 


\subsection{1e Thermomechanical Properties of Porous Rock \\ J. D. Blacic, P. H. Halleck, P. D'Onfro \\ Los Alamos Scientific Laboratory}

\section{OBJECTIVES}

Objectives of the program are to assess the effects of temperature, effective pressure, and cyclic stress on elastic constants and compressive strength of a typical sandstone. The deliverables are 1) identification of changes in properties and 2) characterization of these changes, including identification of physical mechanisms, for inclusion in models of porous media CAES systems.

\section{TASKS}

Task 1. Elastic Constants and Compressive Strength

Experiments are performed in which samples of a typical porous medium (Galesville Sandstone, Illinois) are deformed in compression to determine Young's modulus, Poisson's ratio, and ultimate strength. These properties are determined at temperatures of 37,120 , and $204^{\circ} \mathrm{C}$; confining pressures of $0.5,20.3$ and $41.4 \mathrm{MPa}$ and gas pore pressures of 0 and $10.3 \mathrm{MPa}$. A11 samples are water saturated.

Task 2. Low Stress Cyclic Loading Effects on Elastic Constants and Compressive Strength

Experiments are performed on Galesville sandstone in which compressive stress of 10 to $30 \%$ of the faiture stress is applied repeatedly for 100 , 1000 , or 10,000 cycles. Young's modulus and Poisson's ratio are measured and compared before and after cyclic loading in order to identify cyclic loading effects. Ultimate strength is determined after cycling and compared to results from Task 1 . The same ranges of temperature and pressures as in Task 1 are used. 


\section{TECHNICAL PROGRESS}

\section{Task 1. Elastic Constants and Compressive Strength}

Previous reported work identified a nonlinear variation of Young's modulus and Poisson's ratio versus applied compressive stress, and large scatter of elastic constants and ultimate compressive strength for this sandstone. Additional work has confirmed these observations and determined the cause to be small scale inhomogeneities in cementation and porosity. Galesville sandstone is a dolomite-cemented sandstone of Cambrian age that occurs widely within the northcentral midwest U.S. The samples used in our experiments range in porosity from 15 to $24 \%$ and permeability from 100 to 600 millidarcies. The dolomite cement varies widely from near zero to about $30 \%$. Inhomogeneity of this sandstone makes experimental indentification of fundamental physical phenomena and properties difficult. However, scatter and variability in properties is more likely similar to those that will be encountered in an actual CAES reservoir.

A summary of the variation of Young's modulus versus temperature and effective pressure (confining pressure minus pore pressure) is given in Figure 15. At any given temperature, modulus first increases markediy then increases more slowly or decreases somewhat as effective pressure increases. At a particular effective pressure, modulus increases substantially with increasing temperature. A summary of the variation of Poisson's ratio is shown in Figure 16. In general, Poisson's ratio decreases markedly with both increasing temperature and effective pressure over the ranges studied. In all cases, scatter in values of the elastic constants is large and increases with the number of repeat tests.

In order to help understand the mechanism of elastic constant change with increasing temperature and effective pressure, a few hydrostatic compressibility and thermal expansion tests were performed. As expected, most of the hydrostatic compression is due to pore space in the sandstone. Results of the thermal expansion tests likewise indicate that the quartz 


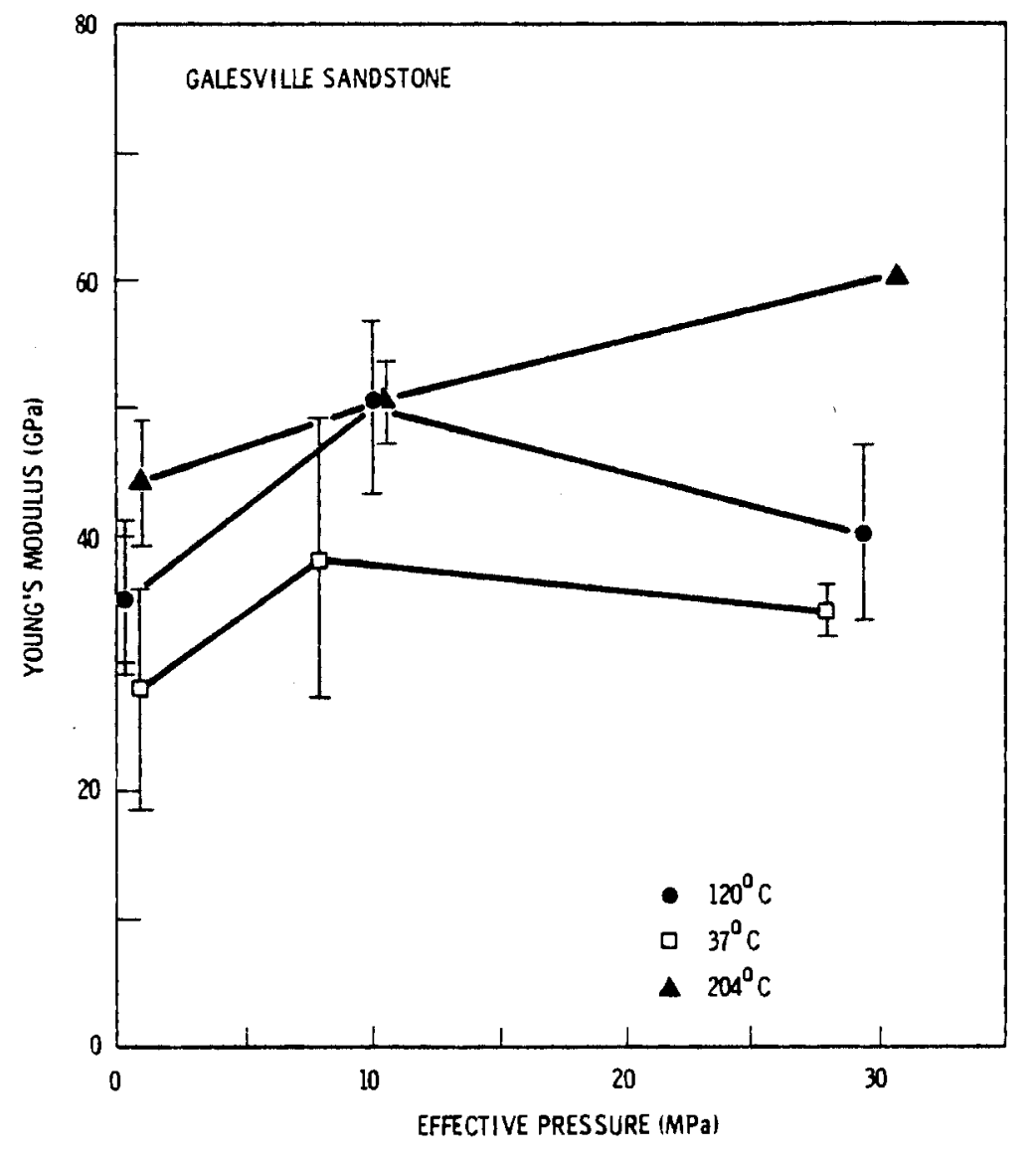

FIGURE 15. Young's Modulus Versus Effective Confining Pressure for Three Temperatures. Error bars are one standard deviation or the range where only two test repeats are available.

grains are expanding into this pore space. (Large anisotropy in thermal expansion is also noted: Perpendicular to bedding, $\alpha=16 \times 10^{-6}$ per ${ }^{\circ} \mathrm{C}$; parallel to bedding, $\alpha=5 \times 10^{-6}$ per ${ }^{\circ} \mathrm{C}$.) Thus, with both increasing temperature and increasing effective pressure, pore space of this sandstone is apparently being reduced. This apparent densification of the samples can explain why Young's modulus increases with increasing temperature and effective pressure - a dense rock is stiffer than a porous rock. Poisson's ratio of a zero porosity quartz aggregate should be about 0.05 . Therefore, densification of the samples also explains why Poisson's 


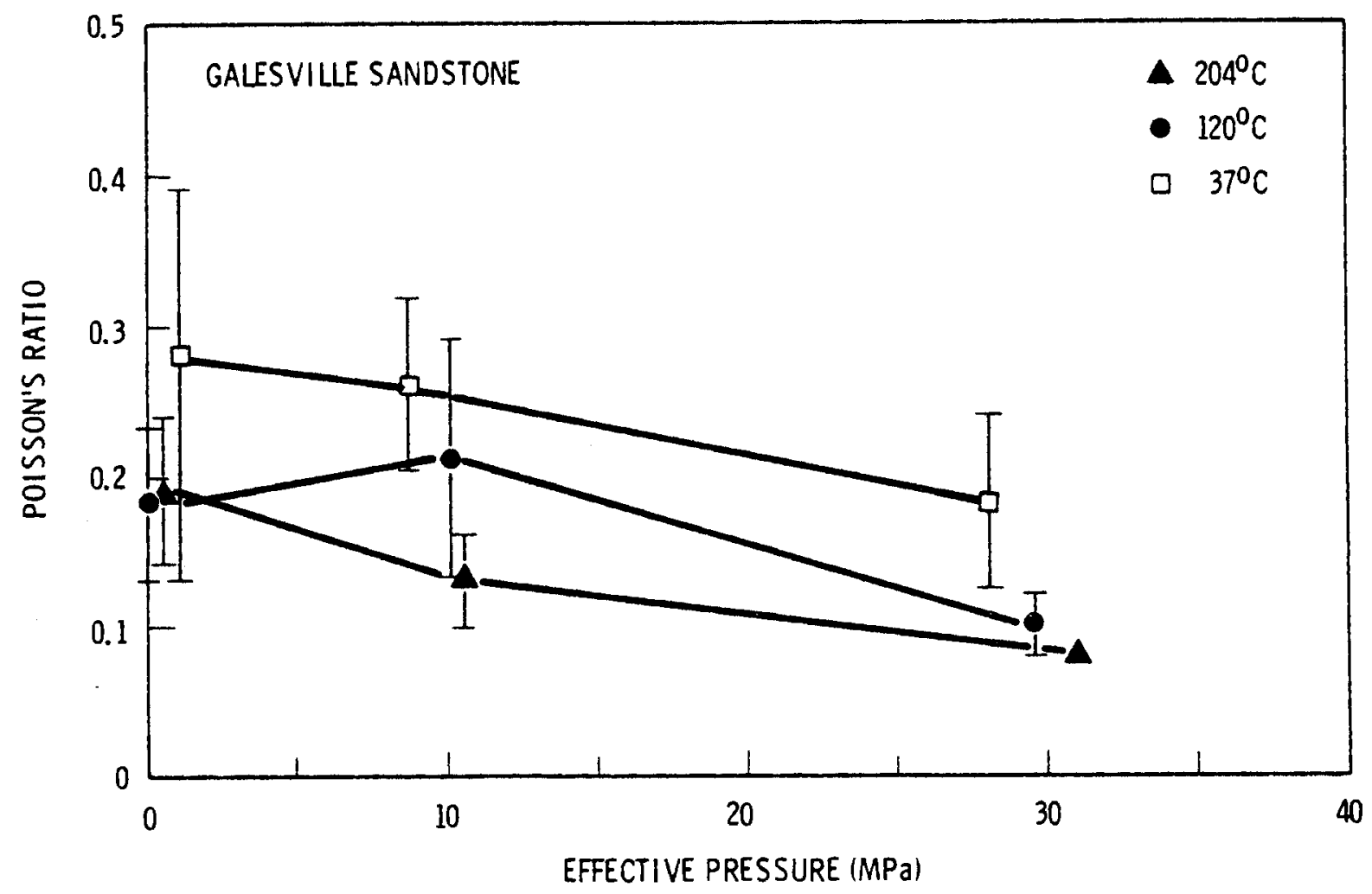

FIGURE 16. Poisson's Ratio Versus Effective Confining Pressure for Three Temperatures. Error bars mean the same as in Figure 15.

ratio decreases from about 0.3 to less than 0.1 with increasing temperature and effective pressure.

A summary of the ultimate compressive strength tests is shown in Figure 17 in the form of a shear stress versus effective normal stress plot for the temperature range 37 to $204^{\circ} \mathrm{C}$. Combinations of shear stress and normal stress that plot above the experimentally determined strength envelopes are unstable, those below the envelopes are stable. Nonlinearity of the envelopes compared to Berea sandstone is due to plastic deformation of the dolomite cement in Galesville sandstone. Expected operating ranges of stress for a porous medium CAES reservoir shown shaded in Figure 17 


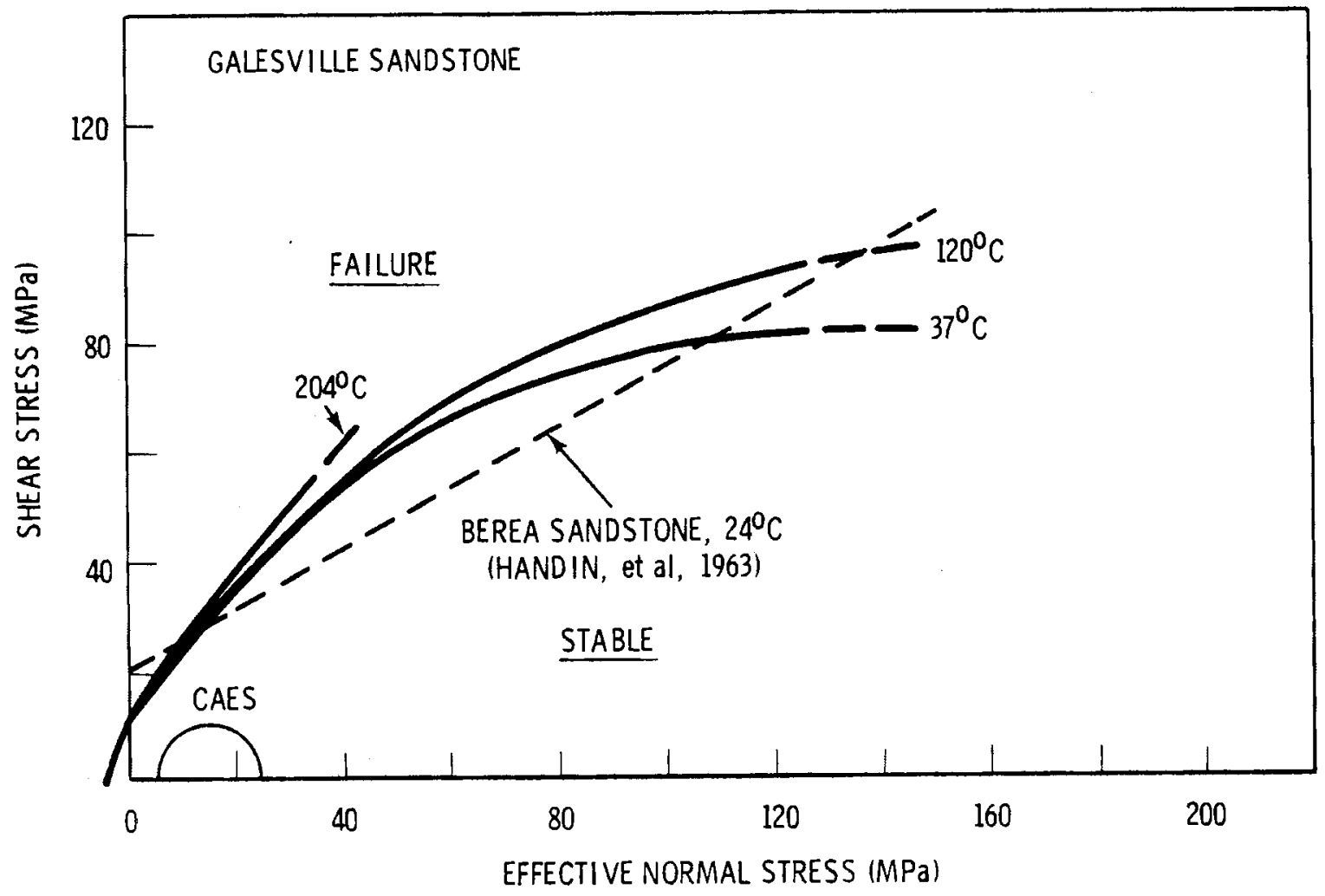

FIGURE 17. Mohr Failure Envelopes for Three Temperatures. The semicircle represents states of stress for an operating porous medium CAES reservoir.

indicate a substantial safety factor. However, coefficients of friction based on the residual strengths determined in our tests indicate that sliding movement along pre-existing faults, joints, or bedding planes may be possible under certain stress conditions. While it seems unlikely that this would affect operation of a CAES system, this possibility should be investigated. A potential beneficial effect could be an increase in "fracture" permeability of the reservoir.

Task 2. Low Stress Cyclic Loading Effects on Elastic Constants and Compressive Strength

Experiments to evaluate effects of cyclic stress on elastic constants and strength were performed in the following way. After attaining the 
planned temperature and pressure for a particular test, samples were loaded in compression to about $50 \%$ of the failure stress in order to determine the initial elastic constants. After subsequent unloading, the samples were repeatedly loaded at stresses ranging from 5 to $15 \mathrm{MPa}$ for up to 10,000 cycles with a 5-second cycle period. The samples were then loaded to failure to determine the final elastic constant values and ultimate strength. Some of the results of these tests are shown in Table 5. It should be noted that changes in Young's modulus $(\triangle E)$ of \pm $10 \%$ and in Poisson's ratio $(\Delta v)$ of $\pm 15 \%$ are judged not to be significant because of inaccuracies in the method.

Results indicate that for up to 1000 cycles there is generally no significant change in elastic constants of Galesville sandstone until $204^{\circ} \mathrm{C}$ is reached. However, at 10,000 cycles there are marked, but somewhat inconsistent, changes in both Young's modulus and Poisson's ratio at all temperatures. The changes are generally consistent with the densification interpretation given above; that is, Young's modulus increases and Poisson's ratio decreases. No effect on ultimate compressive strength due to low stress cyclic loading could be discerned within the rather large scatter of this property.

\section{RECOMMENDATIONS}

- If our interpretation of the elastic constant changes is correct then densification of the sandstone could have adverse effects on permeability of a reservoir. This possibility should be investigated both for carbonate- and silica-cemented sandstones.

- Possible sliding movement along pre-existing planar discontinuities in an operating CAES reservoir should be incorporated into models and evaluated.

- The strong anisotropy in thermal expansion should be incorporated into models if further testing indicates this is a phenomena common to other sandstones. 
TABLE 5. Changes in Elastic Constants Due to Cyclic Loading

\begin{tabular}{|c|c|c|c|c|}
\hline $\begin{array}{c}\text { Tempera ture } \\
{ }^{\circ} \mathrm{C} \\
\end{array}$ & $\begin{array}{l}\text { Effective } \\
\text { Pressure } \\
\mathrm{MPa} \\
\end{array}$ & $\begin{array}{c}\text { Cycles } \\
\mathrm{N}\end{array}$ & $\begin{array}{l}\Delta E \\
\% \\
\end{array}$ & $\begin{array}{l}\Delta v \\
\% \\
\end{array}$ \\
\hline 37 & 10.6 & 100 & +7 & -5 \\
\hline 37 & 9.0 & 1000 & +5 & -11 \\
\hline 37 & 7.3 & 10,000 & -10 & -26 \\
\hline 120 & 0.5 & 100 & +4 & -11 \\
\hline 120 & 0.5 & 1000 & +8 & 0 \\
\hline 120 & 0.5 & 10,000 & +19 & +22 \\
\hline 120 & 10.5 & 100 & +7 & +10 \\
\hline 120 & 10.6 & 1000 & -1 & -5 \\
\hline 120 & 10.6 & 10,000 & +28 & -6 \\
\hline 204 & 10.6 & 100 & 0 & -12 \\
\hline 204 & 10.5 & 1000 & +17 & -59 \\
\hline 204 & 10.6 & 10,000 & +12 & -54 \\
\hline
\end{tabular}


- Understanding of the fundamental mechanisms of thermal mechanical response of porous media should be attained by testing "clean", single phase sandstone samples.

\section{TECHNICAL PROBLEMS}

The major technical problems associated with this study have all been due to the large variability of the Galesville sandstone sample material. Inhomogeneities in porosity and cementation have made it difficult to conclusively identify physical phenomena within the data scatter. Several experimental difficulties were encountered in early tests but all were satisfactorily resolved.

\section{PUBLICATIONS}

J. D. Blacic, P. H. Halleck, and P. D'Onfro, "Thermo-Mechanical Properties of Galesville Sandstone," Proc. 1979 Mechanical and Magnetic Energy Storage Contractors Review Meeting. CoNF-790854, Washington, D.C., 1979.

J. D. Blacic, P. H. Halleck, and P. D'Onfro, "Effects of Temperature, Pressure, and Cyclic Loading on Elastic and Strength Properties of Galesville Sands tone" (abstract), EOS, Trans. Amer. Geophys. Union, V. 60, p. $960,1979$. 


\subsection{1f Moist Air Flow Tests}

C. Cooley

Terra Tek, Inc.

\section{OBJECTIVE}

The objective of this program is to experimentally investigate in the laboratory, geophysical and geochemical permeability alterations in reservoir rock and sands that affect compressed air energy storage facility performance. Permeability alteration possibilities include silica dissolution, time dependent consolidation, particulate plugging, pore fluid viscosity changes, hydrolytic weakening, thermal fragmentation, and thermal expansion.

To conduct this investigation, Terra Tek is modifying an existing core testing system to simulate conditions typical of CAES, namely stresses to 300 bars, pore pressure to 60 bars, temperatures to $150^{\circ} \mathrm{C}$ with $\pm 50^{\circ} \mathrm{C}$ temperature cycles, and steady-state flow with heated gas for 24-hour durations. Several measurements will be made including permeability and deformation.

\section{TASKS}

\section{Task 1. Variable Importance Analysis}

A workshop, limited to invited participants, will be organized and conducted by Terra Tek. The services of four to six of the leading researchers in the field of porous media physics and chemistry wi11 be acquired. Emphasis will be on critiquing the suggested experimental approach of both Seasonal Thermal Energy Storage (STES) and CAES programs. Possible independent and dependent variables to be discussed include:

- independent variables -- temperature, temperature range, cycling frequency, confining pressure, stress difference, humidity, flow rate, gas composition, and experimental duration. 
- dependent variables -- permeability, compressibility, effluent chemistry, and post-test fabric and texture.

Task 2. Sample Acquisition, Preparation, and Characterization

Testing will be conducted on quartz-cemented sandstone. Samples shall have porosities greater than $10 \%$ and unconfined permeabilities to gas greater than 350 millidarcies. The dried sandstone will be characterized as follows: gas permeability, total porosity, compressibility, and strength (failure envelope).

Task 3. Laboratory Testing

Based on input from the consultants, a test program will be devised by which the major contributors to permeability alteration could be identified. Subsequently, this program will be conducted in Terra Tek's flow system.

Task 4. Reporting

Monthly reports will be submitted no later than the 25th of each month. At the end of the contract period a final report will be submitted.

\section{TECHNICAL PROGRESS}

The CAES contract was initiated on December 15, 1979. Progress in each task is as follows.

Task 1. Variable Importance Analysis

On January 7, 1980, Terra Tek, Inc. hosted a mini-conference. Attending consultants included: W. F. Brace, MIT; R. J. Clifton, Brown University; M. Friedman, Texas A\&M; Kenneth Wolgemuth, Terra Tek; Dan Stright, Northwest Pipeline; John Schatz, Terra Tek; and John Winchester, Florida State University. Because of time constraints, discussion was limited to quartz sands at temperatures to $250^{\circ} \mathrm{C}$ and effective stresses to 300 bars. 
Phenomena discussed by workshop participants were grain thermal cracking, boundary layer physics, hydrolytic weakening, pressure solutioning, and solid-fluid adhesion.

Task 2. Sample Acquisition, Preparation, and Characterization

Modification of Terra Tek's equipment is necessary to conduct the tests requested by PNL. Modification work is expected to be completed by April 1980. Galesville and Massillon sandstones and Ottawa sand have been selected as test specimens.

Task 3. Laboratory Testing

Progress for this task is being reported in Section 4.1.1c entitled Air-Water-Rock Interaction in CAES Reservoirs.

TECHNICAL DIFFICULTIES

None

PUBLICATIONS

None 


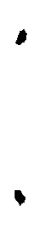




\subsection{1g Design and Construction of Porous Media Flow Facility M.A. McKinnon \\ Pacific Northwest Laboratory}

\section{OBJECTIVE}

The program objective is to design and construct a flow facility to generate data needed to gain a basic understanding of the behavior of porous rock subject to CAES loadings. The design objectives for the facility include temperatures up to $560^{\circ} \mathrm{K}$, confining pressures up to $69 \mathrm{MPa}$ and pore pressure up to $10 \mathrm{MPa}$. The facility is to be capable of flowing humidified air, up to $90 \%$ relative humidity at temperature and pressure, through a porous rock sample. Initial tests in the facility are to be used for code verification of a porous rock desaturation model and fundamental studies of geochemical, mechanical, thermal and fluid flow alterations during desaturation. Subsequent tests will examine elastic, post elastic, strength, porosity, permeability, structural, and chemical alteration of porous rock subject to CAES conditions.

\section{TASKS}

The development of the flow facility has been divided into six tasks. These tasks are 1) design, including mechanical and electrical design, 2) procurement, 3) site selection and preparation, 4) software development, 5) component fabrication and loop assembly, and 6) testing.

\section{TECHNICAL PROGRESS}

Task 1. Design

The design has progressed through several iterations from preliminary conceptual design to final design of components, piping assemblies and installation drawings. The design has faced interesting challenges posed by a desire to control and measure humidity at low flow rates, high temperatures, and high pressures. Component identification and 
selection has also been impacted by low flow, high temperature, and high pressure requirements.

At present, the mechanical design is complete and the electrical design is being wrapped up. The design drawings are being completed with the exception of those areas where specific vendor information has not been received on the sample holders, signal conditioning equipment, and on the trace heaters control and operation. Figure 18 shows an isometric view of the piping arrangement at the test stand.

\section{Task 2. Procurement}

Over fifty separate procurement orders have been placed for piping components and instrumentation. Delivery is complete for over half of these orders and the remainder of the procurement should be complete by May. We are still waiting for long lead items such as special high temperature high pressure valves, a small electrically heated high pressure boiler and equipment needed to confine and load a porous rock specimen prototypically. Several items such as fittings, piping, and trace heaters could not be ordered until the design was near completion. With the recent completion of the mechanical design, procurement action has begun on these items.

\section{Task 3. Site Selection and Preparation}

Several sites have been considered for possible location of this facility. The initial site selected had access to an existing high pressure air supply system but lacked any control of environmental temperature needed to insure instrument reliability. The current site in the Engineering Development Laboratory (EOL) provides the temperature environment needed for reliable data acquisition and instrumentation. It also has access to a minicomputer which will be the heart of the data acquisition and control system. This location has required the relocation of a small air compressor. Construction in the EDL location has been initiated. A schematic of the systems layout is shown in Figure 19. 


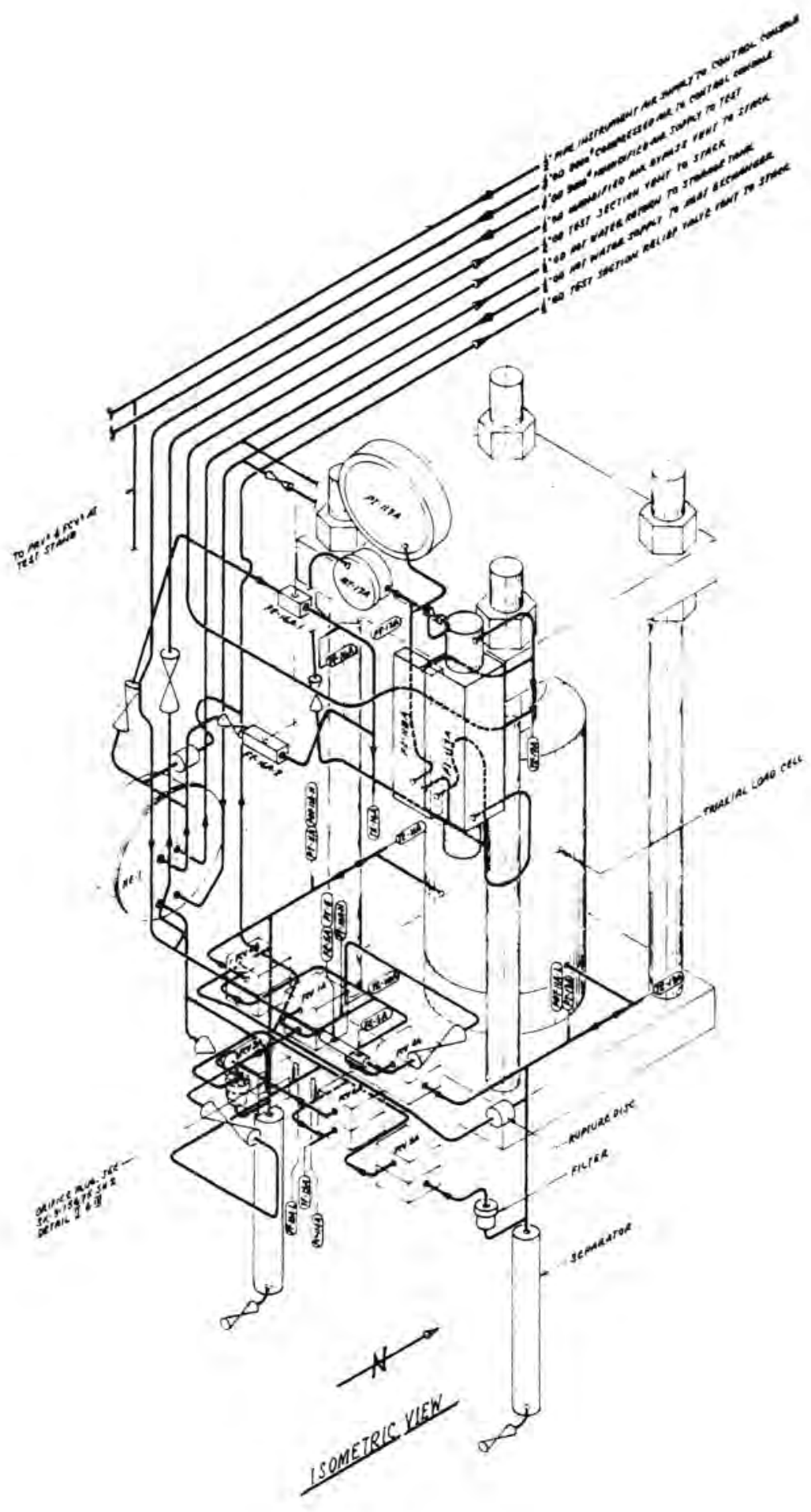

FIGURE 18. Isometric View of Porous Media Flow Facility's Test Stand 


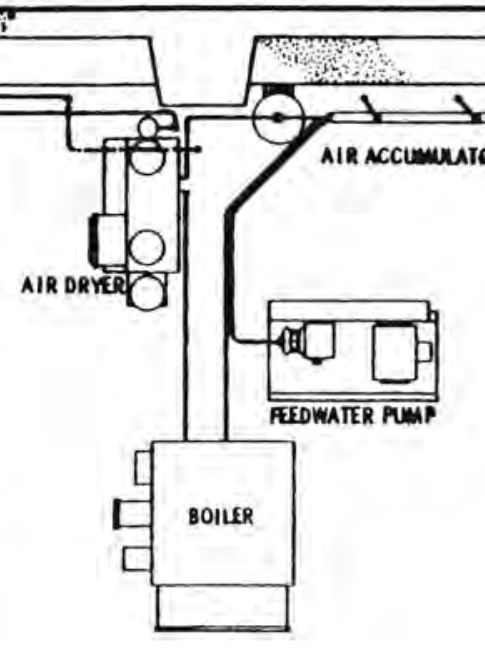

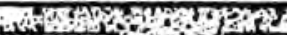
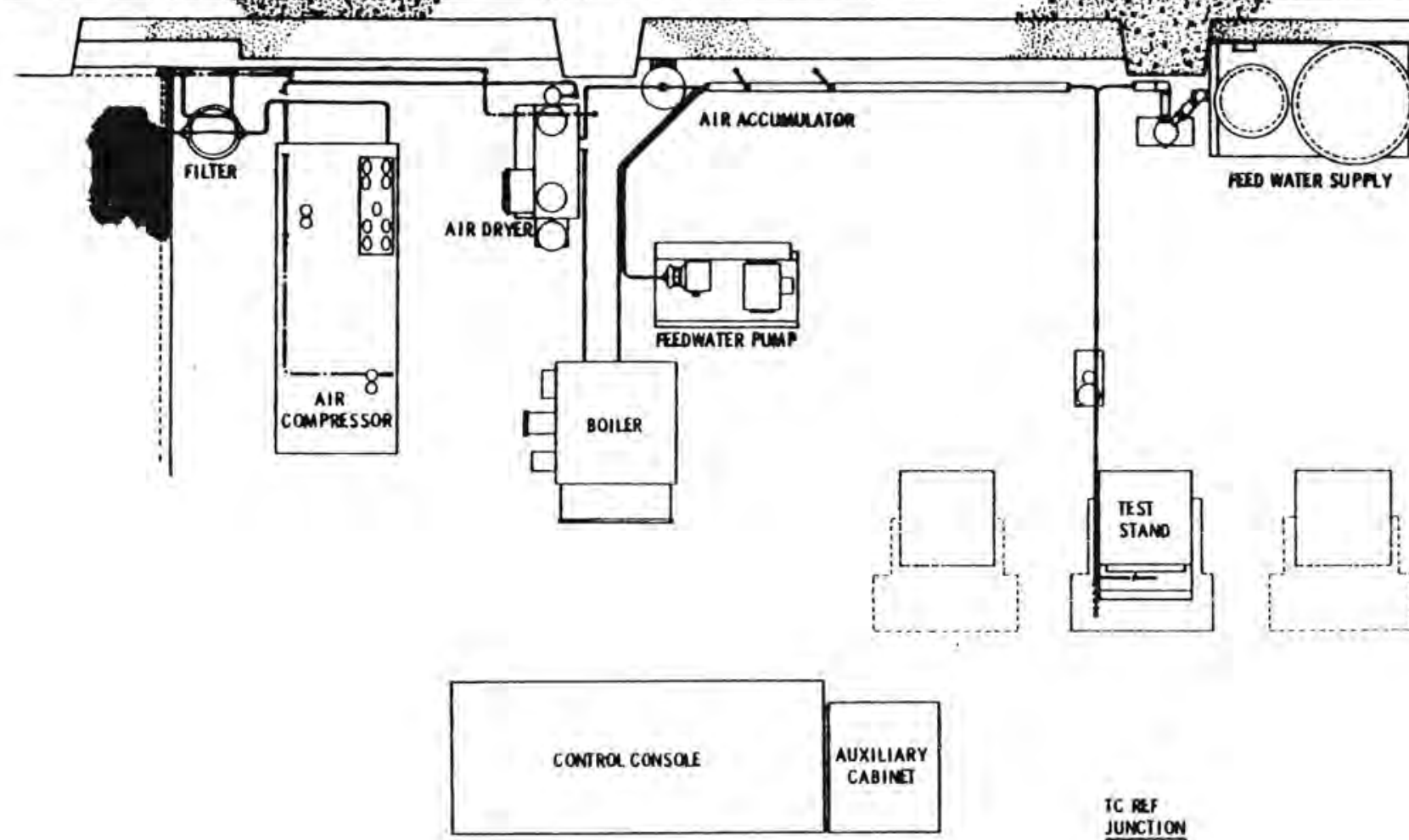

FED WAIER SUPAYY

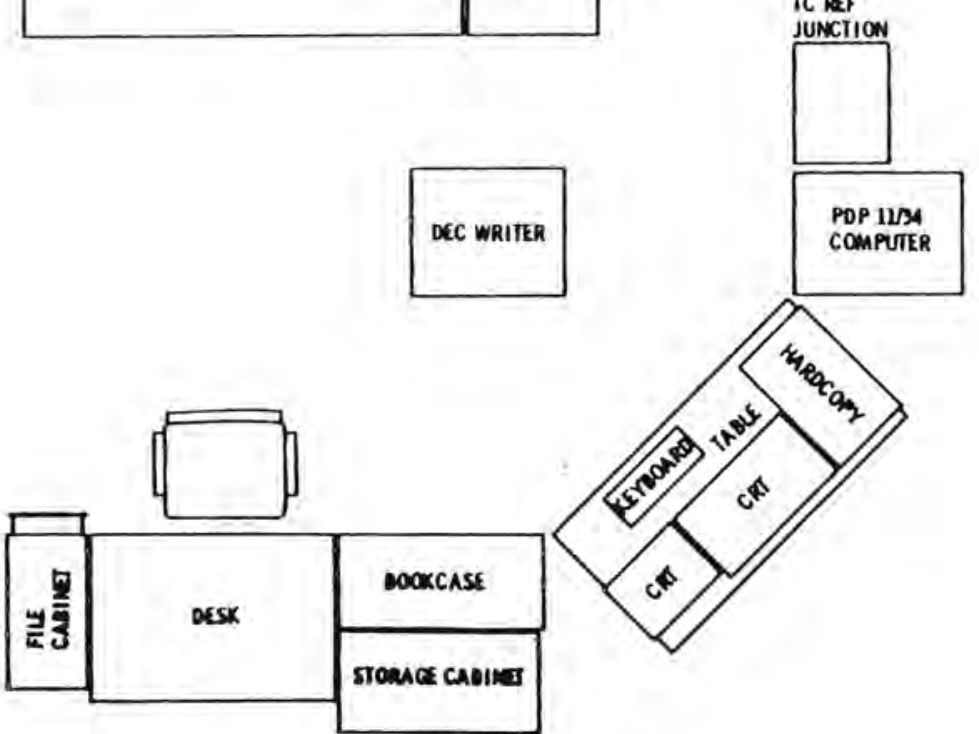

FIGURE 19. Schematic of Porous Media Flow Facility Layout 
Task 4. Software Development

The PDP/11 computer system is in the process of being programmed to provide the data acquisition and control features required by the flow facility. The PDP/11 system has sufficient expansion capability to provide some data reduction and unattended long-term operation of the facility.

Task 5. Component Fabrication and Loop Assembly

Fabrication has begun on a steam superheater, air preheater, air/water separators, and jeweled orifice flowmeters. We are currently in the process of scheduling craftsmen for loop assembly.

\section{Task 6. Testing}

Functional tests will be performed as each component and subassembly is put together, to assure proper operation and to provide an opportunity to debug the system before experimental programs are initiated. The test plan required to guide this testing is being developed.

TECHNICAL PROBLEMS

None

PUBLICATIONS

None 
1) 


\subsection{7h Field Studies of Porous Rock Reservoirs}

R. D. Allen and P. J. Gutknecht

Pacific Northwest Laboratory

\section{OBJECTIVE}

Field studies of porous rock reservoirs have been conceived to fulfill four program objectives:

- Demonstrate the feasibility of storage of warm compressed air in an aquifer

- Investigate physical, chemical, mineralogical and biological effects of CAES on reservoir rock and caprock and compare with laboratory results

- Verify and evaluate numerical modeling of dehydration and water displacement, thermal growth, and cyclic thermal performance

- Evaluate system performance with respect to bubble growth rate, mass transfer rates, thermal development and recovery, water production, and entrainment of mineral particulates.

TASKS

The program is divided into three broad phases: I. Field Test Plan and Preliminary Site Screening, II. Site Acquisition and Exploration by Seismic Reflection and Confirmatory Drilling, and III. Site Development, Surface Plant Installation, Complete Field Testing Program, and Laboratory Examination. Within these phases nine discrete tasks are identified.

Task 1. Develop Aquifer Field Test Plan

A field test plan is to be developed to embrace all program activities; i.e., technical, scheduling, contractual and financial.

Task 2. Identify Necessary Site Characteristics

This task involves defining the geological and depth requirements of the site. 
Task 3. Perform Regional Site Screening and Select Candidate Sites

Task 3 involves a) screening of geologic data from all available sources; i.e., federal and state geological surveys, well drilling information, geophysical surveys, etc., b) evaluating the top ranking sites and, c) recommending a site for further development.

Task 4. Acquire Testing and Development Rights

This task requires the drafting of land leases to permit seismic exploration, confirmatory drilling and subsequent site development. The latter includes installation of a surface facility, driliing of wells in defined locations for air injection and reservoir monitoring, instrumentation of wells, air injection/cycling, and final coring near the injection wel1. A single legal instrument has been drawn. Leasing is to take place after there are suitable public relations activities to explain the program. A "land man" will provide direct contacts with the landowners.

Task 5. Qualify Test Site for Development

This task involves drilling of a single well to measure the seismic velocity profile from the surface through at least the upper portion of the reservoir rock. Shallow high resolution seismic reflection surveys will be used to determine the presence or absence of substructural traps, e.g., second order domes, anticlines. Confirmatory holes will be used to a) log the stratigraphy, b) develop structure contour maps and isopach maps of caprock and reservoir, and c) obtain cores for laboratory qualification of caprock and reservoir.

Task 6. Develop Site by Drilling, Instrumentation and Installation of Surface Plant

The injection/monitoring well geometry will be determined by the presence or absence of a substructural trap. Given a suitable trap, a single injection well will be monitored at various radial distances by thermisters, thermocouple psychrometers and heat dissipation units in closed-instrument wells; and piezometers in packer-isolated wells at 
various depths. Tracer tests will be performed in the closed-instrument wells. Monitor wells will be arrayed to follow reservoir development. The surface plant will consist of compressor/receiver, aftercooler, pressure regulator, heater, flowmeter, hygrometer, thermistors, various valves and outlet muffler.

\section{Task 7. Conduct CAES Field Tests}

Injection of cool air will occur for up to six months to develop the original air bubble. Air cycling at ambient temperatures will be followed by cycling at incrementally higher temperatures from $65^{\circ} \mathrm{C}$ $\left(150^{\circ} \mathrm{F}\right)$ to $190^{\circ} \mathrm{C}\left(374^{\circ} \mathrm{F}\right)$. Physical characteristics of reservoir performance and air injection/withdrawal will be monitored.

Task 8. Conduct Pre- and Post-Test Coring and Laboratory Analys is

Pre- and post-test cores of reservoir rock and caprock will be compared with respect to mineralogy and microstructure, rock mechanical properties, permeability and porosity, thermal properties, and residual water content and composition. The threshold pressure of the caprock from near the injection wellbore will be compared with the original value.

Task 9. Analyze Field and Laboratory Data

Changes in reservoir and caprock physical, chemical, mineralogical and possibly biological properties will be evaluated. Results will be compared to numerical modeling and laboratory predictions. System characteristics and performance with time will be evaluated. Overall results will be extrapolated to predict full scale system performance.

\section{TECHNICAL PROGRESS}

Task 1. Aquifer Field Test Plan

This task is complete. The field plan includes program management, site-selection procedures, test plan development, field setup and operation, 
activities for FY-1980 thru 1982, and projected expenditures. The test plan will evolve during the program requiring periodic updating.

\section{Task 2. Site Characteristics}

This task is complete. The site criteria adopted include:

- Reservoir depth - 152 to $213 \mathrm{~m}$

- Reservoir rock - sandstone

- Reservoir thickness - more than $4.6 \mathrm{~m}$

- Reservoir permeability - more than $300 \mathrm{md}$

- Reservoir porosity - at least $10 \%$

- Caprock thickness - at least $6 \mathrm{~m}$

- Caprock threshold pressure - more than $1380 \mathrm{kPa}$

- Structure - substructural dome or "closed" anticline with at least $4^{\circ}$ slope and horizontal area ca. 2 to 10 ha.

- Vertical closure - more than $4.6 \mathrm{~m}$.

Task 3. Site Selection

This task is complete. A site in Illinois has been identified as most suitable based on existing information. Other potential sites were rejected for the following reasons:

- insufficient borehole data

- reservoir too shallow or too deep

- shale lenses in reservoir rock

- absence of permeability data

- anticlines offset by transverse faulting.

The site selected has the following characteristics:

- History - former gas field within the Silurian section

- Structure - doubly plunging anticline with minor domal substructures

- Caprock - Joachim formation - fine argillaceous dolomite $10 \mathrm{~m}$ thick (Ordovician)

- Reservoir - St. Peter sandstone at depth of 186 to $197 \mathrm{~m}$ (Ordovician). 
Task 4. Testing and Deveropment Rights

This task is underway. An agent under contract with PNL has identified land ownership, land values and approximate lease costs for the proposed area. Most of the land is occupied by 160 to 320 acre farms.

An Option and Air Storage Easement and Lease instrument was originally drawn up in draft form by an Illinois law firm. A final instrument has been be drawn by PNL Legal and Contract Services in cooperation with the Illinois firm.

Task 5. Qualify Test Site

Two procurement invitations to submit qualifications have been published in the Commerce Business Daily. These are:

- Drilling Services for a Seismic Survey West Central Illinois February 22, 1980

- High Resolution Siesmic Reflection Surveying West Central Illinois February 22, 1980

Responses have been received and evaluated. Work statements have been prepared for fixed price RFP's which are scheduled for issue on May 2, 1980. Task 6. Develop Site, etc.

A procurement invitation to submit qualifications has been published in the Commerce Business Daily. This is:

- Storage of Compressed Air for Subsequent Withdrawal as an Energy Source - February 20, 1980.

Responses have been received and evaluated. The RFP is scheduled for issue on July 15, 1980.

TECHNICAL PROBLEMS

Acquisition of testing and development rights is a potential problem because many property owners will be involved. 


\section{PUBLICATIONS}

R. D. Allen and P. J. Gutknecht, Porous Media Experience Applicable to

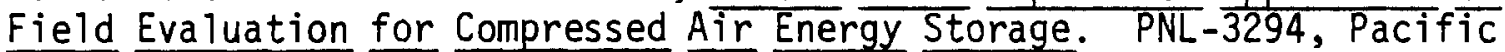
Northwest Laboratory, Richland, WA, (in process).

R. D. Allen and P. J. Gutknecht, CAES Aquifer Field Studies Plan, Pacific Northwest Laboratory, Draft December 1979, to be published. 


\title{
4.1.2a Numerical Studies of CAES Hard Rock Caverns
}

\author{
A. F. Fossum \\ $\mathrm{Re} / \mathrm{Spec}$, Inc.
}

\section{OBJECTIVES}

The program objectives are to 1 ) establish a numerical model to predict the behavior of excavated hard rock caverns subject to the conditions experienced by a compensated compressed air energy storage (CAES) system, and 2) formulate a rational set of stability and design criteria that are both practical to the designer and applicable to numerical simulation (modeling).

\section{TASKS}

Task 1. Parametric Operational Thermoelastic Stress Analysis for CAES Caverns

Finite element calculations will be made of the thermoelastic states of stress in the rock mass around caverns of different shapes and spacings for realistic ranges of in-situ stress, internal cavern pressures, and cyclic wall temperatures. Internal cavern pressures and in-situ stresses will correspond to depths of between $500 \mathrm{~m}$ and $1000 \mathrm{~m}$; the cyclic wall temperatures shall encompass a range of peak temperatures from 40 to $150^{\circ} \mathrm{C}$. Realistic charge/discharge cycles will be used corresponding to typical daily, weekly, and seasonal power demand curves. Task 2. Thermal/Mechanical Rock Permeability Perturtations

Calculated stresses will be used in stress-dependent hydraulic conductivity relations to obtain variations in the rock secondary permeability after cavern construction and during cavern operation.

Task 3. Air Leakage

Air leakage rates will be calculated for realistic CAES geologic and operating cavern conditions. In-situ permeability measurements will 
be used in this analysis because of the importance of fractures in secondary permeability, not normally measurable in the lab.

Task 4. Complementary Support

A survey and evaluation of design, construction, and operation procedures for underground storage caverns in Scandinavia will be conducted by Hagconsult (Re/Spec subcontractor in Stockholm).

\section{Task 5. Special Topics}

Assessments will be made of the influence of joints and bedding planes on the potential for rock failure and enhanced air leakage. Assessments will be made of the influence of mineralogical composition and water saturation on thermal spalling, as evaluated from a numerical modeling approach.

Numerical modeling of remedial action will be conducted for stability enhancement. Remedial measures may include grouting, shot-creting, and rock bolting. Since no CAES site can be explored in total by siteselection procedures, particular deleterious geologic conditions may be encountered during construction. Rock improvement measures would be the economic alternative to compromise or abandonment.

Task 6. Design Handbook

A handbook-type treatise will be prepared that will provide practical meaning and use of failure criteria for static and cyclic loadings of CAES caverns.

\section{Task 7. Reliability Study}

The basic elements of a CAES numerical simulation model and of the probabilistic approach to cavern design for the excavation phase have been formulated. The feasibility of this approach will be investigated for the operational phase. If appropriate, case history simulations and parametric evaluations will be made. 


\section{TECHNICAL PROGRESS}

Task 1. Parametric Operational Thermoelastic Stress Analysis for CAES Caverns

A thermal analysis of a CAES cavern has been performed for the operational behavior during 50 days of CAES operation. The cavern was assumed to experience one operational cycle per day. A temperature range of 10 to $40^{\circ} \mathrm{C}$ was used corresponding to assumed temperatures of compensating water and compressed air, respectively. The initial rock temperature was assumed to be $29^{\circ} \mathrm{C}$. Some of the heat transfer results for half and full operational cycles are shown in Figure 20. This figure illustrates steep temperature gradients in the rock near the vicinity of the wall. Figures 21 and 22 show how the temperature decays

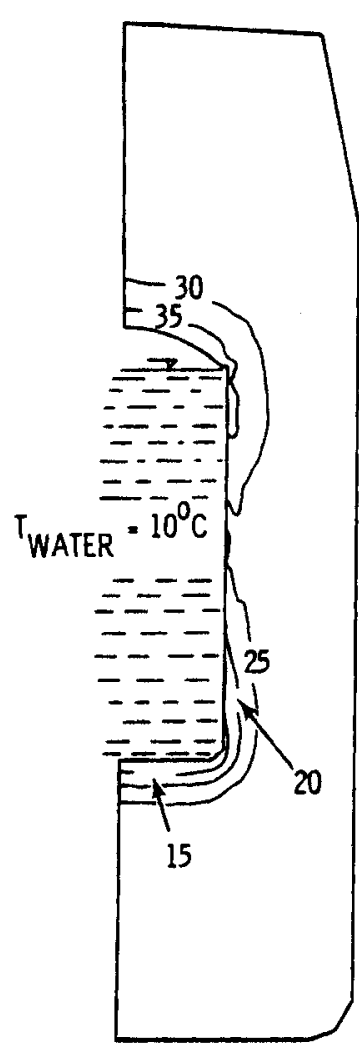

CYCLE $=10.0$

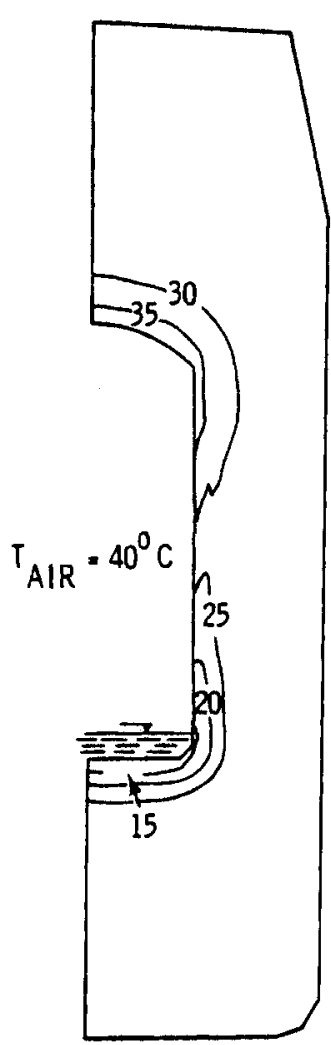

CYCLE $=10.5$

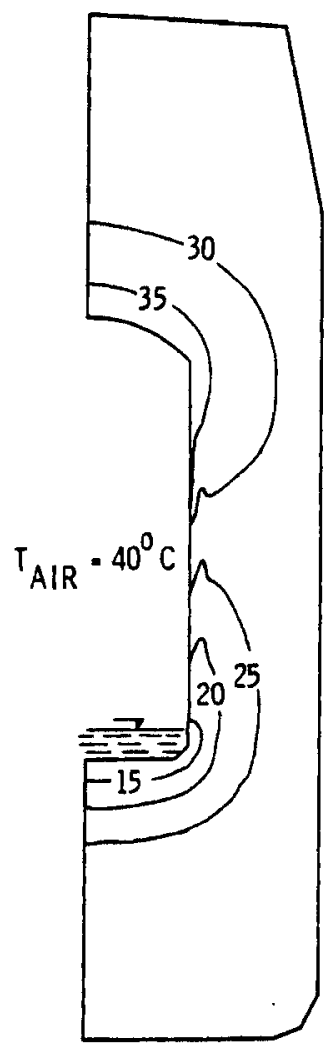

CYCLE $=49.50$

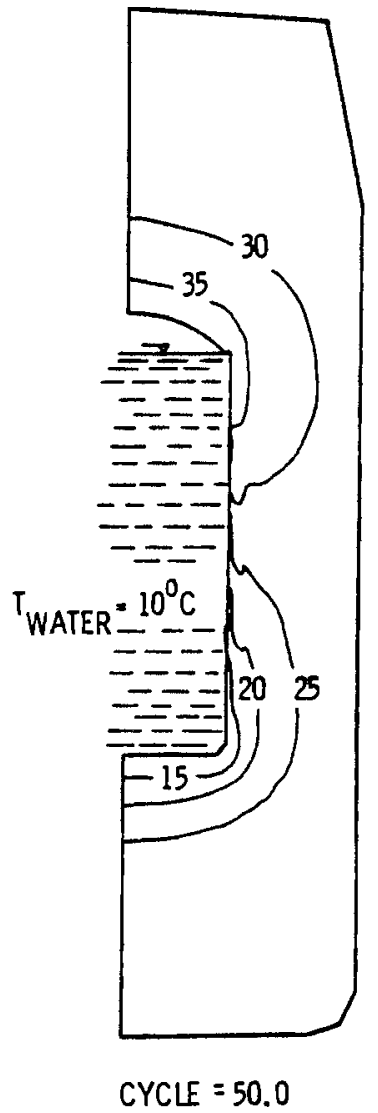

$C Y C L E=50.0$

FIGURE 20. Temperature Contours $\left({ }^{\circ} \mathrm{C}\right)$ Around CAES Cavern for Different Operational Cycles 


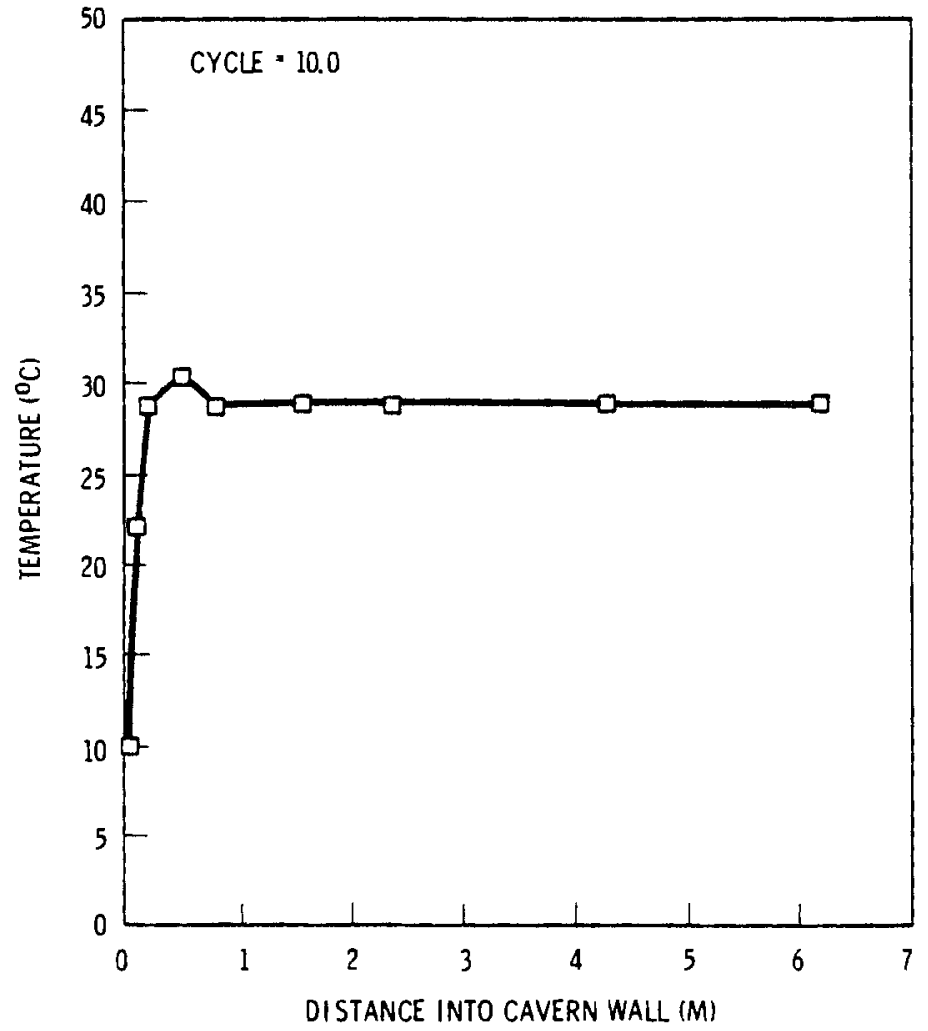

FIGURE 21. Temperatures $\left({ }^{\circ} \mathrm{C}\right)$ into Cavern Wall

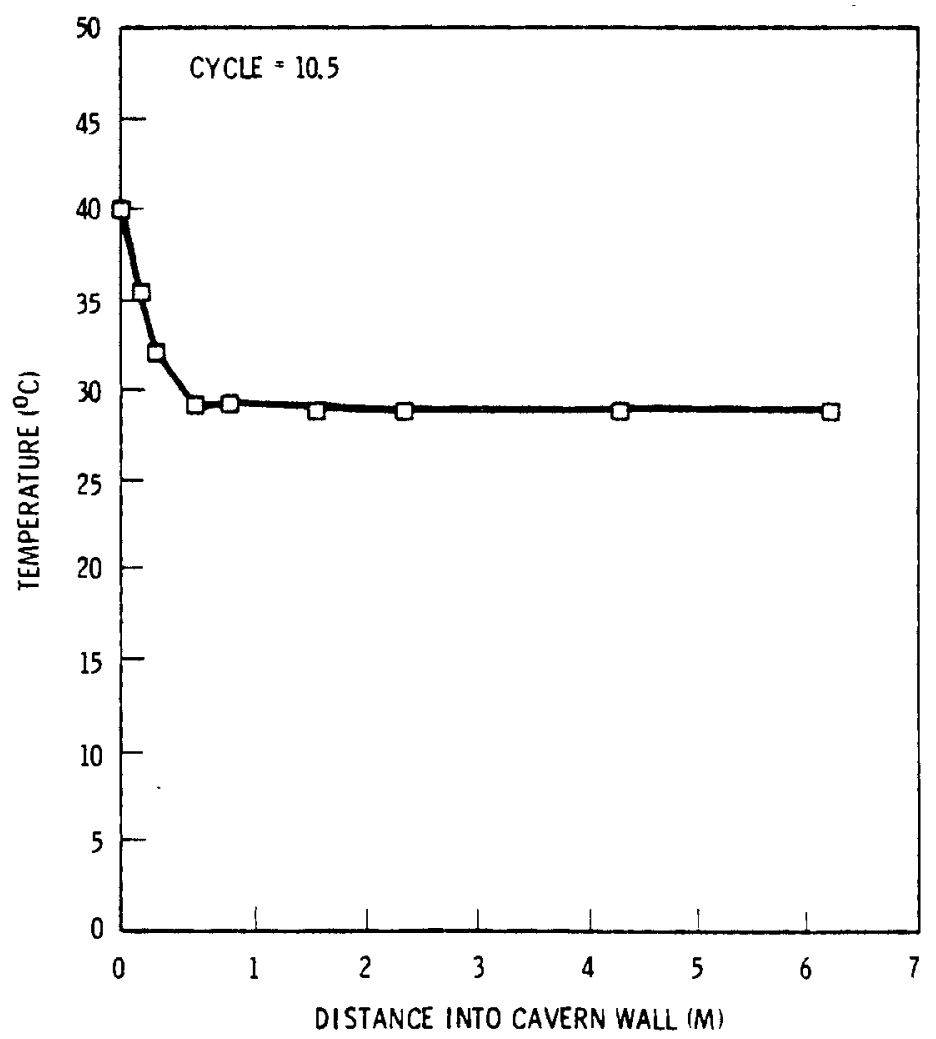

FIGURE 22. Temperature $\left({ }^{\circ} \mathrm{C}\right)$ into Cavern Wall 
along a line emanating from the wall halfway between the roof and the floor. Again the steep temperature gradient can be seen adjacent to the wall.

The thermomechanical response of the rock was also investigated for the 50-day period following startup. The cavern was given an internal pressure of $7.4 \mathrm{MPa}$ corresponding to the pressure exerted from a $750 \mathrm{~m}$ tall column of water. Despite the relatively low temperature range, severe cyclic stresses developed along the cavern wall. For example, the vertical stress at the wall ranges from $9.6 \mathrm{MPa}$ in tension to $2.2 \mathrm{MPa}$ in compression as the compensating water rises and falls. High compressive stresses are also observed in the roof. Figure 23 shows the principal stress trajectories around the cavern for cycle 9.5 and 10 . Figures 24 and 25 show the corresponding vertical stress into the wall.
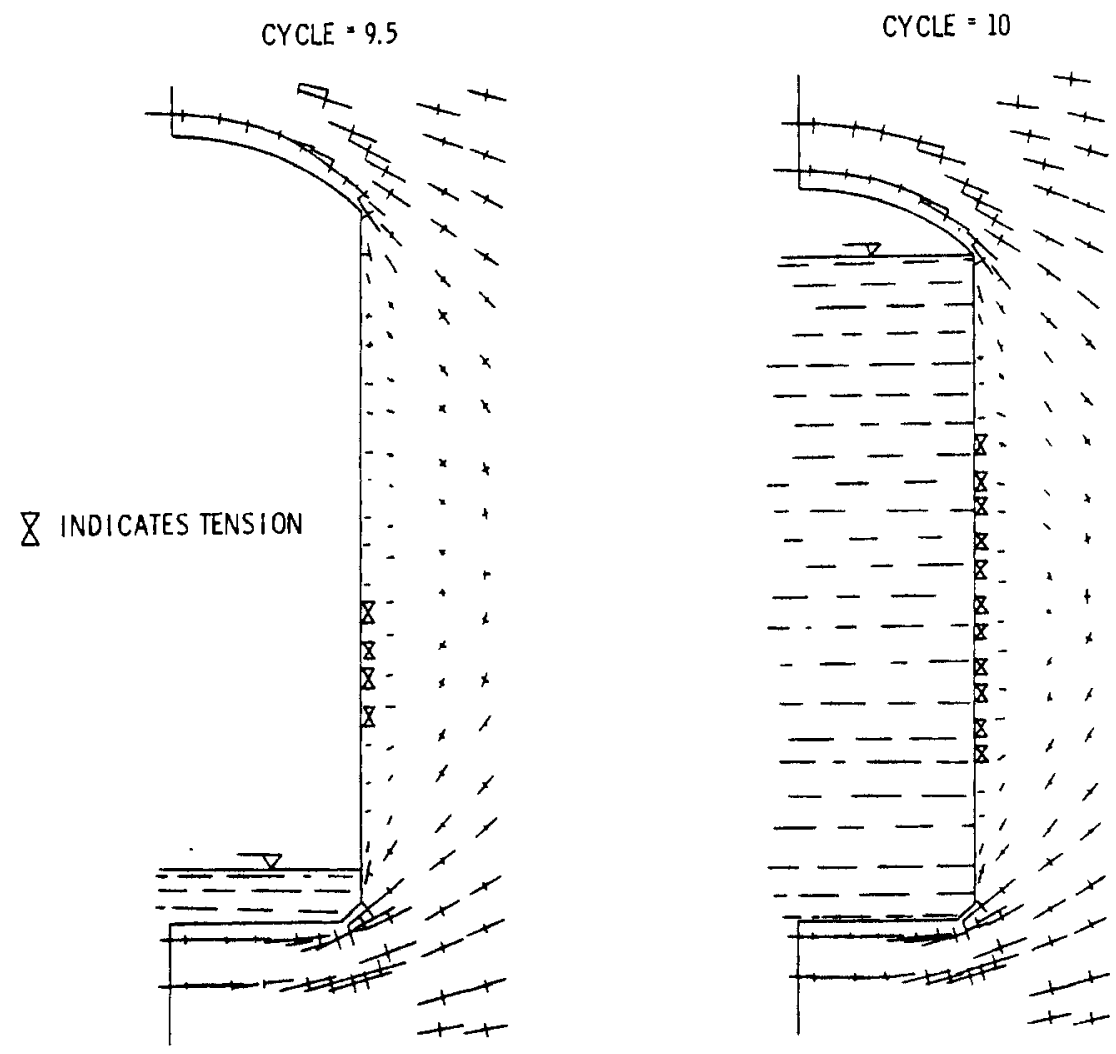

FIGURE 23. Principal Stress Trajectories Around CAES Cavern for Different Operational Cycles 


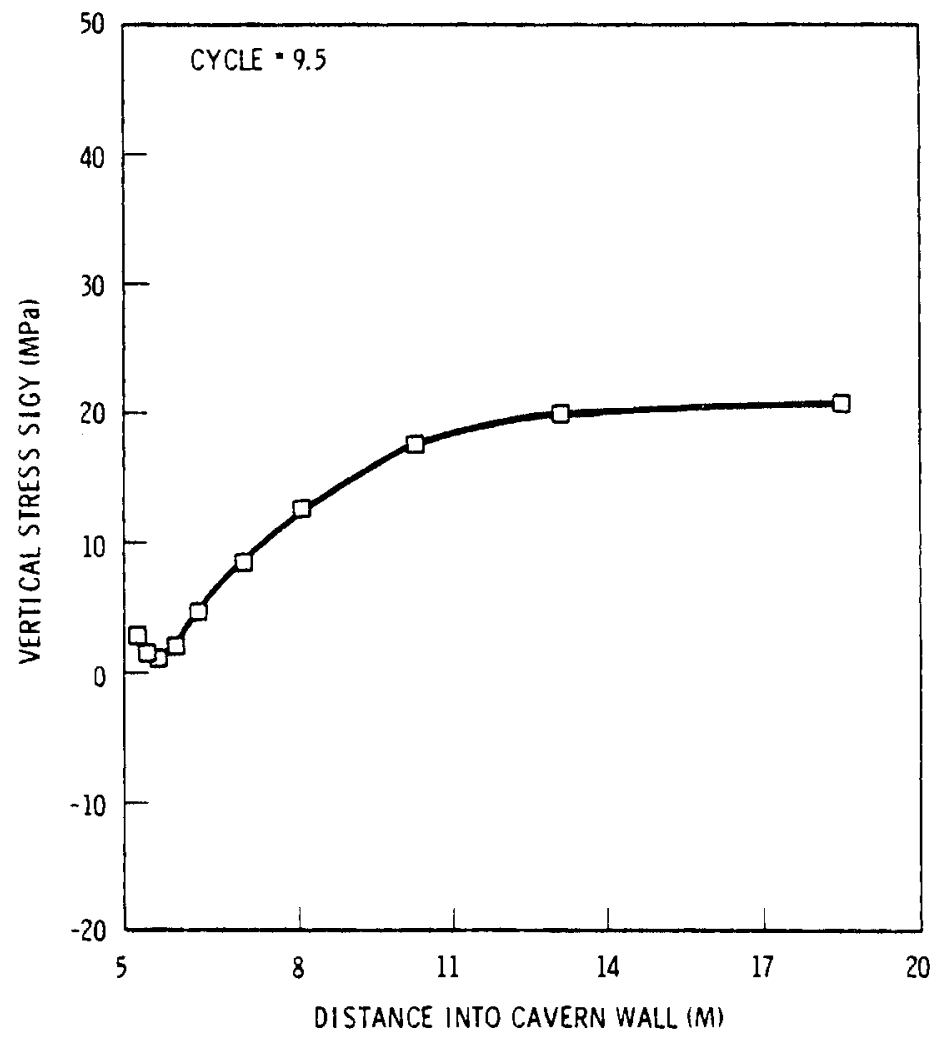

FIGURE 24. Vertical Stress into Cavern Wall

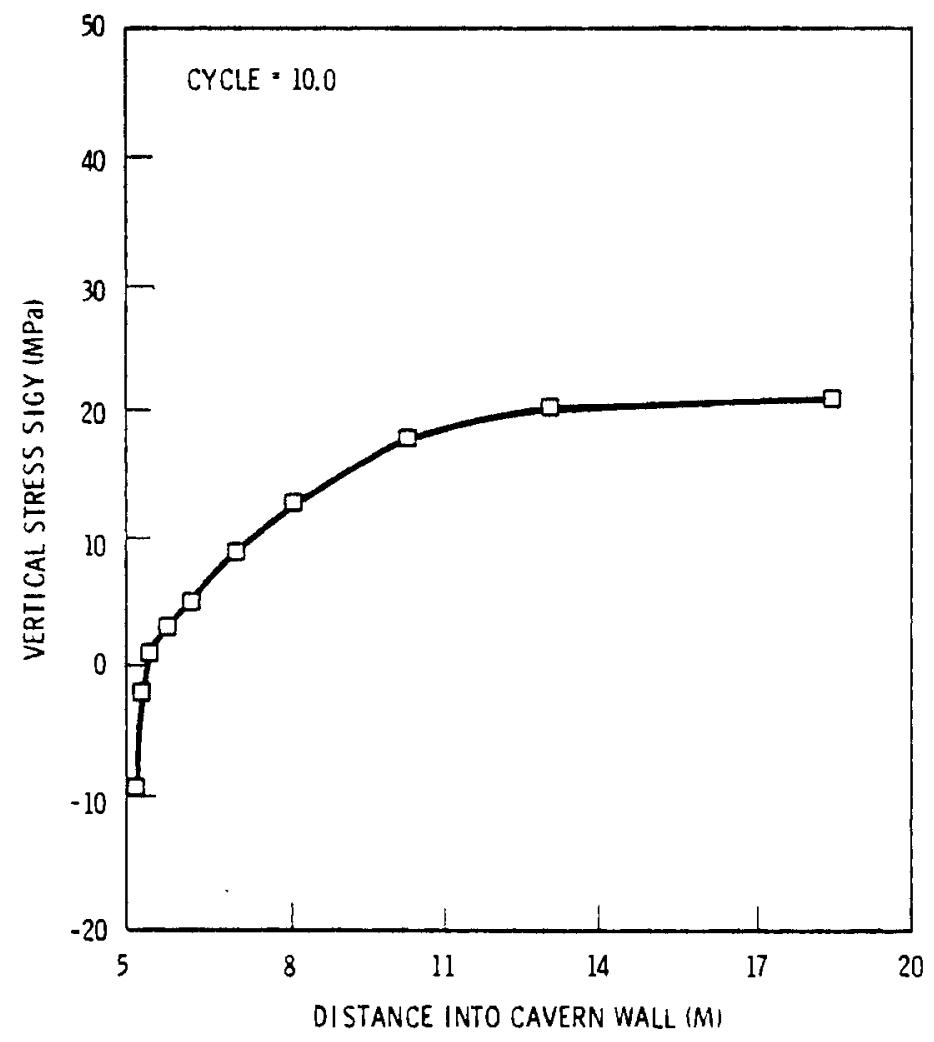

FIGURE 25. Vertical Stress into Cavern Wal1 
Task 2. Thermal/Mechanical Rock Permeability Perturbations

No work on this task has been initiated.

Task 3. Air Leakage

No work on this task has been initiated.

Task 4. Complementary Support

A report entitled "Design and Stability Aspects of Air Chambers in Scandinavia" has been received from Hagconsult ab of Stockholm. This report outlines the design and stability aspects for surge chambers and LPG storage in Scandinavia.

Task 5. Special Topics

No work on this task has been initiated.

Task 6. Design Handbook

No work on this task has been initiated.

Task 7. Reliability Study

No work on this task has been initiated.

TECHNICAL PROBLEMS

None 


\subsection{2b Laboratory Studies of CAES Hard Rock Caverns}

A. F. Fossum

Re/Spec, Inc.

\section{OBJECTIVE}

The program objective is to formulate preliminary design and stability criteria for compressed air energy storage (CAES) caverns based on laboratory investigations of the response of rock specimens to loading conditions typifying those of an operating CAES cavern. The design and stability criteria should relate to the unknowns which could affect the technical and economic feasibility of CAES caverns so that their long lifetime suitability can be assured and encouragement given to early commercialization of the CAES concept.

\section{TASKS}

\section{Task 1. Determination of Significant Rock Properties}

The goal of this task is to establish those significant physical, geometrical, petrophysical, thermal and mechanical characteristics and properties of rock types and geological formations for which the CAES concept is applicable; i.e., for the range of conditions of temperature, pressure, and moisture that exist in CAES systems.

Task 2. Procurement of Specimens

The objective of this task is to procure and prepare generic rock specimens for the testing program.

Task 3. Selection of Specific Procedures for Rock Characterization Before and After Testing

This task provides a means by which the rocks being tested can be categorized and/or identified by their physical characteristics.

Task 4. Laboratory Scale Testing of Rock Specimens

The objective of this task is to obtain properties of hard-rock specimens subjected to conditions simulating or approximating the operating conditions at a CAES plant. 
Task 5. Formulation of Stability and Design Criteria

Formulation of consistent CAES cavern design and stability criteria will be made on the basis of this laboratory program, state-of-the-art, and numerical modeling studies sponsored by PNL. Also included under this task is the writing of the final report.

TECHNICAL PROGRESS

Task 1. Determination of Significant Rock Properties

Rock properties have been identified that will have a bearing on the selection of design and stability criteria. These properties can be classified broadly into physical, thermal, hydrological, and mechanical.

A survey of the literature has been completed to determine the extent to which the significant rock properties have been evaluated. The results from this survey showed that the greatest inadequacies were in the properties of nonintact rock at nonambient conditions followed by intact rock at nonambient conditions.

Representations of a generic nature have been derived that provide a relationship between some of the global rock properties and the properties of the rock's mineralogical composition.

Task 2. Procurement of Specimens

Large quantities have been obtained of four major rock types including igneous intrusive (granite), metamorphic foliated (gneiss), metamorphic nonfoliated (quartzite), and sedimentary chemical (dolomite). Specimens of these rocks have been prepared, logged, and conditioned for testing.

Attempts were made to obtain samples of naturally jointed rock but were unsuccessful. Techniques were then developed for creating realistic artificial joints from intact rock specimens. A technique has been found that enables joints to be created with consistent characteristics from one specimen to another and that allows joints to be oriented arbitrarily in the specimen. Negotiations are being made with Commonweal th Edison to obtain granitic rock core at depth $(650$ to $1800 \mathrm{~m})$. 
Task 3. Selection of Specific Procedures for Rock Characterization Before and After Testing

The mineralogical composition of all selected rock types has been determined. Magnifications of 35 and $200 \mathrm{X}$ were used with the optical microscope and 250 to $1000 \mathrm{X}$ magnifications were used on an SEM. Both fractured and polished sections were examined. Post test examination of specimens that have been subjected to nonambient conditions will be performed.

Task 4. Laboratory Scale Testing of Rock Specimens

The testing program has concentrated primarily on obtaining mechanical and hydrological rock properties. Roughly, 300 mechanical properties tests have been completed on Taboratory scale specimens of Redfield Granite, Biotite Granite, Sykesville Gneiss, Sioux Quartzite, and Kasota Dolomite.

Elastic and strength properties have been obtained for intact specimens of these rocks at room temperature for dry and saturated moisture conditions. Failure envelopes were obtained from indirect tension, unconfined compression, and triaxial compression tests. Confining pressures in the triaxial compression tes ts ranged from $1.5 \mathrm{MPa}$ to $20 \mathrm{MPa}$. These pressures correspond to in-situ stress levels that a CAES installation would experience at depths ranging from 50 to $1000 \mathrm{~m}$. Figure 26 shows portions of Mohr failure envelopes for Kasota Dolomite corresponding to the two above mentioned moisture conditions labeled "dry" and "wet" in the figure. These results demonstrate that as the moisture content of the rock increases, its shear strength decreases. In a compensated CAES cavern the walls will likely be fully saturated.

Figure 27 shows the differential axial stress, volumetric, axial, and lateral strain behavior during a triaxial compression test on Kasota Dolomite. The stress-volumetric strain plot clearly shows that the rock begins to undergo inelastic behavior when the axial stress is approximately $40 \%$ of the peak stress. Eventualiy the volume of the rock begins to 


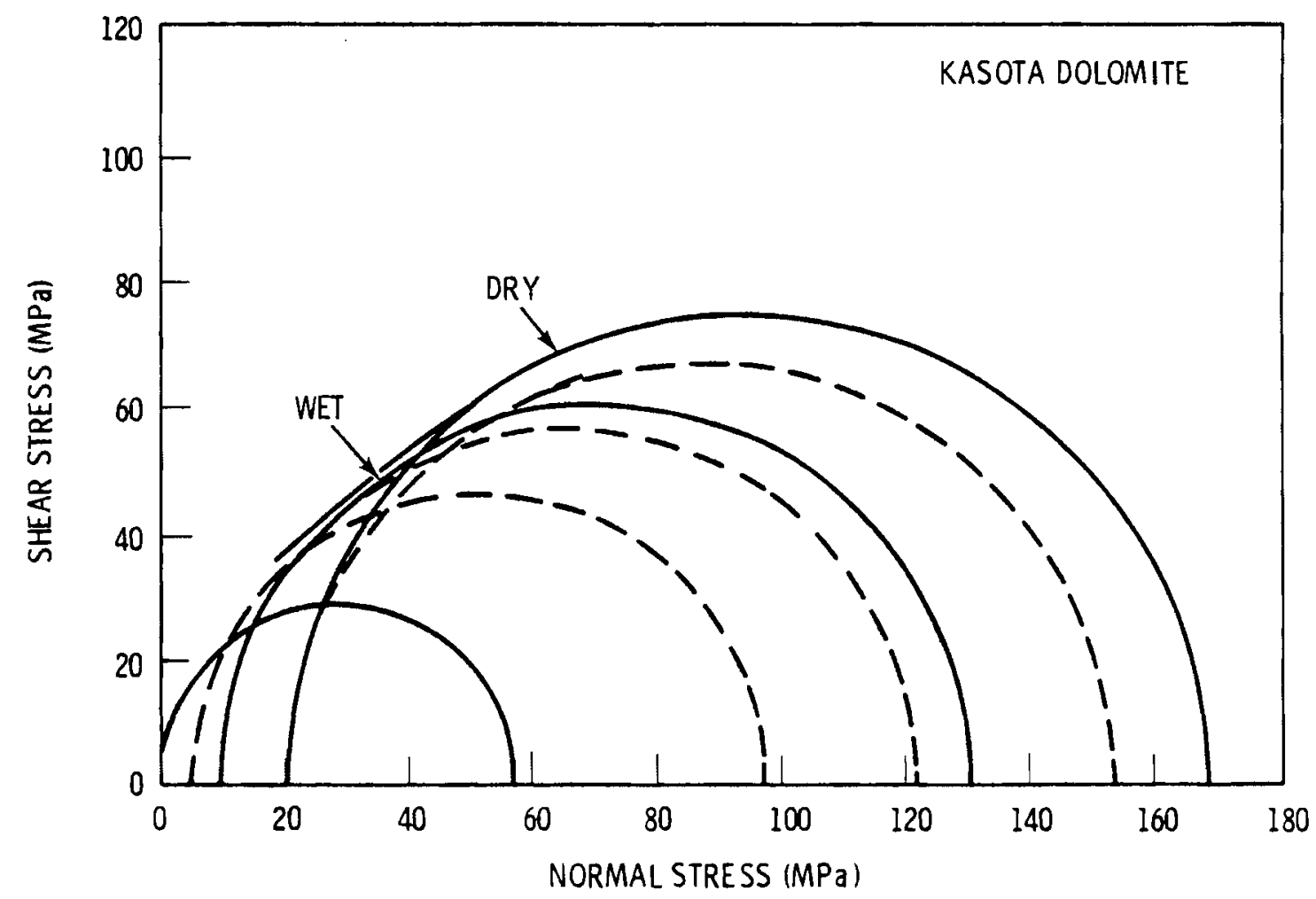

FIGURE 26. Mohr Failure Envelopes for Dry and Saturated Kasota Dolomite
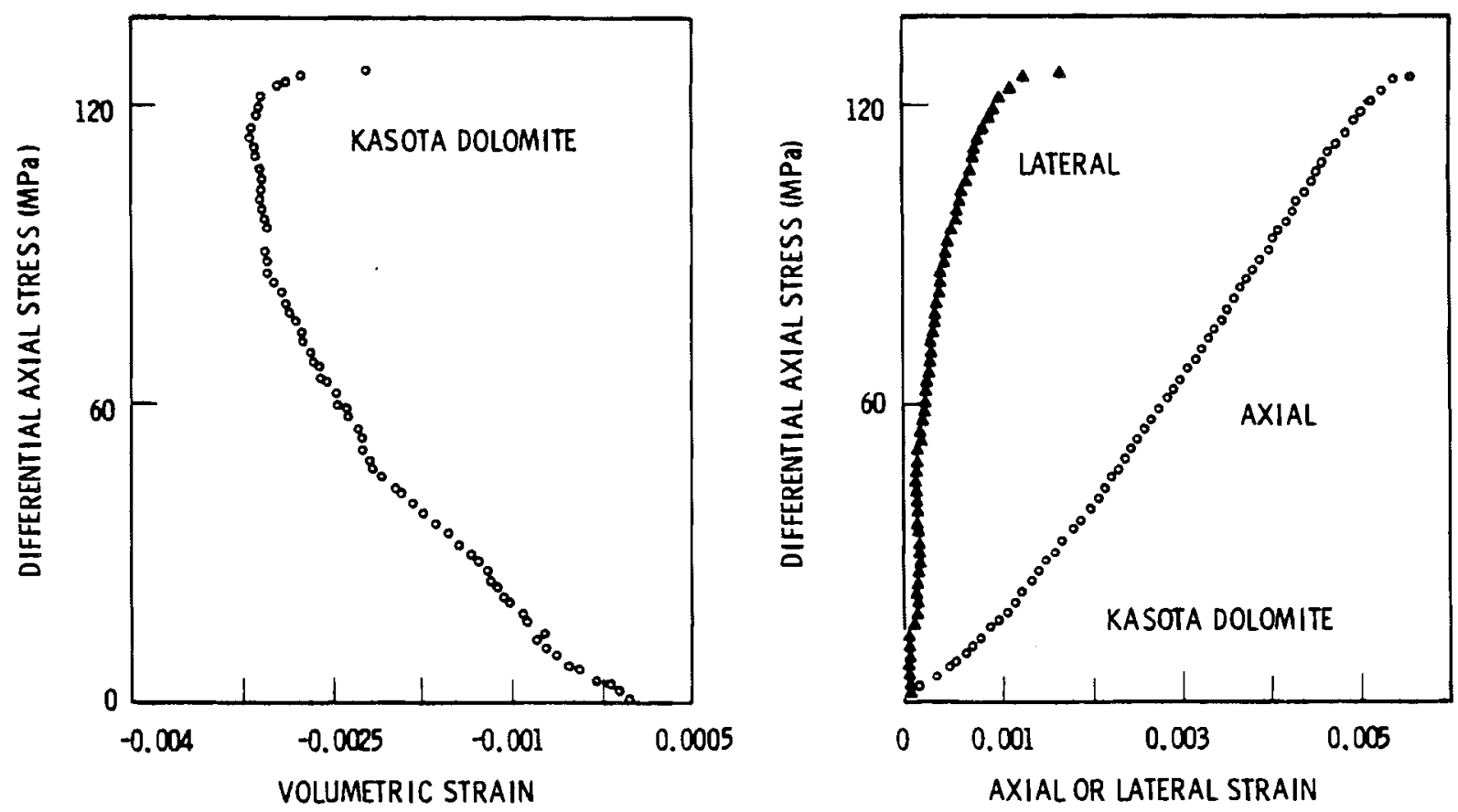

FIGURE 27. Plots of Differential Axial Stress Versus Volumetric, Axial, and Lateral Strain 
increase as the axial stress is increased. This behavior is the outcome of a chain of events including frictional sliding on microscopic fissures, attended by the outgrowth of localized tensile cracks from the tips of the fissures, and the overriding of asperites. The cumulative effects of these latter features may alter the permeability of the rock. The onset of dilatant behavior does not appear to be discernible from the axial stress-strain plot.

The Sykesville Gneiss is a foliated metamorphic rock and as such exhibits pronounced anisotropy. The data presented in Figure 28 show that, for the given confining pressure, the compressive strength perpendicular to the foliation is greater than that parallel to the foliation. The minimum compressive strength has a minimum when the plan of foliation is inclined at an angle of the order of $35^{\circ}$ to $45^{\circ}$ to the major principal stress. Additional test data show that with increasing confining pressure, the compressive strength parallel to the foliation increases more rapidly than that normal to $i t$. The conclusion is that the coefficient of internal friction must vary with direction and be greatest parallel to the foliation. Most simple theories assume that only shear strength depends on direction.

Tests that are currentiy in progress include tension-tension fatigue tests at ambient conditions and elastic and strength tests of jointed rock at ambient conditions.

Tests that are planned include tensioncompression fatigue tests, elastic and strength tests at elevated temperatures, and hydraulic conductivity tests in which hydraulic conductivity is determined as a function of normal stress across fracture planes.

Task 5. Formulation of Stability and Design Criteria

Based on the results obtained to date from the state-of-the-art review, numerical studies, and this testing program, a collection of stability and design guidelines has been assembled in list form. 


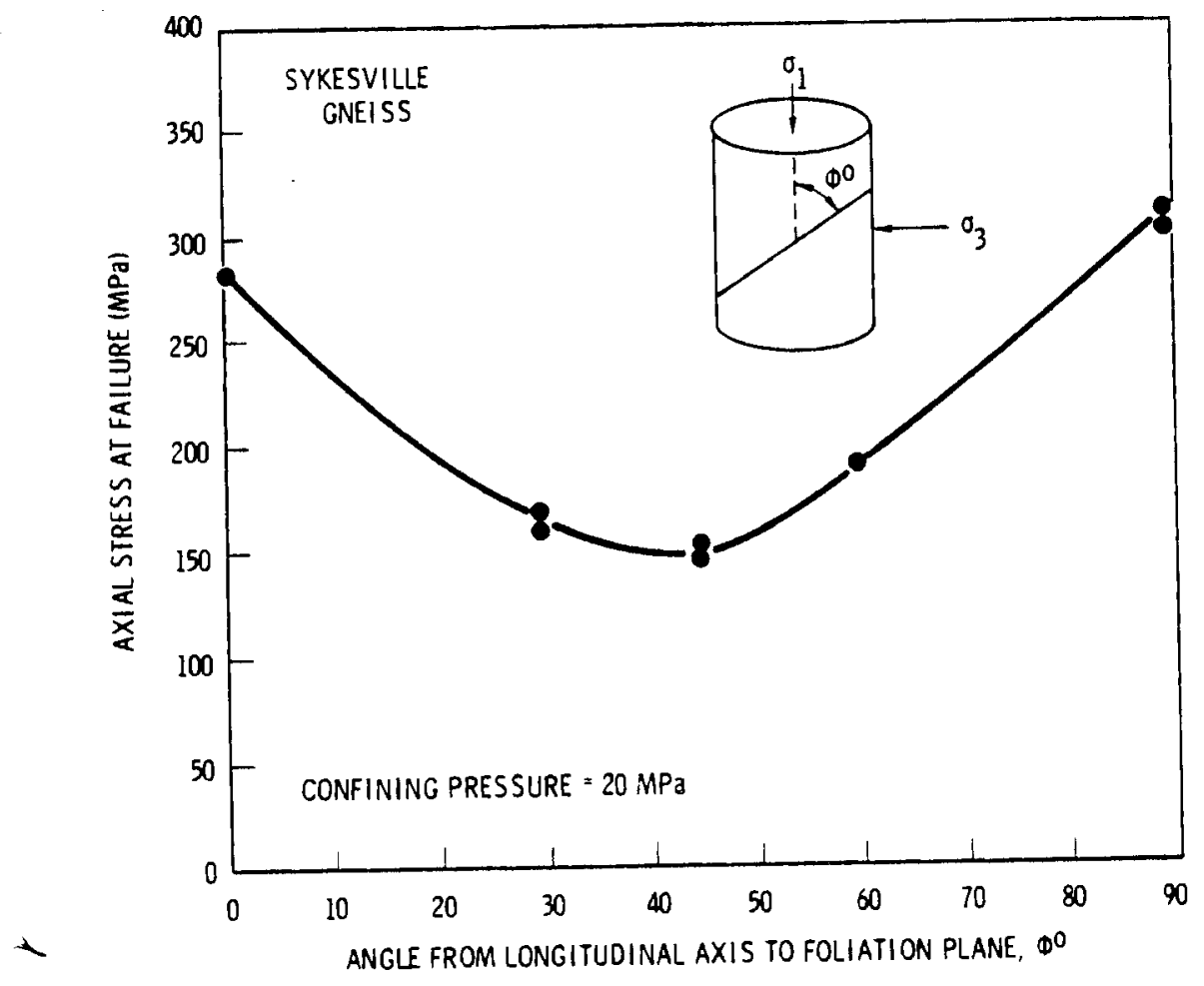

FIGURE 28. Variation of Compressive Strength of Sykesville Gneiss with Foliation Angle

A report has been prepared on the work directed towards formulating representations for the thermal conductivity of rocks in terms of the thermal conductivities of the rock's constituent minerals and their volume fractions. This work has demonstrated that al though the type and volume fractions of the mineral constituents of a rock play an important role in the determination of rock effective thermal conductivity, they do not determine it uniquely. The distribution of phases also plays a role. To quantify the latter, series and parallel models were constructed to give bounds on the thermal conductivity, limiting the amount of variation possible due to difference in phase distribution. For rocks which are macroscopically isotropic and homogeneous, HashinShtrikman bounds further limit the variation of thermal conductivity due to variations in phase distribution. The report shows that the 
decrease in thermal conductivity due to porosity and increase due to water content can be described fairly well by one or another of the simple models. The effect of temperature, generally but not always leading to a decrease of thermal conductivity with increasing temperature, was considered. Comments about the effect of mineral orientation were given. Finally, complications due to radiation, damp pores, cracks, pressure and possible permanent decrease of thermal conductivity due to heating were briefly and qualitatively considered.

TECHNICAL PROBLEMS

No major technical problems have occurred that might have affected costs, schedule, or overall program objectives.

PUBLICATIONS

None 
* 


\subsection{3a Experimental Studies of Domal Rock Salt}

R. L. Thoms

Louisiana State University

\section{OBJECTIVE}

The objective of this study is to obtain data on the response of rock salt subjected to cyclic long-term loads associated with a compressed air energy storage (CAES) reservoir. The data are collected from laboratory tests and also from in-situ bench scale tests in salt mines. In addition, limited complementary numerical modeling is performed to aid in planning tests and analyzing resulting data.

The data will be used as a basis for formulating long-term stability criteria for CAES salt reservoirs. Plans include subjecting the criteria to verification studies in an intermediate step involving a field-study CAES reservoir in a Gulf Coast salt dome.

TASKS

Task 1. Cyclic Loading of Salt

Specimens of domal and bedded salt will be subjected to cyclic, thermal and mechanical loading in a triaxial cell to simulate typical CAES conditions. Thermal and mechanical response (temperature, strain, and strain rate) are the primary variables to be monitored.

Task 2. Cyclic Pressurization of Salt Mine Boreholes

Core will be drilled from a mine borehole and the holes packed off and cyclically pressurized with air. The flow of air to neighboring boreholes will be monitored as well as any deterioration or excessive strain of the salt.

\section{ABSTRACT OF PROGRESS}

Activities and results are presented for some laboratory and in-situ bench tests of salt under cyclic loading conditions simulating in part 
the environment associated with a salt compressed air energy storage (CAES) reservoir. Salt was found to yield strong and identifiable acoustic emissions (AE) in association with cyclic loading. This indicates that monitoring $A E$ is a potentially viable method for tracking the performance of a salt CAES reservoir.

\section{PROGRESS}

The methodology and work plan for this study have been reported previously at the 1979 midyear and annual reviews for the Department of Energy (DOE). Thus in this report attention will be focused on recent primary results and current status of this study.

Task 1. Cyclic Loading of Salt

The most dramatic result from the cyclic laboratory test program thus far involves the use of acoustic emissions (microseismic) monitoring. Figure 29 depicts acoustic emissions (AE) associated with cyclic uniaxial loading of Jefferson Island salt. From left to right, each AE "peak" and "secondary peak" corresponds respectively with a maximum and minimum axial stress application (load) on the specimen. The clearly identifiable output associated with cyclic loading of salt implies that AE monitoring potentially is a viable technique for assessing the status of CAES salt reservoirs.

Figure 30 depicts the parameters of the test along with associated overall axial displacement behavior of the salt specimen. The displacement behavior during this cyclic test can be characterized as relatively similar to typical salt creep response under constant load, but with a "band" of short-term perturbations corresponding to cyclic load effects.

Figure 31 provides details of a typical load cycle with associated uniaxial stress application and corresponding strain. The "permanent" strain increment associated with the cycle can be noted as the "failure" of the strain curve to return to the initial value at the beginning of the period. 


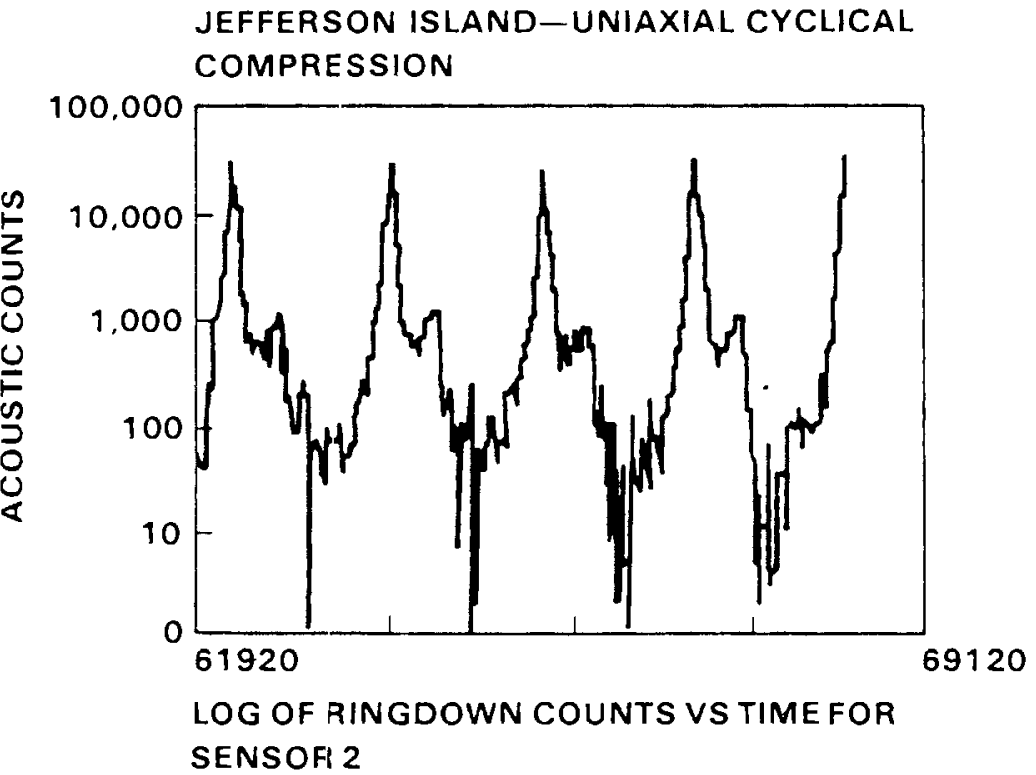

FIGURE 29. Acoustic Emissions for Cyclic Test of Salt

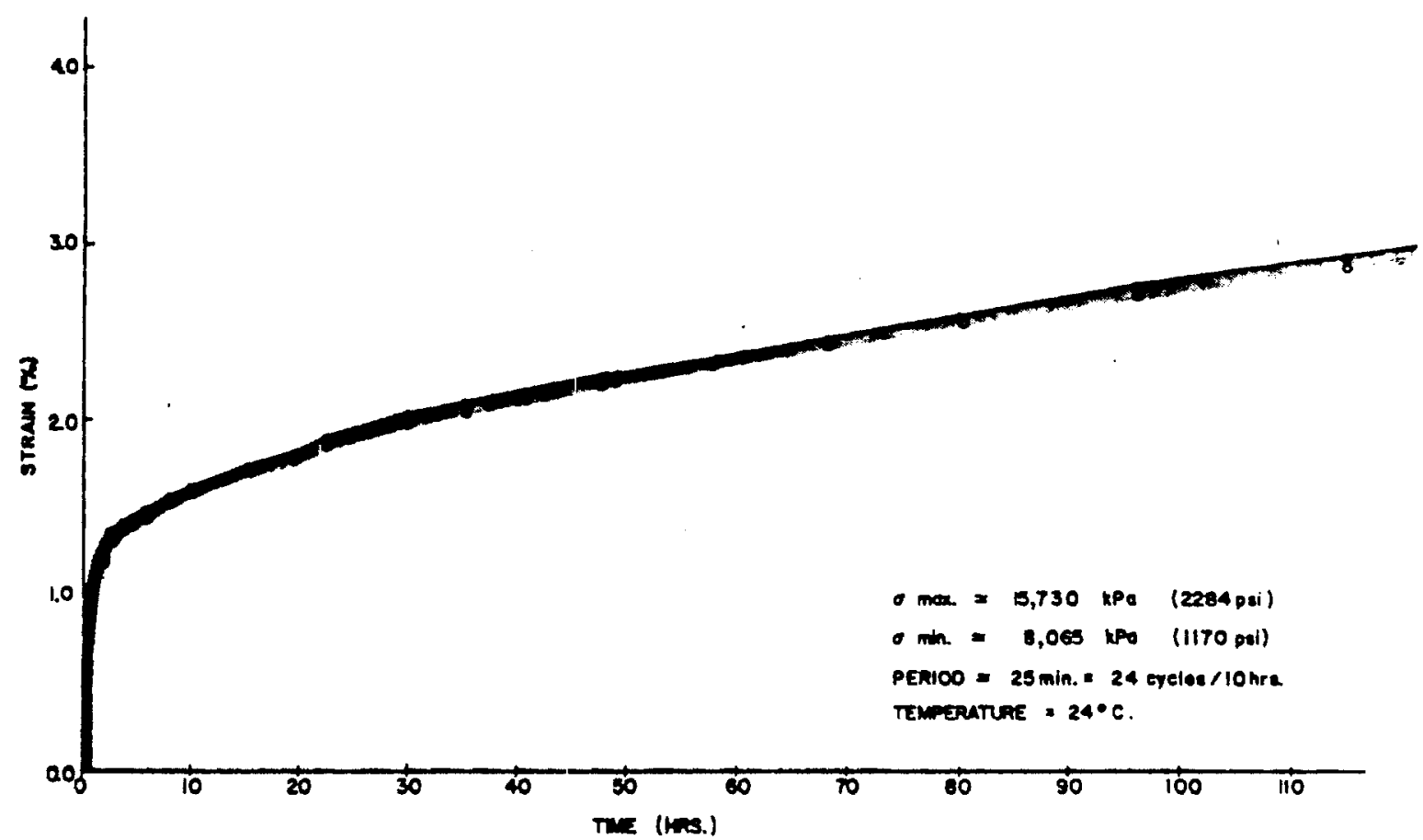

FIGURE 30. Cyclic Uniaxial Test on Jefferson Island Dome Salt 


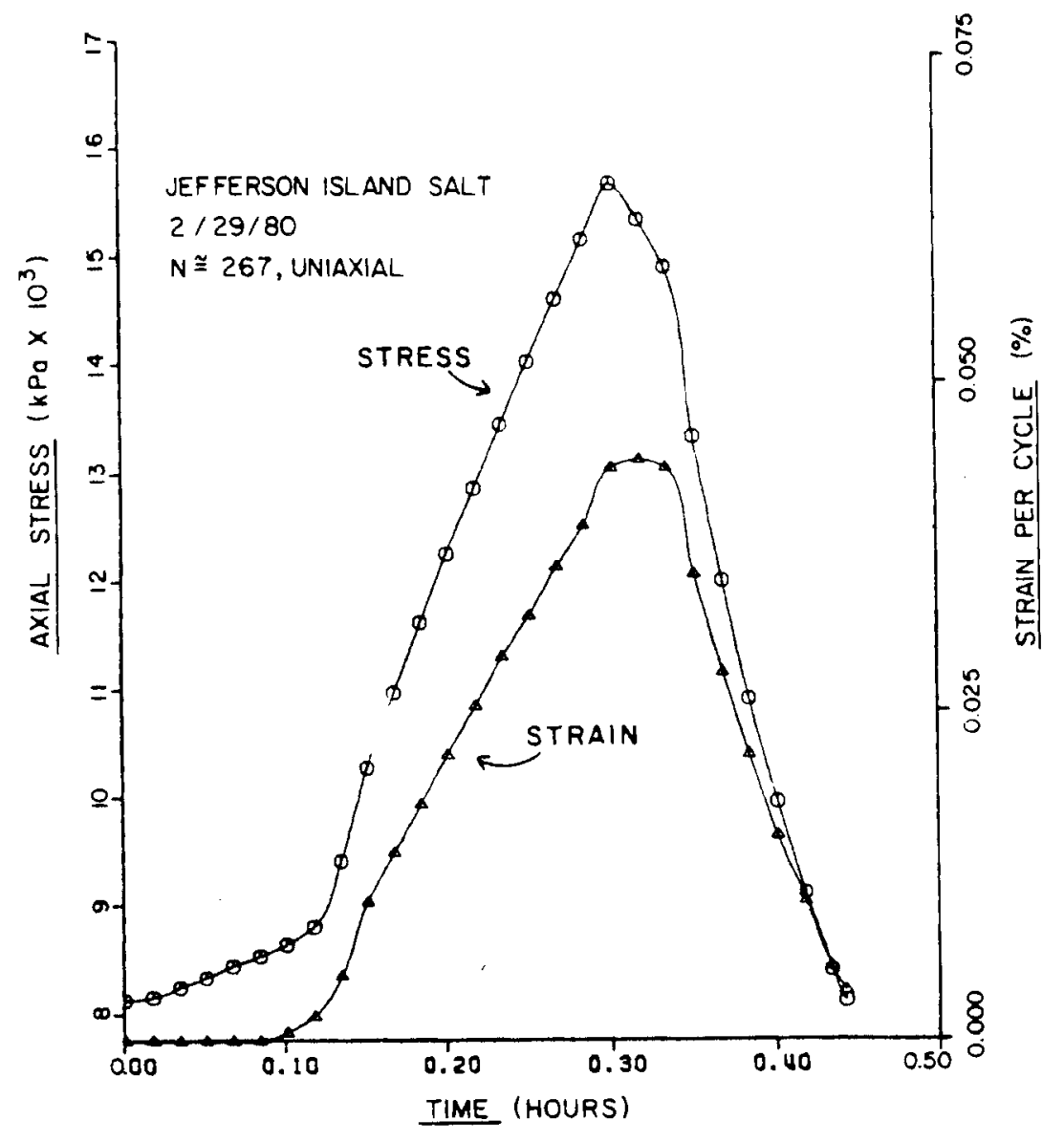

FIGURE 31. Typical Cycle, Salt Stress-Strain Versus Time

At the end of around 100 hours, the fabric of the salt specimen had deteriorated to some extent, with evidence of opaque bands and fracturing across some crystals.

Figure 32 illustrates data associated with a uniaxial creep test of Jefferson Island salt subjected to cyclic thermal loads and constant uniaxial stress. The salt exhibited strong short-term thermal strain effects in association with applied cyclic heat flux. This could possibly enhance fabric deterioration over extended time periods; however, confining stresses under in-situ conditions may attenuate this effect. 


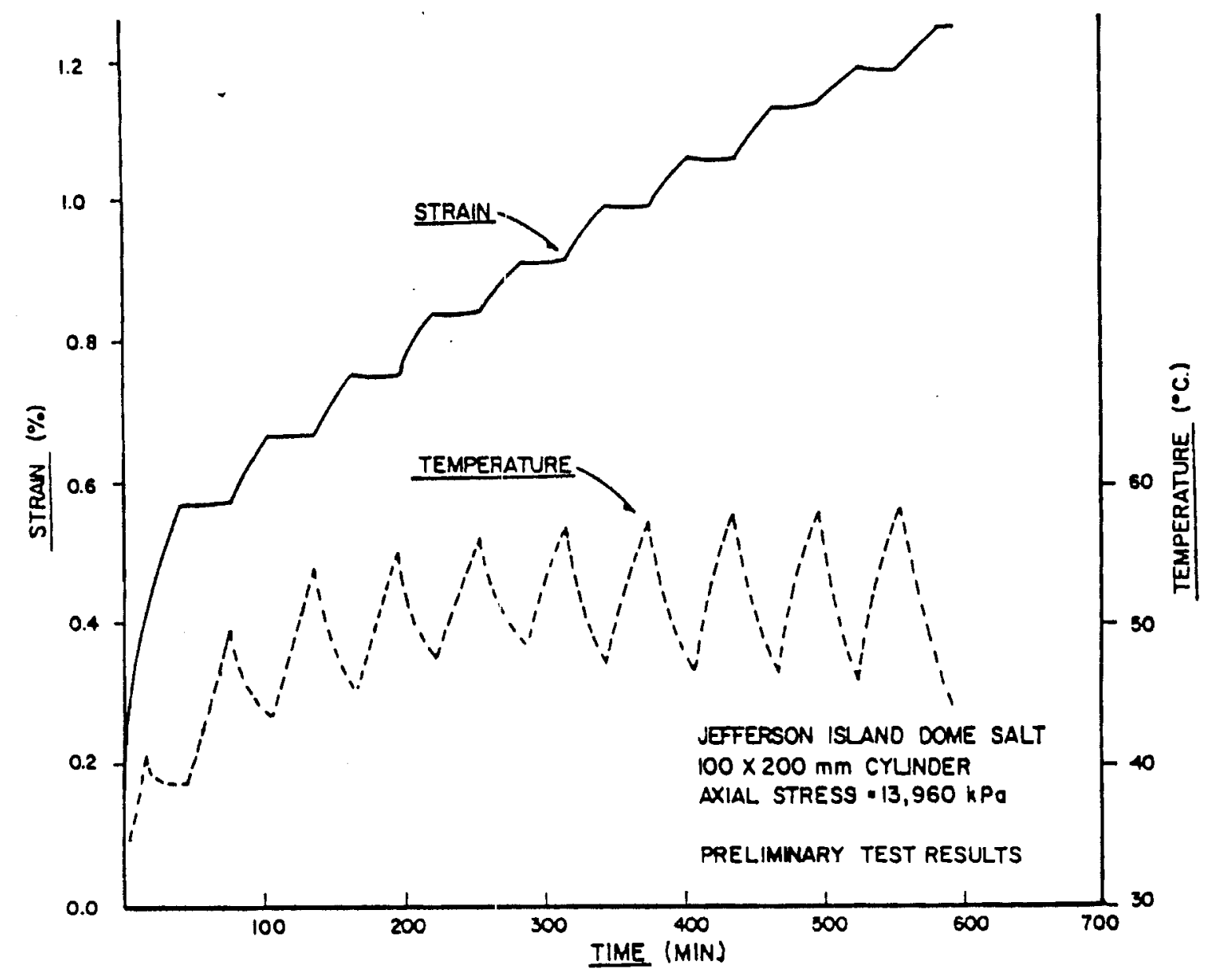

FIGURE 32. Strain and Temperature for Cyclic Thermal Loading and Constant Axial Stress on Salt

Plans for future laboratory tests include coupled cyclic thermal and triaxial stress environments applied to salt specimens. The test parameters will be selected on the basis of anticipated thermal and stress field environments around CAES reservoirs.

Salt from a variety of sources will be tested in the LSU CAES laboratory. In addition to more complicated triaxial tests, index tests will be performed to correlate behavior of salt from different - sources. 
The indirect tension or "Brazilian" test will be used as a basis for index testing of salt response in the laboratory. Specimens for this test are readily prepared, and the test itself can be easily performed.

Since salt is a strongly time-dependent and nonlinear material, linear elasticity theory is not applicable for analyzing this test. Subsequently, a nonlinear and time dependent analysis of a "typical" salt Brazilian test specimen was performed, and results are presented in Figure 33. The results correspond to 24 hours of constant load application to a salt specimen. Results indicate that the stress state in the

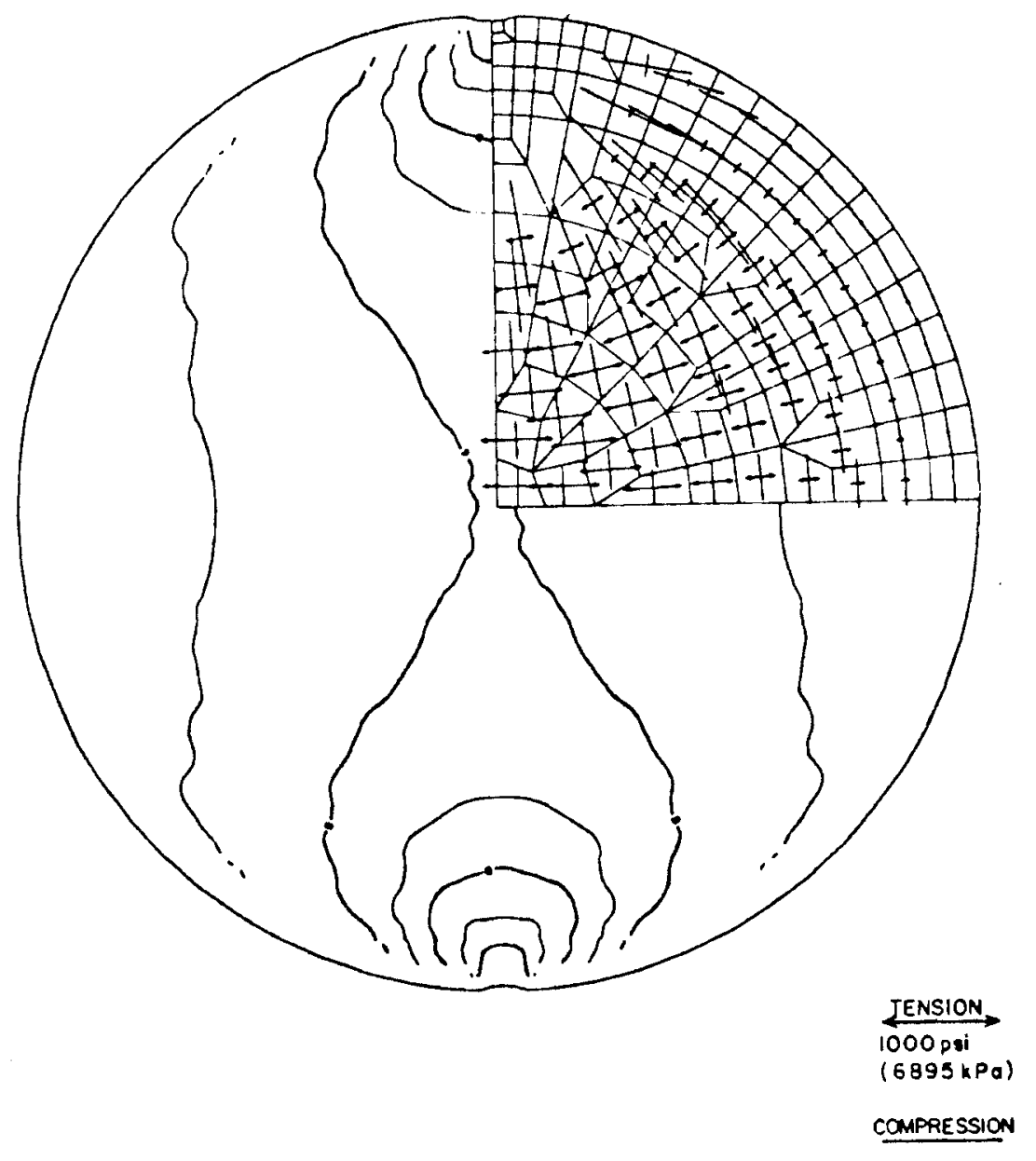

FIGURE 33. Index Tension Test 
Brazilian specimen was relatively sensitive to the nonlinear (as contrasted to linear) behavior of salt, but relatively insensitive to time-dependent (creep) effec:s.

Task 2. Cyclic Pressurization of Salt Mine Bore Holes

The in-situ bench scale tests of this study are located in the Jefferson Island (JI) and Cote Blanche salt mines in southern Louisiana. At the Jefferson Island site, a series of ten holes have been drilled into the mine floor within a shed. Six holes are of $110 \mathrm{~mm}$ (4.25 in) dia and range in depth from 463 to $925 \mathrm{~mm}$ (18 to $36 \mathrm{in}$ ). Five other holes are of $58 \mathrm{~mm}(2.25 \mathrm{in})$ dia and 617 to $771 \mathrm{~mm}$ (24 to $30 \mathrm{in}$ ) depth, and will be used for monitoring instrumentation. A hydraulic stress cell has been installed in one of the smaller holes to a depth of around $762 \mathrm{~mm}(30 \mathrm{in})$ beneath the mine floor. It has apparently stabilized at approximately $952 \mathrm{kPa}$ (138 psi), which is plausible for the site since it is not close to support pillars.

A technique for sealing the holes and applying cyclic air pressure has been implemented. Further, a recent test at the Jefferson Island site involved monitoring acoustic emissions during application of cyclic air pressure ranging from around 345 to $760 \mathrm{kPa}$ (50 to $110 \mathrm{psi}$ ). Apparently because of these low pressures, only insignificant AE occurred. However, it was noted that two sensors displayed similar output when one was placed on an aluminum sleeve "epoxied" into the test hole, and the other was pressed against the wall of a neighboring observation hole. This implies the steel casirg of a hole into a CAES reservoir possibly could serve as a "waveguide" for monitoring AE at depth.

A revised technique for loading the shallow Jefferson Island test holes with hydraulic "packers" is now in the planning stage. This technique could be used to apply large lateral stresses (without vertical components) on the walls of the test holes, and thus avoid risk of possible "blow-outs".

A test site at the Cote Blanche (CB) salt mine includes six holes slant drilled beneath a mine pillar as depicted in Figure 34 . The holes 


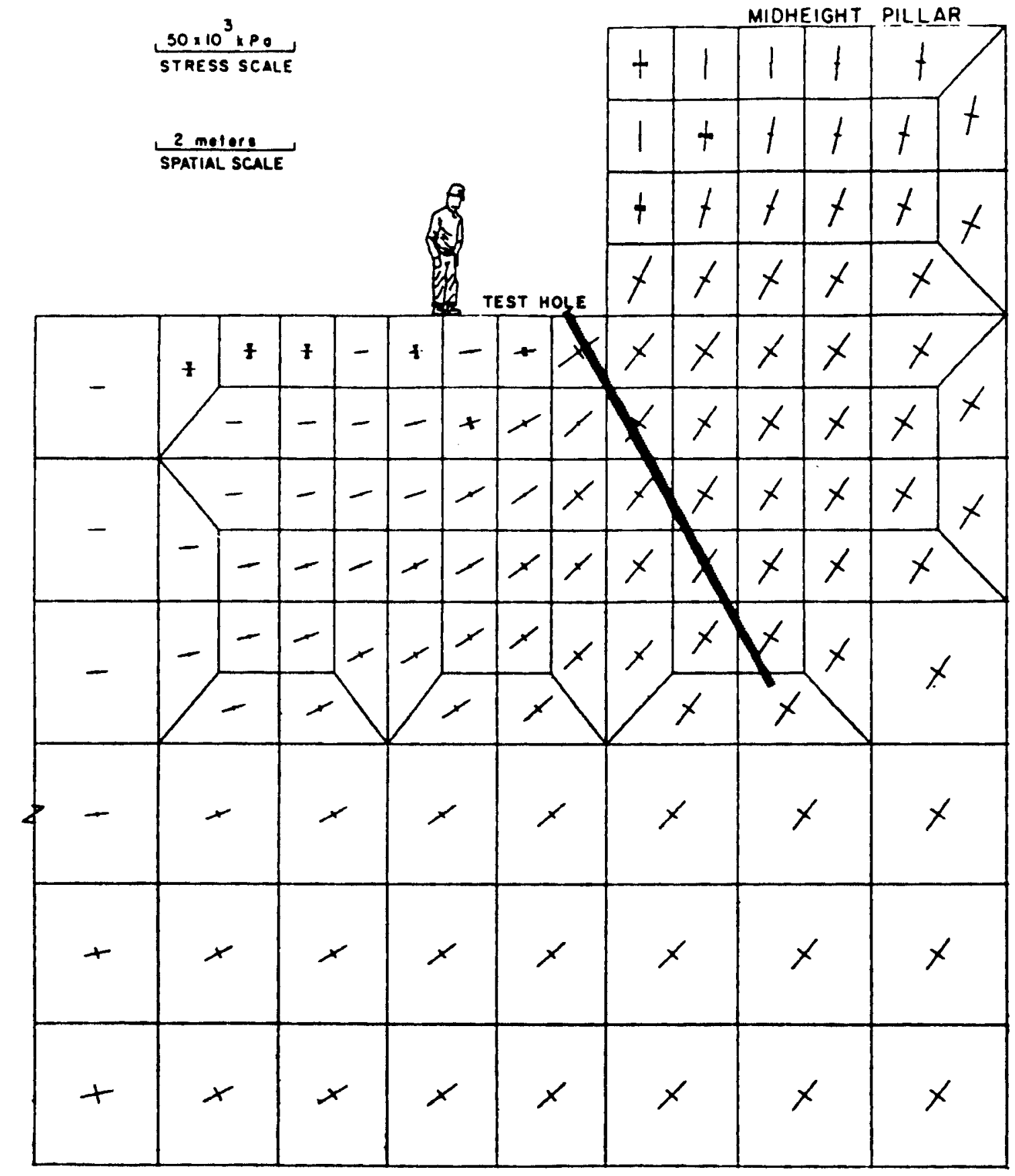

FIGURE 34. In-Situ Test Beneath Salt Pillar, $-418 \mathrm{~m}(-1370 \mathrm{ft})$ 
are of approximately $50 \mathrm{~mm}(\hat{z}$ in) dia and $6.1 \mathrm{~m}(20 \mathrm{ft})$ depth. Figure 34 also includes the plane-strain stress state beneath the pillar as calculated with the same nonlinear finite element program used previously for the Brazilian index test.

The test holes at the CB site will be subjected to relatively large confining pressures beneath the pillar which will more closely simulate pressures around a CAES reservoir. Design and fabrication of methods for sealing and monitoring these holes under cyclic pressure loads are in progress. A hydraulic stress cell has also been installed in the pillar above the CB test site, and it will be "pressured up" soon.

\section{CONCLUSIONS}

Salt exhibits creep and also perturbations in displacement under sustained cyclic loads. Further, similar strong acoustic emissions occur at the maximum and minimum values of loads even after over two hundred cycles of application. It may be possible to partially monitor acoustic emissions from CAES reservoirs with sensors placed on the exterior of well casings, provided other background "noise" can be filtered out.

\section{RECOMMENDATIONS}

Acoustic emissions have been used previously by other workers for monitoring structures, rock bursts in mines, and storage caverns in rock. It was proposed for CAES reservoirs at an early stage in this study, and laboratory and in-situ tests thus far indicate that applications of this technique should be pursued further.

\section{ACKNOWLEDGEMENTS}

M. Nathany and R. Gehle contributed to the technical data in this report, and $\mathrm{J}$. Whisman assisted in preparation of the manuscript. 
TECHNICAL PROBLEMS

None

PUBLICATIONS

None 


\subsection{3b Field Studies of Salt Cavities \\ J. J. Jacobson \\ Pacific Northwest Laboratory}

\section{OBJECTIVES}

The objectives of the Salt Field Study are:

- perform in-situ studies of salt cavern response to CAES conditions to verify the accuracy of numerical model predictions and applicability of laboratory results to field conditions

- develop measurement methodologies for operational CAES caverns to predict and monitor long-term cavern stability

- evaluate and improve CAES salt reservoir stability criteria.

\section{TASKS}

\section{Task 1. Field Studies Literature Review}

This task provides for a literature review to determine the goals, status and results of previous, or ongoing, salt field efforts which may contribute to CAES technology needs.

\section{Task 2. CAES Salt Field Program Plan}

This task requires the resolution of laboratory, numerical modeling and CAES specific geotechnical in-situ testing needs with feasible cost effective field efforts to resolve issues not being adequately treated in salt field studies by other groups.

\section{TECHNICAL PROGRESS}

Task 1. Field Studies Literature Review

A review of the literature pertaining to field studies in salt was performed and documented covering the salt field studies or in-situ measurements published for the Huntorf CAES facility, other storage 
programs (gas, petroleum, and radioactive waste), and mining. It was observed that very little in-situ salt cavern or surface monitoring was performed at Huntorf. Cavern sites were located based on test drill holes and laboratory tests on core samples. Field monitoring or measuring - has also been very limited for natural gas and petroleum storage programs. Bench scale tests were performed on cores and storage facility sites being monitored with microseismic equipment. Field measurements and monitoring were not planned for petroleum reserve storage reservoirs. However, after a severe cavern failure, a program was initiated consisting of research, field measurement and monitoring. Studies implemented to date include microseismic monitoring during decompression tests, sonar mapping of the caverns, logging and brine tests as well as the standard bench tests on salt samples.

The Office of Nuclear Waste Isolation (ONWI) is conducting large detailed field studies of salt cavern response to long-term thermal influence. Long-term salt cavern stability is required for successful storage of nuclear wastes in salt. The total field evaluation program for possible radioactive waste storage in a salt dome provides valuable input for design of commercial CAES facilities, however, CAES activities will develop substantially different stress fields and will involve cyclic loadings with humid air. The nuclear waste storage field program includes an evaluation of the general dome stability, the precision of predictive methods used to evaluate salt behavior, and an assessment of the hydrologic stability of the dome within its geologic province. This program also involves extensive geophysical and geological measurements spread over several years. The data obtained from this program is being analyzed with respect to long term stability in containing the waste. For a CAES operation the stability of the salt is of great interest, but additional analysis would be needed to evaluate the pressure cycling effects on the salt.

Testing programs in conventional salt mines deal mainly with creep rates and cavern closure. Conventional mines, however, have an advantage over solution-mined caverns in that access for in-situ measurements is 
not difficult. All measurements in solution-mined CAES caverns must be made from ground surface. Extrapolation of the creep data to stability predictions is a fairly controversial area at this time because of the complexity of salt response to various stress and strain states and rates.

None of the programs currently in progress address the question of whether or not there is progressive deterioration of the salt-air interface in a cavern as a result of the pressure cyciing or seek to establish how strain rates, creep rupture, and stress relief are affected by cyclic loading.

Task 2. CAES Salt Field Proggram Plan

A program plan for field measurements for a commercial CAES cavern was developed. However, with access to Huntorf limited and no operational CAES cavern planned in salt in the U.S. in the next few years, the idea of an optional test cavern was pursued. The small test cavity concept which emerged has been approved and a field test plan is being implemented.

The small test cavern provides a cost effective means of accelerating the effects of CAES operation on the cavern wall. The small size of the test cavern will facilitate sidewall core retrieval and detailed study of cycling effects. It is planned to utilize a small (less than $100 \mathrm{~m}^{3}$ ) cavern which will be solution mined in the Grand Saline Dome in Texas. Utilizing this dome will allow the small cavern test to be carried out in the FY-1980 through FY-1982 time frame. The test cavern will be operated at increasing cyclic pressure differentials on an accelerated cycle time schedule in order to approximate long-term effects. Wall performance will be monitored during the tests to evaluate the occurrence and rate of wall deterioration. Sidewall cores will be retrieved, if possible, following the cycling tests for additional evidence of any wall deterioration.

It is anticipated that the cavern lease will be in place by the end of FY-1980 at the latest, and that the pressure cycling tests can begin in early $F Y-1981$. 
TECHNICAL PROBLEMS

None

PUBLICATIONS

None 


\subsubsection{Feasibility Study of CAES Augmentation by FBC}

R. D. Lessard and A. J. Giramonti

United Technologies Research Center

\section{- OBJECTIVE}

The objective of the pragram is to provide a technical and economic assessment of Compressed Air Energy Storage (CAES) concepts which use coal-fired fluid bed combustors $(F B C)$ instead of oil-fired conventional combustors.

$\underline{\text { TASKS }}$

To achieve the stated program objective, a five-task analytical and preconceptual design proglram is currently being performed.

Task 1. Technology Assessmerit

Provide data on coal-fired atmospheric and pressurized $F B C$ and related turbomachinery technologies pertinent to application in a CAES power plant system. The scope of the effort includes a review and assessment of the current anc projected state of FBC technology, an evaluation of the technological and cost characterization of the FBC systems to be considered during the program, and an assessment of major FBC component availability. The scope also includes a review and assessment of the turbomachinery technology pertinent to FBC/CAES application along with an assessment of the availability of turbomachinery equipment designed for operating conditions consistent with projected coal-fired $\mathrm{FBC} / \mathrm{CAES}$ operating requirements.

Task 2. System Analysis

Identify a preferred coal-fired FBC/CAES power plant system configuration which has the potential for early commercialization. Included in this task are the synthesis of $\mathrm{FBC} / \mathrm{CAES}$ system configurations based upon compatible technology between the FBC and CAES turbomachinery; the screening of these configurations relative to performance, cost and risk; and the identification of a preferred system. 
Task 3. Power Plant Preconceptual Design

Transform the selected $\mathrm{FBC} / \mathrm{CAES}$ configuration into a preconceptual power plant design. This task involves the implementation of the preconceptual design approach which mandated maximum utilization of existing power plant major equipment components, and the characterization of the power plant in sufficient detail to serve as the basis for the preconceptual design effort. However, the primary function of this task is to prepare preconceptual designs of the FBC, the CAES turbomachinery, and the balance of plant, and to integrate these three into a power plant design. Also included in the task are major equipment costing and economic comparisons between the $\mathrm{FBC} / \mathrm{CAES}$ power plant and al ternative competing power plants.

Task 4. Application of Thermal Energy Storage

Explore the application of thermal energy storage (TES) to coalfired CAES systems including FBC/CAES systems. This task involves supplying technical assistance to PNL in their evaluation of CAES/TES power plant system configurations.

Task 5. Load-Following and Part-Load Capability

Provide an introductory evaluation of the FBC/CAES power plant selected for the preconceptual design during part-load and transient operations. Included in this task is an assessment of utility loadfollowing requirements, a preliminary estimate of the part-load and transient operation of the selected FBC/CAES power plant, and an evaluation of a scheme, based upon the selected power plant system, which provides for continuous rather than cycling operation to meet utility load following requirements.

TECHNICAL PROGRESS

Task 1. Technology Assessment

This task has been completed. It was found that the most probable operating temperature for both the PFBC and $A F B C$ was identified as being 
$1560^{\circ} \mathrm{F}\left(850^{\circ} \mathrm{C}\right)$, and the operating pressure for the PFBC as 15 atm (bar). Concern for the integrity of the in-bed heat transfer tubes of an immersedtube PFBC or an AFBC 1 imited the metal temperature to about $1200^{\circ} \mathrm{F}$ $\left(650^{\circ} \mathrm{C}\right)$ for near-term applications. This, in turn, limited the temperature of the gas heated in the tubes and, thus, the gas turbine inlet temperature to $1000^{\circ} \mathrm{F}\left(550^{\circ} \mathrm{C}\right)$. The gas turbine inlet temperature in an open-bed $\mathrm{PFBC} / \mathrm{CAES}$ could correspond to the bed-temperature of $1560^{\circ} \mathrm{F}\left(850^{\circ} \mathrm{C}\right)$ while the inlet temperature for an immersed-tube PFBC would lie between $1000^{\circ} \mathrm{F}\left(550^{\circ} \mathrm{C}\right)$ and $1560^{\circ} \mathrm{F}\left(850^{\circ} \mathrm{C}\right)$.

In a CAES application, advanced erosion and corrosion resisting materials would be required for the immersed tubes of an $A F B C$, the turbine of an open-bed PFBC, and both the tubes and turbine of an immersedtube PFBC. The turbine requirements are similar to those in a combinedcycle application and are being extensively investigated; consequently, the CAES fluid bed combustor and its hot gas cleanup system would be the pacing item.

Task 2. System Analysis

This task is also complete. Application of an FBC to the CAES concept creates the potential for a large number of possible $\mathrm{FBC} / \mathrm{CAES}$ power plant configurations incorporating either an $A F B C$ or a PFBC. The performance, cost, and risk of nine different $\mathrm{FBC} / \mathrm{CAES}$ system configurations were analyzed over a wide range of operating conditions. These system configurations included open-bed PFBC/CAES systems, open-bed PFBC/CAES systems with low-temperature tubes, AFBC/CAES systems with low temperature tubes, and PFBC/CAES and AFBC/CAES systems with advanced features such as high temperature and/or high pressure tubes and high to very high temperature heat exchangers. The open-bed PFBC/CAES system configuration with bed operation at $1560^{\circ} \mathrm{F}\left(850^{\circ} \mathrm{C}\right)$ and $15 \mathrm{~atm}$ (bar) was selected as the recommended configuration for the preconceptual design effort. This selection was based on the relatively low risk for the PFBC design (no tubes in the bed), the moderate costs, and the respectable performance exhibited by this system plus the near-term commercialization potential of the open-bed PFBC. 
Task 3. Power Plant Preconceptual Design

This task has been completed. The recommended system configuration was transformed into a power plant preconceptual design. Maximum utilization was made of existing design data. The key power plant parameters were

- then characterized to serve as a basis for the design. Designs were prepared for the FBC plant, the turbomachinery plant, and the balance of plant. These three plant designs were then integrated into a four-unit power plant. As part of the preconceptual design effort, a listing of the major equipment items, along with their capital costs, was prepared. The direct capital cost of $\$ 459$ million (1980 dollars) for the 876-MW plant was translated into a capital investment cost for a 1990 commissioning date and then discounted to January 1980 dollars (using a prescribed DOE procedure) yielding a total capital investment of $\$ 707$ million. The operating costs were estimated, and levelized cost comparisons were made with alternative competing systems.

Task 4. Application of Thermal Energy Storage

The technical portion of this task has been completed. Two coalfired CAES system concepts incorporating thermal energy storage (TES) were investigated, a PFBC/CAES/TES system and a coupled-steam/CAES/directheated TES system. The first system concept evolved by adding thermal storage for recovery of the heat of compression. The second system was suggested by PNL and utilizes a high-performance steam system integrated with a CAES and TES system to maintain a constant coal rate during both compression and generation modes.

A four-unit PFBC/CAES/TES system was estimated to produce 887 MW of electric power with a round-trip heat rate of $12598 \mathrm{Btu} / \mathrm{kWh}$. A single unit coupled-steam/CAES/direct-heated TES plant would produce 589 MW of electric power with a round trip heat rate of $10870 \mathrm{Btu} / \mathrm{kWh}$. A cost analysis of the PFBC/CAES/TES system indicated that adding TES to the preconceptual design PFBC/CAES plant would require an additional capital investment. Even though the initial capital cost of a PFBC/CAES/TES 
plant would be higher, the levelized annual energy cost beyond a capacity factor of 24 percent still looks attractive compared to oil-fired alternative peaking systems.

Task 5. Load-Following and Part-Load Capability

This task has been completed. One approach to achieving part-load operation to enable the plant to load follow with an open-bed PFBC/CAES power is to change coal-fired and air flow rates proportionally. Throttling the flow in this manner would have relatively minor effect on the overall system performance. To achieve part-load operation, the plant must have good transient response characteristics. A cursory dynamic analysis of PFBC response to a $10 \%$ change in both coal fuel and airflow rates indicated that the maximum fluid bed temperature excursion would be on the order of $25^{\circ} \mathrm{F}\left(14^{\circ} \mathrm{C}\right)$; thus, the PFBC should be tolerant of anticipated transient operation. The turbines should also be tolerant.

A continuously operated open-bed PFBC/CAES power plant system, wherein the PFBC need not cycle, is another approach to part-load operation. In this system, the CAES turbines are sized to drive variable geometry compressors. Load following is achieved by changing the compressor flow rate and thus their power requirement. The round trip heat rate of this continuous firing concept is almost twice as high as that for the cycling PFBC/CAES system. The levelized annual cost is about seven percent higher; however, the utilization rate is lower.

\section{CONCLUSIONS}

The major conclusions reached in this study may be summarized as follows:

- Coal-fired fluid bed augmented compressed air energy systems should be technically feasible in the near future and potentially attractive for peak-load power generation. 
- An open-bed PFBC/CAES configuration would provide the best candidate for early commercialization. It has relatively low risk combined with moderate cost and reasonable round-trip heat rate. It also has the potential for future growth options which tend to reduce costs and lower fuel consumption.

- Commercial implementation of PFBC/CAES power plants requires continued R\&D for both the fluid bed combustor and the turbomachinery. The PFBC R\&D would concentrate on extending and improving current designs for cycling operation while turbomachinery R\&D would be directed toward establishing materials and blade designs resistant to corrosion and erosion.

- A PFBC/CAES power plant would be designed and built by utilizing many standard equipment items and modifications of existing equipment designs. Commercial application during the latter half of the 1980 decade is possible.

- The economic competitiveness of the PFBC/CAES power plant is strong. It could produce lower cost of electricity than conventional oilfired gas turbine and combined cycle competitors for annual utilitization above about $1225 \mathrm{hr} / \mathrm{yr}$. Above about $1925 \mathrm{hr} / \mathrm{yr}$, it could produce lower-cost power than oil-fired CAES plants.

- Preliminary indications are that an open-bed PFBC/CAES power plant should have good part-load performance. Furthermore, it appears that the PFBC and turbomachinery could respond to modest changes in load demand (on the order of 10\%) within reasonably short periods (on the order of five minutes).

\section{PUBLICATIONS}

A. J. Giramonti and R. D. Lessard, Technical and Economic Assessment of Fluidized Bed Augmented Compressed Air Energy Storage System Quarterly Progress Report No. 1 . UTRC Report No. R79-954490-5, United Technologies Research Center, March 1979.

A. J. Giramonti and R. D. Lessard, Technical and Economic Assessment of Fluidized Bed Augmented Compressed Air Energy Storage System - Quarterly

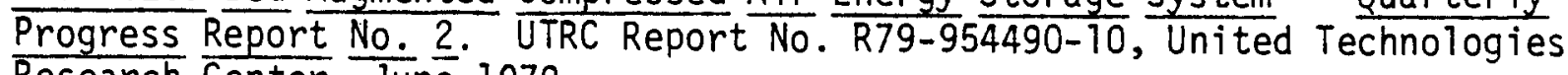
Research Center, June 1979. 
R. D. Lessard, Technical and Economic Assessment of Fluidized Bed Augmented Compressed Air Energy Storage System - Progress Report for Quarters No. 3 and 4. UTRC Report No. R79-954490-17, United TechnoTogies Research Centêr, December 1979.

R. D. Lessard, A. J. Giramonti, D. Merrick, and M. J. Hobson, Technical - and Economic Assessment of Fluidized Bed Augmented Compressed Air Energy Storage System - Draft Final. UTRC Report No. R80-954480-20, United TechnoTogies Research Center, January 1980.

R. D. Lessard and R. L. Sadala, Incorporating Thermal Energy Storage into a Coal-Fired CAES System - Draft FinaT. UTRC Report No. R80-954490-21, United Technologies Research Center, in process. 


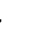




\subsection{2a Preconceptual Design of CAES/TES Systems}

M. K. Drost

Pacific Northwest Laboratory

OBJECTIVE

The objective of this study was to evaluate thermal energy storage (TES) technology suitable for application with compressed air energy storage. Attractive TES concepts were identified and performance and economic data characteristic of each concept were developed. In addition, innovative applications of TES technology were to be considered.

$\underline{\text { TASKS }}$

This study consisted of five tasks.

Task 1. Review of TES Technology for CAES Applications

This task consisted of reviewing the literature to determine what TES concepts had been proposed for CAES applications. In addition, thermal storage technology was reviewed to identify other promising concepts. Particular emphasis was placed on reviewing work currently being done for solar thermal applications. Upon completion of the screening process, the attractive concepts were compared with each other when installed in a hybrid CAES cycle.

Task 2. Review of TES Costs

This task consisted of reviewing the literature to identify capital cost estimates for TES concepts. The cost estimates were modified so that a common set of economic assumptions and unit costs were used. The results were used to develop a normalized set of TES costs that were supplied to another study which included an economic evaluation of adiabatic CAES.

Task 3. Support of Hard Rock and Aquifer Adiabatic CAES Studies

This task consisted of providing technical support for the hard rock and aquifer adiabatic CAES design studies being funded by PNL. 
Activities included the preparation of the statement of work, review of design decisions and evaluation of reports.

Task 4. Preliminary Review of Aquifer Adiabatic CAES Cycles

This task consisted of a preliminary review of TES concepts suitable for application with aquifer CAES. A large number of adiabatic aquifer CAES cycles were considered. Six generic types were simulated using the CYCLOPS cycle simulation code. A parametric study of each cycle was completed and the most attractive cycle arrangement was identified. The six optimized cycle arrangements will be costed and an economic analysis will be completed. The concepts will then be ranked according to levelized energy cost.

Task 5. Development of Innovative TES/CAES Cycles

This task consisted of the review of innovative CAES cycles which use thermal storage. Three cycles which combine a coal-fired steam rankine cycle, power plant, CAES cycle and a TES were considered. Performance at one set of operating parameters was to be calculated and the most attractive cycle would be simulated by a consultant.

\section{TECHNICAL PROGRESS}

Task 1. Review of TES Technology

Task 1 has been completed and an inhouse paper was issued in August 1979. The results indicated that advanced indirect storage systems such as thermocline draw salt storage may be competitive with above-ground, direct-contact storage for hybrid CAES application. Underground direct contact storage had a wide variation in cost estimates which made a comparison with above ground concepts difficult.

Task 2. Review of TES Costs

Cost estimates for above-ground direct-contact TES, below-ground, direct-contact TES and indirect TES concepts were prepared. The results were used by Cory knutsen in his review of adiabatic CAES economics. 
Task 3. Support of Hard Rock and Aquifer Adiabatic CAES Studies

The statement of work for the Acres American hard rock adiabatic CAES study and the Sargent and Lundy adiabatic aquifer CAES study have been completed. Review of design decisions and evaluation of reports is continuing.

Task 4. Preliminary Review of Aquifer Adiabatic CAES Cycles

The six generic aquifer adiabatic CAES cycles have been simulated and the parametric study has been completed. The six optimized cycle arrangements are currently being costed.

Task 5. Development of Innovative TES/CAES Cycles

The most attractive direct-coupled steam/CAES cycle was identified and UTRC is completing a simulation of the cycle.

\section{TECHNICAL PROBLEMS}

The primary problem encountered in all five tasks was the difficulty in getting accurate cost estimates for thermal energy storage units, particularly the below ground concepts. No other major problems were encountered.

PUBLICATIONS

None 


\subsection{2b Engineering Study of Adiabatic CAES using Hard Rock Caverns \\ M. J. Hobson \\ Acres American Incorporated}

OBJECTIVE

The program objective is to develop conceptual design and engineering studies of an adiabatic CAES system utilizing water-compensated hard rock caverns for air storage. The adiabatic CAES concept, which requires no addition of fuel for firing into or heating of the turbine fluid, involves the integration of thermal energy storage (TES) with a conventional CAES plant. The heat of compression is stored in a TES system when the air is pumped to the rock cavern. The stored-heat energy is then used to raise the temperature of the air leaving the cavern and entering the turbines during the power generation mode. The plant will be based on the Potomac Electric Power Company 600-MW conventional CAES design project located in the state of Maryland.

\section{TASKS}

The required work effort is divided into six work tasks.

Task 1. Thermal Energy Storage Technology

The current state-of-the-art of TES will be reviewed and the feasible TES concepts for application to an adiabatic CAES facility will be evaluated. The work will include:

- Assemble concepts of TES in terms of location, storage media, and containment

- Perform numerical modeling of selected TES to determine temperature profiles, response rates, and heat recovery

- Prepare TES comparative cost estimates

- Evaluate and assess each TES concept for its application to the CAES plant in terms of design, construction, performance, maintenance, and capital cost. 
Acres' work efforts will be assisted by MIT/Energy Laboratory (Boston, Massachusetts), and Central Electricity Generating Board (London, England). NASA/Lewis Research Center (Cleveland, Ohio) will provide peer review.

Task 2. Turbomachinery System Technology

The current state of the technology of turbomachinery systems will be reviewed for utilization in the adiabatic CAES cycle. The work will include:

- Assemble information on turbomachinery system

- Assess the availability of high pressure/temperature/flow rate compressor train

- Predict temperature and flow limitations

- Assess the availability of low-temperature turbine expanders

- Prepare capital cost estimates.

Acres' work efforts will be assisted by Dresser-Clark Incorporated (0lean, New York).

Task 3. Cycle Arrangement for Conceptual Design

The adiabatic CAES cycle configurations will be reviewed and the most effective electric energy storage system will be selected. The work will include:

- Review recent studies on cycle configuration

- Develop selection criteria for an effective cycle based on findings of Tasks 1 and 2

- Perform preliminary assessment of cycle performance and screenpromising adiabatic CAES cycles

- Identify the most effective cycle and model on Acres CAES computer program

- Perform sensitivity analysis. 


\section{Task 4. Conceptual Design}

The conceptual design of an adiabatic CAES plant will be developed based on the selected system configuration. The work will include:

- Develop plant arrangement satisfying operational needs and environmental constraints

- Develop turbomachinery layout

- Prepare TES design and conceptual arrangement of underground facilities.

Task 5. Capital and Levelized Energy Costs

The capital and levelized energy costs for the life of the facility will be determined using electric utility costing methods. The work will include:

- Estimate plant capital cost in terms of direct cost, interest during construction, and contingency

- Estimate operating cost in terms of operating and maintenance labor, maintenance supply, and equipment replacement costs

- Estimate and evaluate levelized energy cost for the life of the facility in accordance with the requirements and guidelines of the EPRI Technical Assessment Guide, Report No. PS-866-SR.

Task 6. Final Project Report

Documentation of the work efforts in Tasks 1 through 5 will be assembled; the findings of various subcontractors will be integrated, and the final project report will be produced.

TECHNICAL PROGRESS

Task 1. Therma 1 Energy Storage Technology

Investigation revealed that a direct contact, sensible heat system is the most practical alternative for both the LP and HP TES. Latent heat systems were found to be in need of further technology development 
and indirect sensible heat systems, including oils and molten salts, were found impractical because of storage material limitations or high system costs. Rock, iron ore pellets (blast furnace quality), and white cast iron were the storage materials selected for concept development. Table 6 - presents a sampling of possible storage media.

TES bed dimensions for the HP TES were determined for the three candidate storage materials based on an end temperature difference of $25^{\circ} \mathrm{F}$, bed height of 65 feet, and an air-mass flow rate of 2600 pounds per second. The end temperature difference of $25^{\circ} \mathrm{F}$ was derived from a heat transfer effectiveness of 0.966 and a temperature difference of $730^{\circ} \mathrm{F}$ between the hot and cold air inlets to the bed. The same bed dimensions were used for the LP TES which resulted in a lower end temperature difference for the same bed effectiveness.

The study is focused on underground containment for the TES. Excavation costs for TES caverns and air shafts have been estimated. Preliminary designs of the hot air shaft and containment configurations have been developed and cost evaluations are in progress.

Major developmental problems have been identified, including:

- long term effect of the operating environment on materials, including an oxidizing atmosphere, water condensation, and thermal stressing

- effect of mechanical loadings induced on storage pebbles and containment structure during themal cycling

- effect of bed material loss due to pebble attrition and breakup

- effect of retention or carry-over of particles.

Task 2. Turbomachinery System Technology

Work to date by subcontractor Dresser-Clark Division indicates discharge temperatures of approximately $850^{\circ} \mathrm{F}$ should be achievable with minor modification of existing compressor designs. The volumetric flows, however, require operation of machines in parallel in the 
TABLE 6. Properties of a Sampling of Possible Storage Media

\begin{tabular}{|c|c|c|c|c|c|}
\hline Material & $\begin{array}{l}\text { Physical } \\
\text { Density } \\
\left(1 \mathrm{~b} / \mathrm{ft}^{3}\right) \\
\end{array}$ & $\begin{array}{c}\text { Specific } \\
\text { Heat } \\
\left(\text { Btu/1b- }{ }^{\circ} \mathrm{F}\right) \\
\end{array}$ & $\begin{array}{c}\text { Energy } \\
\text { Density } \\
\left(\text { Btu/ft }{ }^{\circ}-{ }^{\circ}\right) \\
\end{array}$ & $\begin{array}{l}\text { Cost At } \\
\text { Source } \\
\text { (\$/Ton) }\end{array}$ & $\begin{array}{l}\text { Cost For } \\
\text { Storage Capacity* } \\
\left(\$ / 10^{*} \mathrm{Btu}\right)\end{array}$ \\
\hline Granitic Rock & 168 & 0.248 & 41.7 & $5-10$ & 14 \\
\hline Iron Ore Pellets & 218 & 0.210 & 45.8 & 45 & 147 \\
\hline Cast Iron & 480 & 0.155 & 74.4 & 525 & 2320 \\
\hline Alumina Pellets & 247 & 0.245 & 60.5 & 820 & 2292 \\
\hline Fireclay Pebbles & 150 & 0.230 & 34.5 & 400 & 1191 \\
\hline Draw Salt & 113 & 0.370 & 41.8 & 580 & $2118^{\star \star}$ \\
\hline $\begin{array}{r}\text { *Cost for Energy } \\
\text { where } \Delta T=\end{array}$ & $\begin{array}{l}\text { torage } \mathrm{Ca} \\
0^{\circ} \mathrm{F}-120\end{array}$ & $\begin{array}{l}=i t y=\frac{1 \$ / 16}{C} \\
=730^{\circ} \mathrm{F}\end{array}$ & $\frac{\left(10^{6} \mathrm{Btu}\right)}{\Delta T}$ & $=\$ / 10^{6}$ & \\
\hline
\end{tabular}

compressor train. Expander design capability is considered well above needs for the ACAES cycle, and no problems are forseen. Per unit power output appears to be approximateiy $75 \%$ of BBC fired CAES unit at same mass flow. Work is underway to detail machine selection, with drawings and cost estimates scheduled for delivery in early May.

Task 3. Determine Cycle Arrangement for Conceptual Design

Experience with construction and equipment costs, and their respective limitations, suggests a storage pressure of approximately 1200 psi. This storage pressure can be achieved with a two-stage cycle as iliustrated on Figure 35 . The relationships between the second-stage compressor inlet temperatures, turbine output and electric energy ratio for various 


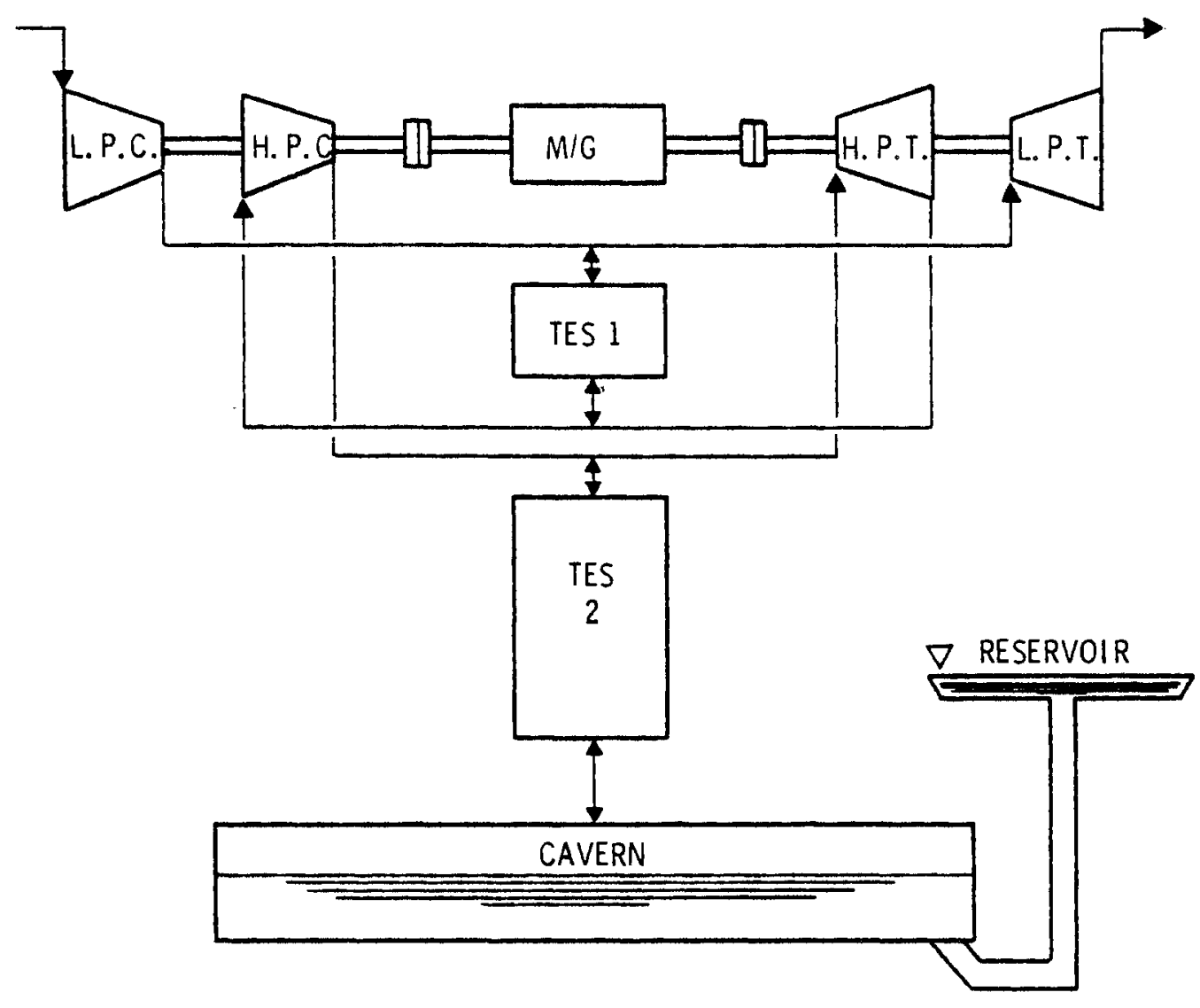

FIGURE 35. Two-Stage Cycle Configuration

storage pressures of this cycle is shown in Figure 36. Clearly, higher storage pressures yield more output power and more attractive electric energy ratios.

Total compressor train input power calculations were performed for storage pressures of $900,1000,1200$, and 1300 psi based on discharge temperatures of $850^{\circ} \mathrm{F}$ and mass flow rates of $720 \mathrm{lb} / \mathrm{sec}$. Figure 37 shows that the required input power to the compressor train is minimized with higher pressure first-stage compressor discharges. This requires low first-stage inlet air temperatures, obviating inlet air preheating with centrifugal or second-stage compressors requiring higher inlet air temperatures. Higher input temperatures to the centrifugal compressors will narrow the TES\#1 operating temperature and possibly simplify its design. 


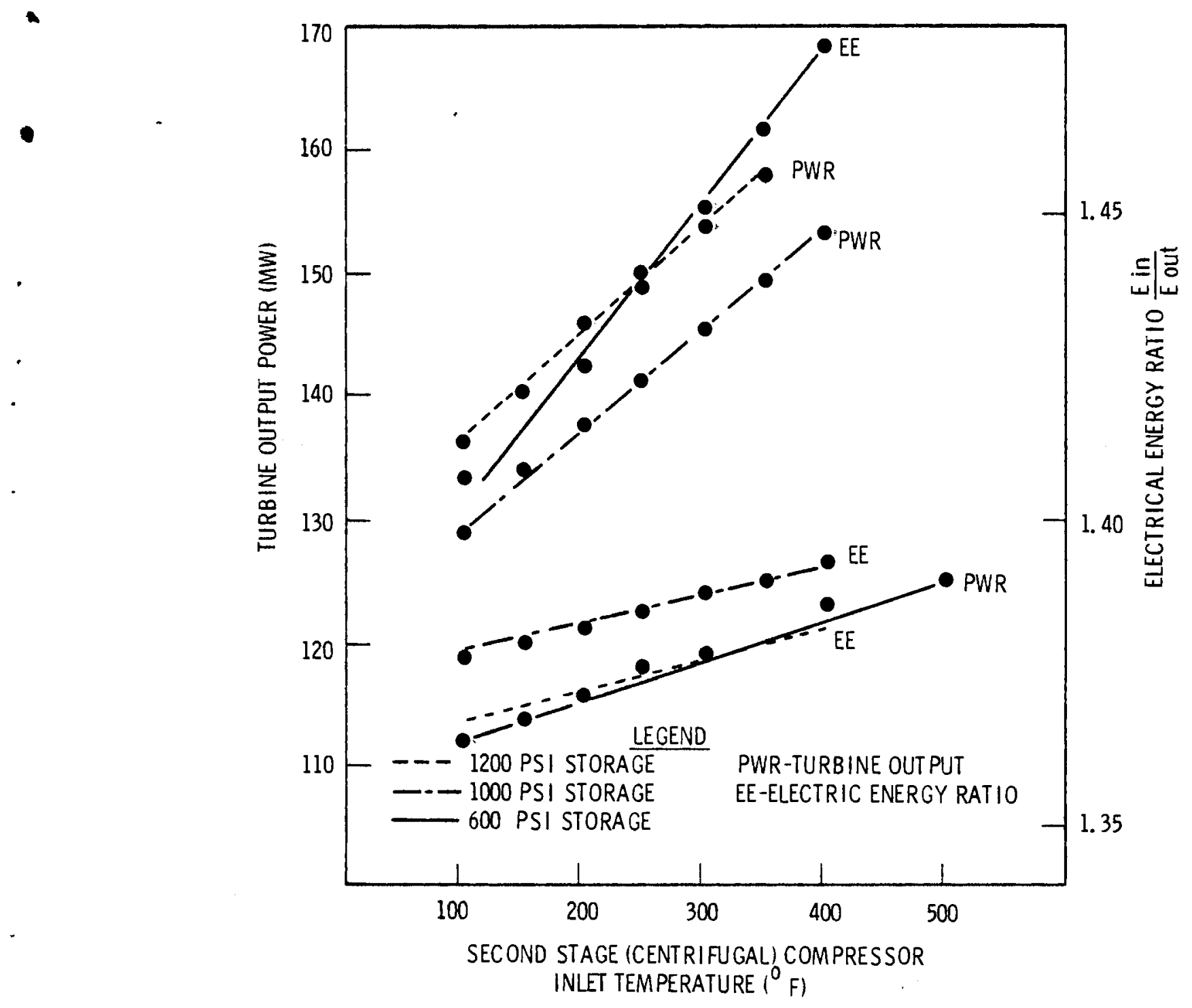

FIGURE 36. Inlet Temperature of Second-Stage Compressor Effects on ACAES Cycle Performance for Varied Storage Pressures 


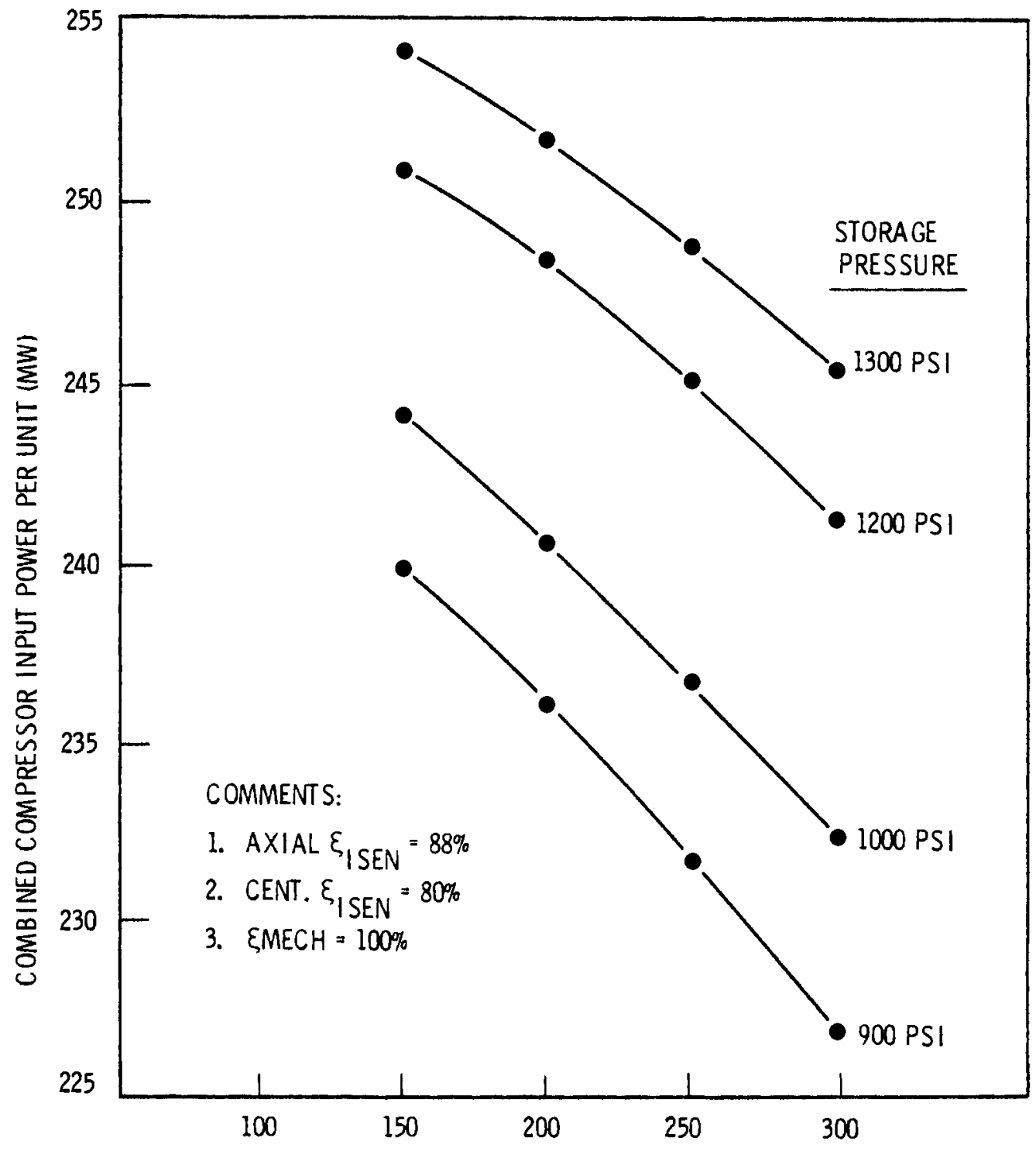

PRESSURE AT FIRST STAGE COMPRESSOR OUTLET (PSI)

FIGURE 37. Required Combined Compressor Train Input Power to Deliver $850^{\circ}$ Air to Both TES \#1 and \#2 
Task 4. Conceptual Design

No activity.

Task 5. Capital and Levelized Energy Costs

Break-even costs for the ACAES plant have been roughly estimated based upon PEPCO oil-fired plant economics. Results indicate that plant economics are highly sensitive to oil price escalation. A 1990 distillate oil price (with 10\% escalation over 1990 to 2020) of $\$ 12$ per million Btu is probably not adequate to justify the plant. A price of $\$ 16$ per million Btu appears to allow an adequate margin for TES system costs anticipated. Cost confirmation is scheduled for later in the project.

Task 6. Final Project Report

No activity

TECHNICAL PROBLEMS

The delay in the finalization of terms and conditions for the participation of Dresser Clark, Inc., MIT/Energy Laboratory, and Central Electricity Generating Board has caused six weeks slippage in the project schedule at this time, which may reduce to two weeks as the project progresses. No significant problems have been identified which may affect overall program costs or objectives.

PUBLICATIONS

None 


\title{
4.2.2c Engineering Study of Adiabatic CAES using Aquifers
}

\author{
for Air Storage \\ Under Negotiation with \\ Sargent and Lundy
}

\section{OBJECT IVE}

The objective of this project is to perform an engineering design and cost study of an adiabatic CAES plant using aquifers for air storage. A major element of this project is the idea of storing thermal energy along with the air, in the aquifers.

\section{TASKS}

Currently PNL is negotiating with Sargent and Lundy Engineers to perform this study. The project outline as given in the statement of work is as follows.

- Task 1 - Review of Thermal Energy Storage for CAES Applications

- Task 2 - Review of Turbomachinery System Technology

- Task 3 - Determine Cycle Arrangement for Conceptual Design

- Task 4 - Conceptual Design of an Adiabatic Aquifer CAES Plant

- Task 5 - Determine Levelized Energy Costs

- Task 6 - Reporting.

TECHNICAL PROGRESS

None

TECHNICAL PROBLEMS

None

PUBLICATIONS

None 


\subsubsection{Feasibility of Coal Gasification and CAES (CAES/CG) \\ W. C. Cliff \\ Pacific Northwest Laboratory}

OBJECTIVE

The objective of this task was to evaluate the feasibility of integrating coal gasification technologies with CAES.

TASKS

Task 1

Examine current literature and explore potential synergisms between CAES and coal gasification technologies.

Task 2

Develop recommendations to DOE on whether development of CAES with coal gasification should be pursued.

\section{TECHNICAL PROGRESS}

Task 1

The most important document for this project was the study by United Technologies Research Center entitled Concept Screening of Coal Gasification CAES Systems (EPRI EM-1077, May 1979). A7though other reference material was used, this was the only directed study. Conclusions reached by the UTRC study were as follows.

- A strong synergistic effect of coupling coal gasification and CAES is the ability for CAES to supply air at controlled pressures and flow rates to the coal gasification system.

- High quality heat generally rejected from coal gasification could be transferred to air being retrieved from CAES.

- Estimated plant costs for a continuous coal gasification/CAES plant range from $\$ 700$ to $\$ 865 / k$ le (1976 dollars) with nominal round trip heat transfer rates between 9,700 and $11,000 \mathrm{Btu} / \mathrm{kWh}$. 
- Coal gasification product gas contaminants, such as carbon particulates (greater than $10 \mathrm{~mm}$ ) and volatile alkaline metal compounds and other harmful vapors must be removed prior to use in gas turbines.

- Estimated bus bar power costs from a CAES/coal gasification system are about $80 \mathrm{mills} / \mathrm{kWh}$ in 1976 dollars.

\section{Task 2}

Recommendations to DOE regarding integration of coal gasification with CAES are currently being formulated. A task force is being formed to assist in developing recommendations.

TECHNICAL PROBLEMS

None

PUBLICATIONS

None 


\subsubsection{Second-Generation CAES Equipment Evaluation}

OBJECTIVE

The objective of this project is to examine current equipment - 1 imitations (compressors, turbines, recuperators, etc.) for secondgeneration CAES concepts and to identify technological developments needed to satisfy midterm commercialization requirements.

\section{$\underline{\text { TASKS }}$}

This task was originally established at Argonne National Laboratory to identify R\&D needs for advanced CAES concepts. The project was to continue at PNL, through subcontracted work, in FY-1980. It has been delayed pending results of the adiabatic CAES studies in projects 4.2.2a, 4.2.2b, and 4.2.2c. Each of these projects has a task on review of CAES turbomachinery requirements. When these tasks are completed, the results will be used to identify future work.

\section{TECHNICAL PROGRESS}

Evaluation of Central Electricity Generating Board and the Massachusetts Institute of Technology studies of CAES plants with thermal energy storage indicate that some equipment development is required. However, no further activities will be initiated until the current engineering design studies of adiabatic CAES plants provide more definitive requirements.

TECHNICAL PROBLEMS

None

PUBLICATIONS

None 


\title{
4.2.5 Second-Generation Concepts Analys is and Support
}

\author{
F. R. Zaloudek
}

Pacific Northwest Laboratory

OBJECTIVE

The objective of this project is to provide technical evaluations of second-generation CAES technologies and to develop the documentation that could be used in making recommendations to DOE/STOR.

$\underline{\text { TASKS }}$

Task 1. Analys is of Second-Generation Concepts

Acquire, compile and integrate data on all major projects related to advanced CAES systems. Develop a screening technique and prepare recommendations to DOE/STOR on which of the second-generation concepts should be continued into the development/demonstration phase.

Task 2. CAES-Cycle Code Development

Modify and use the CYCLOPS code to permit cycle analysis of various advanced CAES alternatives. The code is to be used to support all other related studies that require cycle analysis.

Task 3. Evaluation of Advanced CAES Concepts

Screen and evaluate new CAES concepts and ideas. This includes evaluation of unsolicited proposals and development of new applications.

\section{TECHNICAL PROGRESS}

Task 1. Analys is of Second-Generation Concepts

A screening methodology based on technical merit and technology readiness is underway. A preliminary set of criteria has been developed and is undergoing in-house review. A literature search is ongoing to help finalize the list and to assist with a weighting technique to be 
applied to the criteria. Existing CAES design studies are being reviewed to determine the type and extent of technical information available in such studies for comparative analysis. The major technical criteria under consideration include: economics, constructability, operability maintainability, durability and safety.

Task 2. CAES-Cycle Code Development

Approximation of combustion gas properties in CYCLOPS-MOD1 was completed. The analysis indicated that the error observed in the approximation is probably not enough to effect the calculated results of present CAES cycles, however, it indicates the need for a more sophisticated model if actual turbine designs were to be attempted. A user's guide was rewritten and distributed.

Finally, a performance comparison of a number of cycle configurations was made using CYCLOPS-MODI. Storage pressure and turbomachinery efficiencies were held constant for this study. Analysis showed that the results of the code agreed with the published data.

Task 3. Evaluation of Advanced CAES Concepts

Several novel ideas were identified and evaluated. Most novel was a double reservoir, closed cycle concept that was at high pressures but required very low pressure ratios. It provided an adiabatic concept that had only minimal temperature changes. One weakness in the concept was found to be the large volume required for reservoirs. Other concepts. were also evaluated but none were promising.

\section{TECHNICAL PROBLEMS}

None

\section{PUBLICATIONS}

None 


\subsubsection{Economic Assessment of Second-Generation Concepts R. W. Reiliy \\ Pacific Northwest Laboratory}

\section{-OBJECTIVE}

The objective of this project is to provide an economic assessment of second-generation CAES technologies in order to identify those which have the potential for commercialization. Based upon these study results, PNL will recommend to DOE/STOR those actions which should be taken to facilitate the commercialization of the CAES technology.

$\underline{\text { TASKS }}$

Three major tasks have been identified as necessary to the comparative analys is of second-generation concepts.

Task 1. Preliminary Analysis of the Economics of CAES Employing Thermal Energy Storage (CAES/TES)

A comparative analysis of three independent studies of CAES/TES designs was made to assess the potential for cost-effective operation of CAES/TES systems. The task is complete, and the results are contained in two PNL publications.

Task 2. Development of a Screening Methodology for Comparative Analysis of CAES Concepts

A number of studies are being conducted on the technical and economic performance of second-generation CAES concepts by DOE, industry, and universities. Each of these, however, uses different assumptions and methodologies, making comparisons between the studies (and hence between the concepts) extremely difficult. This task will result in a systematic methodology for reducing these studies to a common basis, thereby enabling a comparative analysis of the economic and technical merits inherent in each of the technologies. 
Task 3. Comparative Analys is of Second-Generation CAES Concepts

Using the methodology developed in Task 2, the most definitive studies for each of the second-generation CAES concepts will be analyzed for economic and technical performance. The concepts to be analyzed include:

- CAES/Fluidized Bed Combustors

- CAES/Coal Gasification

- CAES/TES (hybrid)

- Conventional (fueled) CAES.

These concepts will be compared one against another; and also against al ternative technologies such as underground pumped hydro, gas turbines and other means of providing peaking/intermediate power.

\section{TECHNICAL PROGRESS}

Task 1. Preliminary Analysis of the Economic Performance of CAES Employing Thermal Energy Storage (CAES/TES)

Two studies were made to determine the economic performance of CAES employing thermal energy storage as compared to conventional CAES and gas turbines. The first was performed by Knutsen Research Services, a consultant to PNL, using thermodynamic cycle data and cost estimates developed by PNL. Four examples of commonly proposed advanced CAES systems were analyzed and compared. Under base case conditions the conventional CAES design was found to be most cost effective, with the CAES/TES designs becoming competitive only under the assumption of low compression energy costs and high fuel costs. The gas turbine was more expensive to operate than conventional CAES under almost all conditions studied.

The second comparative study was done in-house. It adopted system design and capital cost estimates from three most recent CAES studies (including Knutsen's) and applied a common set of fuel/energy costs and economic assumptions to develop comparable estimates of levelized energy 
costs for the designs. The results of the study indicate that CAES has the potential for substantial cost savings over the more traditional gas turbine, and that adiabatic systems appear to be slightiy more economical at today's fuel prices than conventional CAES systems.

- Task 2 Development of a Screening Methodology for Comparative Analysis of CAES Concepts

An overal1 screening methodology for second-generation CAES technologies is essentially complete, and consists of:

- a set of common economic and performance assumptions which have been circulated through DOE and ANL for review. These parameters will constitute the base case upon which sensitivity analyses will be performed.

- a methodology for determining levelized bus bar energy cost using the standarized parameters

- a system of standard cost accounts. These will be employed to assist in the generation of other figures of merit (such as dollars/ storage capacity), and as a tool for the comparative analysis of design estimates to ensure completeness and reasonableness of those estimates.

Task 3. Comparative Analys is of Second-Generation CAES Concepts

Eight major studies have been identified which 1) are fairly detailed in nature, 2) are independent of one another, 3) contain up-to-date costs and technology, and 4) cover the major CAES technologies. These will be employed as the design studies for screening the second-generation CAES concepts, with a number of more generalized, older studies serving as reference and/or background materials for the screening. These include three conventional CAES studies (salt, hard rock, and aquifer), one hybrid study, two adiabatic studies, one coal gasification/CAES, and one fluidized bed combustion/CAES. Five of these are expected to result in final reports by the end of the fiscal year; the remaining three 
will be analyzed from progress reports if adequate data are available. The fluidized bed combustion/CAES and the coal gasification/CAES studies are presently available and are undergoing initial technical and economic review.

\section{TECHNICAL PROBLEMS}

The major technical problem associated with this study is the timing of the CAES design studies. At least three of the major reports will be unavailable until after the recommendations are due at DOE; interim reports are often uninformative and the results reported therein are of ten subject to radical change by the end of the study.

\section{PUBLICATIONS}

C. A. Knutsen, Incremental Cost Analysis of Advanced Concept CAES Systems. PNL-3Tा8, prepared for Pacific Northwest Laboratory by Knutsen Research Services, Bothe11, WA, September 1979.

S. C. Schulte and R. W. Reilly, The Economics of Compressed Air Energy Storage Employing Thermal Energy Storage. PNL -3191, Pacific Northwest Laboratory, Richland, WA, November 1979. 


\subsubsection{Thermal Energy Storage Test Facility}

J. P. Joyce

NASA Lewis Research Center

OBJECTIVE

The twofold objective of this study is to develop a facility for testing sensible heat thermal energy storage for use with compressed air energy storage concepts and to perform necessary tests.

\section{TASKS}

\section{Task 1. TES Test Facility}

- Complete a conceptual design based on needs of CAES hybrid and adiabatic plants

- Recommend best system arrangement

- Complete engineering design of appropriately-scaled test hardware. (Assure similitude with full-scale system storage hardware.)

- Identify system operating conditions

- Calculate system performance and heat balance at design point

- Recommend viable startup and shutdown procedures.

Task 2. Design Experiments and Plan Tests

- Identify test objectives to solve thermal storage problems

- Complete a test plan to:

1. identify test equipment and instrumentation

2. predict design point and part power performance

3 . outline test procedures and sequence, and

4. describe inspection procedures

- Clarify and apply techniques for 30-year structural durability. 
Task 3. Procure Test Hardware

- Procure instrumented hardware

- Assemble test module and deliver it to the facility.

- Task 4. Prepare Test Facility

- Identify the requirements to complete the approved tests

- Complete preparations for test

- Install the test module.

Task 5. Complete Test Operations

- Verify the predicted performance of various TES configurations

- Confirm/refine method for calculating performance

- Measure size and quantity of solid particles leaving thermal storage and predict effect on system hardware

- Identify moisture effect to the thermal storage bed

- Demonstrate viable thermal insulation concept

- Evaluate potential for structural containment concept to achieve 30-year life.

Task 6. Reporting

- Monthly technical and financial progress

- Annua 1

- Topical reports

- Final report.

TECHNICAL PROGRESS

Project is scheduled for initiation in FY-1980.

TECHNICAL PROBLEMS

None 


\subsubsection{Advanced Storage Concepts Evaluation and Technical Assistance}

W. A. Moore

Battelle Columbus Laboratories

\section{OBJECTIVE}

To provide technical assistance to DOE/STOR and to evaluate specified advanced energy storage concepts.

SCOPE

Battelle's Columbus Laboratories ( $\mathrm{BCL}$ ) will assist the Department of Energy, Division of Energy Storage Systems, in planning and formulating strategies for the Division's Physical Storage Systems programs. Assistance will be provided in the preparation of multiyear-program plans for physical storage systems and program approval documents. Limited system studies will be performed to identify those technologies and applications with potential for greatest impact on the energy economy. Theoretical and experimental programs will be identified to validate the assumptions of the systems studies, narrow the range of candidate technologies, and advance the state-of-the-art of selected technologies. Assistance will also be provided, as requested, in technological and economic support.

Battelle's Columbus Laboratories will provide key staff skilled in the various disciplines appropriate to those technologies under study. In addition, Battelle staff experts in economics, and those skilled in assessing institutional and societal impacts of technological innovations will be available as needed. 


\section{8

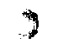

i 


\subsubsection{Application and Design Studies of CAES for Solar Energy Applications \\ G. T. Flynn \\ Massachusetts Institute of Technology}

\section{OBJECTIVE}

The objective of this study was to investigate combining thermal energy storage and CAES concepts with particular attention to solar applications.

$\underline{\text { TASKS }}$

Task 1. Application of CAES to Solar Power

Primary task here was to investigate how CAES could be combined with solar-thermal, electric, and conventional generating schemes. Second, cost performance models for the solar-thermal CAES were prepared. Finally, existing storage modes were compared to CAES and the potential impact of CAES on various solar-electric power generating systems was estimated.

Task 2. Prel iminary Study of Adiabatic CAES

This task included, first, a literature and industrial survey of information related to compressors, turbines, motor generators, and clutches presently available or under development. As the second step, conceptual designs for underground CAES systems with thermal energy storage were made. Consideration was given to both existing and to-bemined reservoirs.

Task 3. Preliminary Design Study of Thermal Energy Storage for CAES

In this task the charge was to compile, review, and summarize the background material related to packed-bed thermal energy storage systems. Then heat and mass flow procedures were developed. This included details 
regarding heat transfer rates, condensation, evaporation, percolation, ground-water infiltration effects, etc. The final step was the conceptual design and cost analysis of a thermal storage bed.

- TECHNICAL PROGRESS

Task 1. Application of CAES to Solar Power

The nature of CAES systems best suited to coupling with solarthermal power systems was identified and evaluated. The cost of solar power components and thermal energy storage was included in the evaluation. Due principally to the high cost of solar plant components, it appears that augmentation of adiabatic CAES energy output using solar-thermal air heating is not economically attractive at this time.

Task 2. Preliminary Study of Adiabatic CAES

Two viable, economically attractive pure adiabatic systems were identified. These could be built today using essentially available technology. The two variants are high-pressure (to 80 bars) and low pressure (to 20 bars) systems. It was shown that both systems were economically superior to all other pure storage systems except conventionallypumped hydroelectric plants; economically competitive with gas turbine peaking units; and strategically superior to gas turbines and conventional CAES since they did not require petroleum fuels.

Task 3. Preliminary Design of Thermal Energy Storage for CAES

The $1 i$ terature survey covering material background related to packed-bed thermal energy storage was done and an analytical model was selected for analysis of the packed-bed thermal storage system. Using the model, the influence of various system parameters on bed length or bed capacity and on the slope of the thermocline were determined. Additional thermal storage bed variables that were considered were bed diameter, rock size, and rock type. The mathematical model was tested with various charge/discharge ratios for efficiency and performance. The results were used in the final design of a thermal storage bed for CAES. 


\title{
4.2.9 Application and Design Studies of CAES for Solar
}

\author{
Energy Applications \\ G. T. Flynn \\ Massachusetts Institute of Technology
}

\section{OBJECTIVE}

The objective of this study was to investigate combining thermal energy storage and CAES concepts with particular attention to solar applications.

TASKS

Task 1. Application of CAES to Solar Power

Primary task here was to investigate how CAES could be combined with solar-thermal, electric, and conventional generating schemes.

Second, cost performance models for the solar-thermal CAES were prepared. Finally, existing storage modes were compared to CAES and the potential impact of CAES on various solar-electric power generating systems was estimated.

Task 2. Preliminary Study of Adiabatic CAES

This task included, first, a literature and industrial survey of information related to compressors, turbines, motor generators, and clutches presently available or under development. As the second step, conceptual designs for underground CAES systems with thermal energy storage were made. Consideration was given to both existing and to-bemined reservoirs.

Task 3. Preliminary Design Study of Thermal Energy Storage for CAES

In this task the charge was to compile, review, and summarize the background material related to packed-bed thermal energy storage systems. Then heat and mass flow procedures were developed. This included details 
regarding heat transfer rates, condensation, evaporation, percolation, ground-water infiltration effects, etc. The final step was the conceptual design and cost analysis of a thermal storage bed.

- TECHNICAL PROGRESS

Task 1. Application of CAES to Solar Power

The nature of CAES systems best suited to coupling with solarthermal power systems was identified and evaluated. The cost of solar power components and thermal energy storage was included in the evaluation. Due principally to the high cost of solar plant components, it appears that augmentation of adiabatic CAES energy output using solar-thermal air heating is not economically attractive at this time.

Task 2. Preliminary Study of Adiabatic CAES

Two viable, economically attractive pure adiabatic systems were identified. These could be built today using essentially available technology. The two variants are high-pressure (to 80 bars) and low pressure (to 20 bars) systems. It was shown that both systems were economically superior to all other pure storage systems except conventionallypumped hydroelectric plants; economically competitive with gas turbine peaking units; and strategically superior to gas turbines and conventional CAES since they did not require petroleum fuels.

Task 3. Pre7iminary Design of Thermal Energy Storage for CAES

The literature survey covering material background related to packed-bed thermal energy storage was done and an analytical model was selected for analysis of the packed-bed thermal storage system. Using the model, the influence of various system parameters on bed length or bed capacity and on the slope of the thermocline were determined. Additional thermal storage bed variables that were considered were bed diameter, rock size, and rock type. The mathematical model was tested with various charge/discharge ratios for efficiency and performance. The results were used in the final design of a thermal storage bed for CAES. 
CONCLUSIONS AND RECOMMENDATIONS

This study has been completed. The major conclusions and recommendations are:

- CAES for storage of solar-thermal electric power is not practical because of high capital costs of solar components and decreases in efficiency due to multiple energy conversions.

- CAES compares favorably with underground pumped hydroelectric and other pure storage modes in terms of costs and technological availability.

- Rotating equipment for adiabatic CAES exists and is competitive with conventional CAES and UPHS.

- Thermal energy storage for CAES is technically and economically feasible for CAES.

- Solar augmentation of CAES is technically feasible but economically unattractive due to high cost of solar components.

- It is recommended that a field test of adiabatic CAES be initiated.

\section{TECHNICAL PROBLEMS}

None

\section{PUBLICATIONS}

N. I. Hamilton, Literature Survey of Packed-Bed, Thermal-Energy Storage. MIT CAES-1, Massachusetts Institute of Technology, Lexington, MA, January 1978.

N. I. Hamilton, Materials Catalogue for Packed-Bed, Thermal-Energy Storage. MIT CAES-2, Massachusetts Institute of Technology, Lexington, MA, June 1978.

G. T. Flynn and J. L. Nash-Webber, Application and Design Studies of Compressed Air Energy Storage for Solar Applications. MIT CAES-7, Massachusetts Institute of Technology, Lexington, MA, September 1979. 
N. I. Hamilton, Heat and Mass Flow Analys is of Packed Bed Thermal Regenerators. MIT CAES-9, Mas sachusetts Institute of Technology, Lexington, MA, August 1978.

N. I. Hamilton, Conceptual Design of a Packed Bed for Thermal Energy Storage. MIT CAES-10, Massachusetts Institute of Technology, Lexington, - MA, December 1978.

N. I. Hamilton, Cost Analysis of Packed Beds for Thermal Energy Storage. MIT CAES-11, Massachusetts Institute of Technology, Lexington, MA, December 1978. 


\section{DISTRIBUTION}

No. of

Copies

- OFFSITE

A. A. Churm

DOE Chicago Patent Group

Chicago Operations Office

9800 South Cass Avenue

Argonne, IL 60439

27 DOE Technical Information Center

B. J. Mueller

Department of Energy

Chicago Operations Office 9800 S. Cass Avenue

Argonne, IL 60439

Chief, APMBR

Division of Energy Storage

Sys tems

U.S. Department of Energy

Washington, DC 20585

Dan $\mathrm{Ha} 11$

P.0. 635

Fairvault, MN 55021

Royal B. Newman

Soyland Power Cooperative, Inc.

P0 Box A1606

Decatur, IL 62525

G. D. Pezdirtz, Director

Division of Energy Storage Systems

U.S. Department of Energy

Washington, DC 20585

5 Gabor D. Karadi

Department of Energy

Division of Energy Storage

600 E Street, Room 416

Washington, DC 20545
No. of

Copies

5 Saul Strauch

DOE Division of Energy Storage Systems

Advanced Physical Methods Branch

600 E Street, Room 416

Washington, DC 20585

J. H. Swisher

Division of Energy Storage Systems

U.S. Department of Energy

Washington, DC 20585

D. W. Boehm

Division of Environmental

Control Technology

U.S. Department of Energy

Washington, DC 20585

Assistant Director for Major

Projects

Division of Solar Energy

U.S. Department of Energy

Washington, DC 20585

Assistant Director for Thermal

Power Systems

Division of Solar Energy

U.S. Department of Energy

Washington, DC 20585

DOE Library

U.S. Department of Energy

Maii Station G-043

Washington, DC 20585

R.F. Kimberlin

DOE Library

U.S. Department of Energy

Room 1223

Washington, DC 20585 
No. of

Copies

D. Willett

Acres American, Inc.

Liberty Bank Building

Main at Court

Buffalo, NY 14202

L. A. Wilson

Middle South Services

P.0. Box 61000

New Orleans, LA 70161

Division of Advanced Energy

Research and Technology

National Science Foundation

Room 1140

1800 G Street, NW

Washington, DC 20550

C. G. Nelson

Manager, Storage Operations

Northern Illinois Gas

Company

P.0. Box 190

Aurora, IL 60507

P. E. Schaub

Potomac Electric Power Company

1900 Pennsylvania Avenue

Washington, DC 20006

T. McCafferty

Public Service Company of Indiana

1000 E. Main Street

Plainfield, IN 46168

Jim Blacic

G-6-LASL-Stop 978

PO Box 1663

Los Alamos, NM 87545

C. Cooley

Terra Tek Inc.

University Research Park

400 Wakara Way

Salt Lake City, UT 84108
No. of

Copies

2 Technical Library

Department 3141

Sandia Laboratory

Albuquerque, NM 87115

S. Serata

Serata Geomechanics, Inc.

1229 Eighth Street

Berkeley, CA 94710

Energy Research Section

Tennessee Valley Authority

1360 Commerce Union Bank B1dg.

Chattanooga, TN 37401

Gerald Phillips

Tennessee Valley Authority

1150 Chestnut, Tower 2

Chattanooga, TN 37401

E. Berman

Technical Library

TRW Energy Systems Group

7600 Colshire Drive

McLean, VA 22101

E. H. King

Underground Design Consultants

820 Cascade Bldg.

Portland, OR 97204

A. J. Giramonti

United Technologies Research

Center

Silver Lane

East Hartford, CT 06108

H. J. Pincus

University of Wisconsin

Department of Geological

Sciences

Sabin Hall and Greene Museum

P.0. Box 413

Milwaukee, WI 53201 
No. of

Copies

D. Ayers
Manager, Fluid Systems
Laboratory
Westinghouse Electric
Corporation
1291 Cumberland Avenue

West Lafayett, IL 47906

American Public Power

Association

2600 Virginia Avenue, NW

Washington, DC 20037

2 J. M. Clinch

Argonne National Laboratory

9700 South Cass Avenue

Argonne, IL 60439

Manager, Research and

Development

Bonneville Power

Administration

P.0. Box 3621

Portland, OR 97208

Research Library, Reference Section

Information Division

Brookhaven National

Laboratory

Upton, NY 11973

Stanley Stys

$\checkmark$ ice President, American

Brown Boveri Corporation

New Brunswick, NJ 08902

Director of Research

Cincinnati Gas and and Electric Company

139 East Fourth Street

Cincinnati, OH 45202

D. E. DeViney

Commonwealth Edison Company

1319 South First Avenue

Maywood, IL 60153
No. of

Copies

R. A. Bell

Consolidated Edison Company

4 Irving Place

New York, NY 10003

T. Schneider

Electric Power Research Institute

Box 10412

Palo Alto, CA 94303

D. Anderson

Fenix and Scisson, Inc.

P.0. Box 15609

Tulsa, OK 74115

Director of Research

GPU Service Corporation

260 Cherry Hill Road

Parsippany, NJ 07054

A. H. Barber

Director of Marketing

Harza Engineering Company

$150 \mathrm{~S}$. Wacker Drive

Chicago, IL 60606

Library

Lawrence Berkeley Laboratory

University of California

B1dg. 50, Room 134

Berkeley, CA 94720

3 Technical Information Department, $L-3$

Lawrence Livermore Laboratory

University of California

P.0. Box 808

Livermore, CA 94550

Director of Research

Louisiana Power and Light

142 Delaronde Street

New Orleans, LA 70174 
No. of

Copies

I. Glendenning

Head of Long-Term Studies

Marchwood Engineering Labs

Southampton, England

A. Ferreira

Electric Power Research Institute

NEPLAN

174 Brush Hill Avenue

West Springfield, MA 01089

W. Stevens ((50/20/B37)

Bechtel National Inc.

Res \& Eng.

PO Box 3965

San Francisco, CA 94119

Fred Ahrens

Argonne National Laboratory

9700 South Cass Avenue

Argonne, IL 60439

Paul Gnirk

$\mathrm{Re} / \mathrm{Spec}$ Inc.

PO Box 725

Rapid City, SD 57701

Donald L. Katz

Department of Chemical

Engineering

The University of Michigan

2042 E. Engr. B1dg.

Ann Arbor, MI 48109

R. L. Thoms

Louisiana State University

Institute for Environmental

Studies

Room 42, Atkinson $\mathrm{Hall}$

Baton Rouge, LA 70803

A. F. Fossum

$\mathrm{Re} / \mathrm{Spec}$ Inc.

PO Box 725

Rapid City, SD 57701
No. of

Copies

O.C. Farquhar

$U$. of Massachusetts

Dept. of Geology \& Geography

Morrill Science Center

Amherst, MA 01003

T. L. Brekke

University of California

Department of Civil Engineering

1847 Yosemite Road

Berkeley, CA 94707

H. Lorenzen

PB-KBB Inc.

Subservice Systems \& Technology

800 Commerce Road West

Harahan, LA 70123

A. H. Warnke

Vice President Power Supply

Central Illinois Public Service Co.

607 East Adams Street

Springfield, IL 62701

Mr. G. E. Huck

Manager of Planning

Illinois Power Company

500 South 27th St.

Decatur, IL 62525

Mr. W. C. Walke

Project Manager

Sargent \& Lundy Engineers

55 East Monroe Street

Chicago, IL 60603

T. J. Maiman

Sta. Mech. Engr. Dept. Manager

Commonwealth Edison Co.

36 FN West

PO Box 767

Chicago, IL 60690

E. M. Mabuce

Manager-Applied Research

Corporate Planning Dept.

Union Electric Co.

PO Box 149

St. Louis, MO 63166 
No of

Copies

W. F. Kobett

CAES Project Manager

Westinghouse Electric Corp.

Combustion Turbine Sys. Div.

Long Range Development-Lab 100

PO Box 251

Concordville, PA 19331

J. C. Smith

Division of Electrical Energy Systems

Department of Energy

12 \& Pennsylvania, Room 6144

Washington, DC 20545

J. Gahimer

Department of Energy

600 "E" Street

Washington, DC 20545

C. Holt

Battelle Columbus Laboratories

505 King Avenue

Columbus, $\mathrm{OH} 43201$

T. Barlow

Lawrence Livermore Laboratory

PO Box 808

Livermore, CA 94550

H. M. Dodd

Organization 5743

Sandia Labs

Albuquerque, NM 87115

R. 0 . Woods

Sandia Laboratories

Org. No. 4715

Albuquerque, NM 87115

J. L. Nash-Webber

MIT

Energy Lab

Cambridge, MA 02139
No. of

Copies

R. D. Lessard

United Technologies Research Denter

Silver Lane

East Hartford, CT 06108

M. J. Hobson

Acres American, Inc.

The Clark Bldg

Suite 329

Columbia, MD 21044

ONSITE

DOE Richland Operations

Office

D. K. Jones

H. E. Ransom

Pacific Northwest Laboratory

R.D. Allen

M.C.C. Bampton

S.M. Brown

T.J. Doherty

M.K. Drost

R.L. Erikson

J.A. Fort

J.R. Friley

P.J. Gutknecht

A.J. Haverfield

J.J. Jacobson

L.D. Kannberg

W.V. Loscutoff (30)

R.P: Marshall

R.A. McCann

M.A. McKinnon

L.T. Pedersen

R.W. Reilly

R.P. Smith

J.A. Stottlemyre

A.M. Sutey

D.S. Trent

L.E. Wiles

Technical Information (5)

Publishing Coordination (2) 
(2)

. 